\title{
Characterization of NOx emissions from Light-Duty Diesel Vehicles during off-cycle operation
}

\author{
Ranjith Reddy Kalluri
}

Follow this and additional works at: https://researchrepository.wvu.edu/etd

\section{Recommended Citation}

Kalluri, Ranjith Reddy, "Characterization of NOx emissions from Light-Duty Diesel Vehicles during off-cycle operation" (2016). Graduate Theses, Dissertations, and Problem Reports. 5924.

https://researchrepository.wvu.edu/etd/5924

This Thesis is protected by copyright and/or related rights. It has been brought to you by the The Research Repository @ WVU with permission from the rights-holder(s). You are free to use this Thesis in any way that is permitted by the copyright and related rights legislation that applies to your use. For other uses you must obtain permission from the rights-holder(s) directly, unless additional rights are indicated by a Creative Commons license in the record and/ or on the work itself. This Thesis has been accepted for inclusion in WVU Graduate Theses, Dissertations, and Problem Reports collection by an authorized administrator of The Research Repository @ WVU. For more information, please contact researchrepository@mail.wvu.edu. 
Characterization of NOx emissions from Light-Duty Diesel Vehicles during off-cycle operation

\author{
Ranjith Reddy Kalluri
}

Thesis submitted

to the College of Engineering and Mineral Resources

At West Virginia University

in partial fulfillment of requirements for the degree of

Master of Science in

Mechanical Engineering

Arvind Thiruvengadam Padmavathy, Ph.D., Chair

V'yacheslav Akkerman, Ph.D.

Cosmin Dumitrescu, Ph.D.

Marc Cyrill Besch, Ph.D.

Department of Mechanical and Aerospace Engineering

Morgantown, West Virginia

2016

Keywords: Light Duty, On-road, Chassis Dynamometer, PEMS, OBS, DPF Regen, NO $_{x}$ Copyright 2016 Kalluri, Ranjith Reddy 


\section{Abstract \\ Characterization of NOx emissions from Light-Duty Diesel Vehicles during off-cycle operation Ranjith Reddy Kalluri}

Persisting air quality problems in the US have triggered several policy responses that are targeted at lowering the emissions of light-duty vehicles. In addition, the promulgation of Clean Air Act of 1963 and other stringent emissions regulations in the recent times (USEPA Tier 2 Bin 5) to improve the quality of ambient air, mandated the OEMs to develop advanced engine combustion strategies and after-treatment pathways to minimize NOx, PM emissions and attain these ultra-low regulatory targets. Significant difference in emissions rates between certification cycles and real world operation has been observed.

The objective of this study is to conduct in-use emissions testing of light-duty diesel vehicles. Four light duty diesel trucks were tested over four pre-defined, on-road routes, certification and non-certification chassis dynamometer cycles to investigate the difference in emission rates during off-cycle operation. Exhaust emissions were measured using Portable Emissions Measurement System (PEMS).

Results from on-road tests show that $\mathrm{NO}_{\mathrm{x}}$ emission rate from one of the four vehicles exhibited 1.2 times higher than the combined average of the other three. All vehicles exhibited $\mathrm{NO}_{\mathrm{x}}$ emission rates of $4-35$ times higher during off-cycle operation compared to FTP-75 standard of $0.04 \mathrm{~g} / \mathrm{km}$. CO emissions during the warm engine starts were $48 \%$ lower than tests with cold start. Of all the vehicles, one vehicle exhibited $\mathrm{CO}_{2}$ emission rate $3 \%$ lower than the combined average of the other three. Fuel economy observed on highway routes is $3 \%$ more than other urban and rural routes. On-road emissions rates are 4-35 times higher when compared to emissions from similar cycles on dynamometer, establishing that real world driving emissions are significantly different from those measured on certification cycles. 


\section{Acknowledgements}

I would first like to express my deepest appreciation and thanks to my committee chair, Dr. Arvind Thiruvengadam, who has the attitude and the substance of a genius. Your support and encouragement has been a tremendous guidance to me. Your office door was always open whenever I had a question regarding research or ran into trouble even before I was your student. You are more than a mentor to me, and always wanted to be like you not just in terms of intellectuality, but even in terms of kindness.

I would also like to thank Dr. Marc who is completely involved in this research project. I also thank Ram and John for helping me out in the lab. I thank my committee members, Dr. V’yacheslav Akkerman and Dr. Cosmin Dumitrescu for giving valuable feedbacks.

Finally, I must express my very profound gratitude to my parents for their love, support and belief in me. Mom and Dad, there was not even a single day without missing you during this journey. I am grateful to my brother, Karthik for his support. I miss fighting with you brother. I thank all my friends, roommates, cricket team colleagues for the fun moments and journey I've shared along.

I specially thank my close friends Bindu, Kiran, Victor, Vinay and Siddu for all your support and source of inspiration. Furthermore, special thanks of gratitude to Anveeksh, Satish for your motivational support. 


\section{Contents}

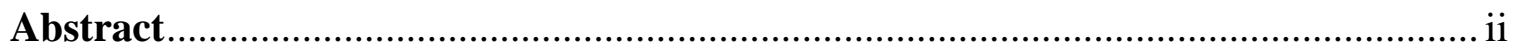

Acknowledgements.............................................................................................

List of Tables....................................................................................................... vi

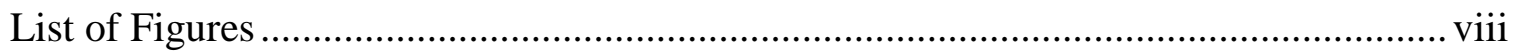

1 Introduction and Objectives .................................................................................. 1

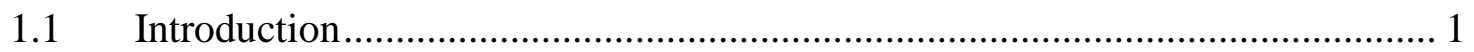

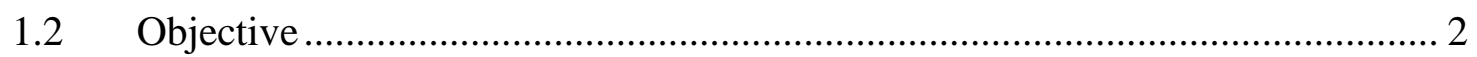

2 Literature Review......................................................................................... 3

2.1 Light Duty Trucks and its Emission regulations ................................................... 3

2.2 Light Duty Diesel Emission Control Technologies ............................................ 7

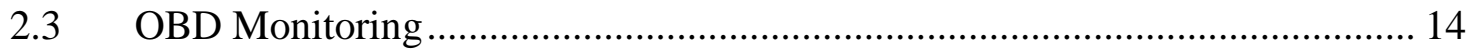

2.4 Comparison of $\mathrm{NO}_{\mathrm{x}}$ emission rates from chassis and real world....................... 16

2.5 Chassis Dynamometer Cycles..................................................................... 18

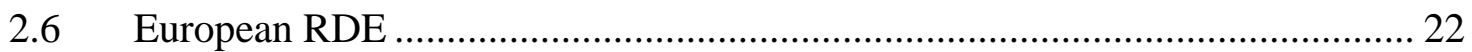

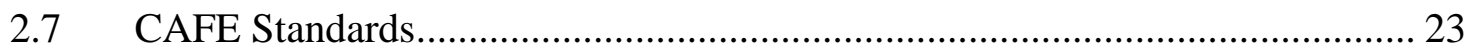

$3 \quad$ Test setup and Methodology …………………….......................................... 25

3.1 Test Vehicle information .................................................................................. 25

3.2 Vehicle test routes and dynamometer test cycles............................................. 25

3.3 Emissions Testing Procedure and Equipment ................................................... 33

3.4 Emissions Sampling - Horiba OBS-one............................................................ 37 
3.5 PEMS Installation and pre-test checks ................................................ 40

Chassis Dynamometer and setup ............................................................. 41

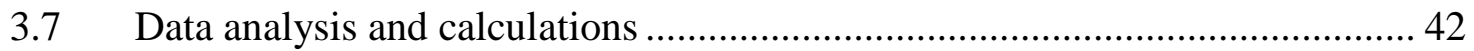

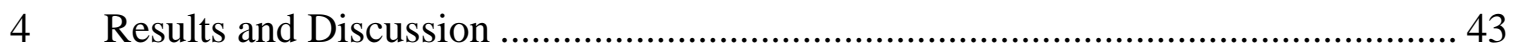

4.1 Average On-Road Emissions of Light Duty Vehicles................................... 46

4.2 Average Emissions from chassis dynamometer........................................... 52

4.3 Comparison of $\mathrm{NO}_{\mathrm{x}}$ from On-road measurements to Chassis Dynamometer cycle measurements .................................................................................. 59

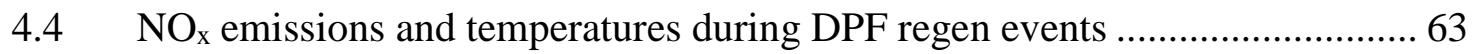

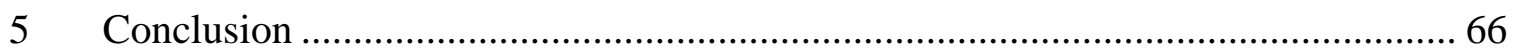




\section{List of Tables}

Table 2.1 Light Duty Truck Classification based on GVWR (U.S. Department of Energy 2012). 3

Table 2.2 Tier I FTP-75 emission standards (U.S. EPA 2016)............................................... 4

Table 2.3 NLEV Emission standards in comparison to Tier I and LEV (U.S. EPA 2016) ............ 5

Table 2.4 Tier II FTP 75 Emission standards................................................................ 6

Table 2.5 Tier III FTP 75 Emission Standards (U.S. EPA 2014) …......................................... 7

Table 3.1 Test Vehicles and engine specifications ....................................................... 26

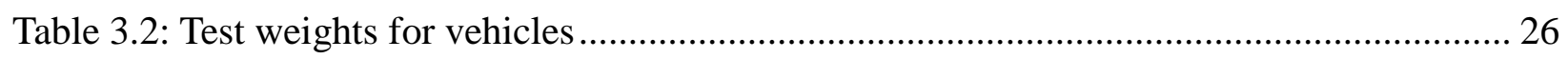

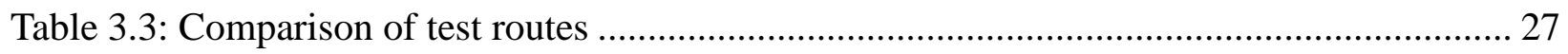

Table 3.4: Comparison of dynamometer cycles .............................................................. 32

Table 3.5 List of measured parameters and respective instruments/analyzers .......................... 36

Table 3.6: Horiba OBS-one, Gaseous analyzer specifications ............................................. 38

Table 3.7 Analyzer checks and their pass criteria .............................................................. 40

Table 3.8 Chassis Dynamometer Coefficients from EPA ................................................. 42

Table 4.1 EPA Vehicle Certification standard ................................................................. 43

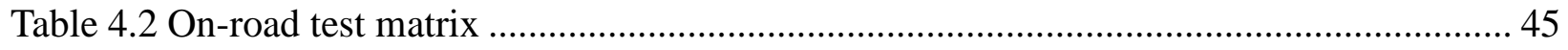

Table 4.3 Chassis Dynamometer test matrix..................................................................... 45

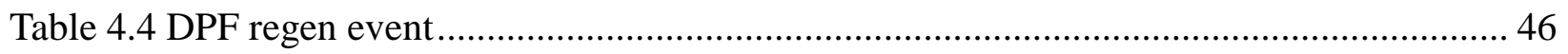

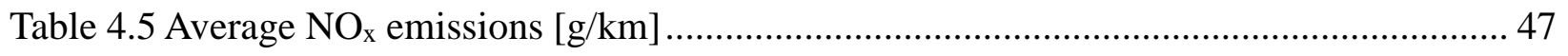

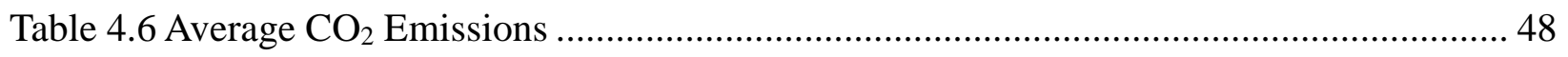

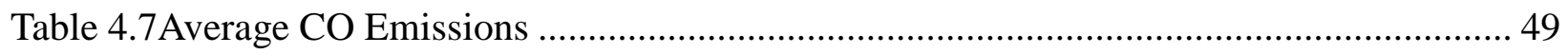

Table 4.8 Average Fuel Economies derived from Carbon Balance [mpg]............................... 51

Table 4.9 Average $\mathrm{NO}_{\mathrm{x}}$ Emissions from chassis dynamometer ............................................. 53 
Table 4.10 Average $\mathrm{CO}_{2}$ Emissions from Chassis Dynamometer

Table 4.11Average CO emissions from Chassis Dynamometer .................................................... 56

Table 4.12 Average fuel economy from carbon balance ................................................................ 57

Table 4.13 $\mathrm{NO}_{\mathrm{x}}$ \& Fuel Economy comparison from Morgantown on-road and chassis test as

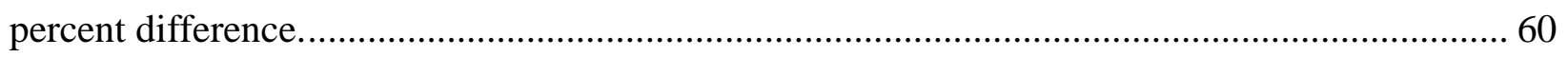

Table 4.14 NOx comparison between on-road Bruceton route \& US06, HWFET......................... 62

Table 4.15 Distance based DPF regeneration frequencies \& Max. Temp, Avg. $\mathrm{NO}_{\mathrm{x}}$ during regen 64 


\section{List of Figures}

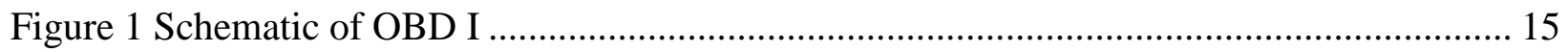

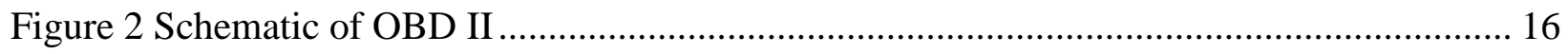

Figure 3 US EPA Urban Dynamometer Driving Schedule (FTP-72) ..................................... 18

Figure 4 US EPA Urban Dynamometer Driving Schedule (FTP-75) .................................... 19

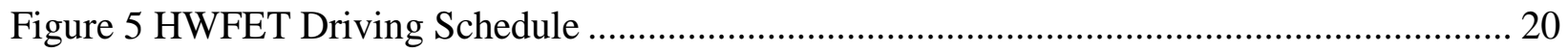

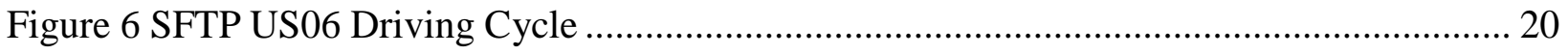

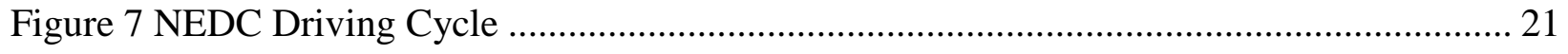

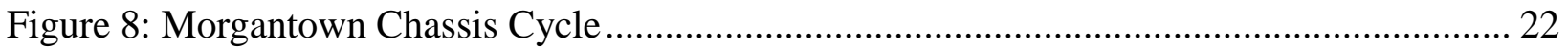

Figure 9 Geographic map of Route 1, rural and highway driving ......................................... 30

Figure 10 Geographic map of route 2, rural, highway and uphill/downhill driving................... 31

Figure 11 geographic map of route 3, urban, rural and highway driving ............................... 31

Figure 12 Geographic map of route 4, rural, highway and uphill/downhill driving................... 32

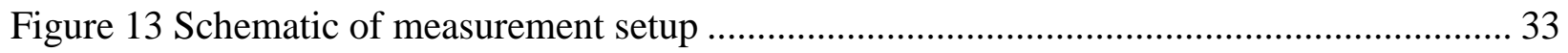

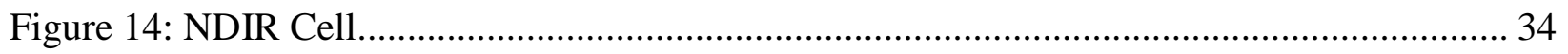

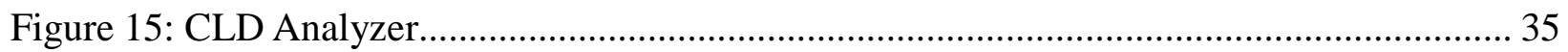

Figure 16 Schematic of CLD analyzers in OBS one ....................................................... 35

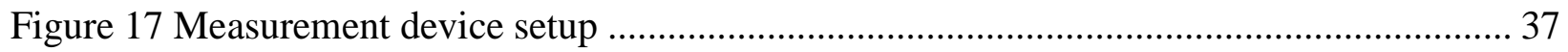

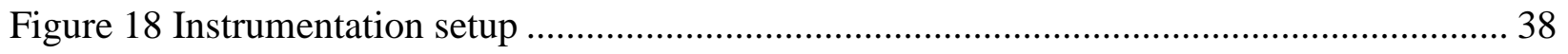

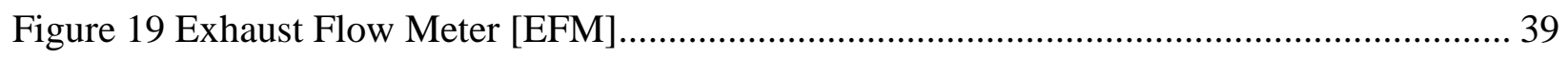

Figure 20 Tail pipe adapter setup for all Vehicles .............................................................. 39

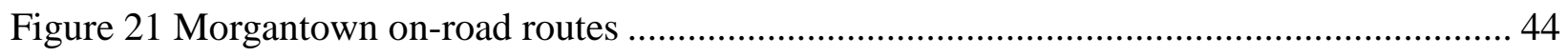

Figure 22 Bruceton on-road routes ................................................................................. 44 


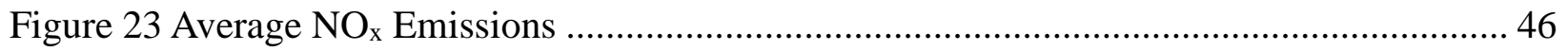

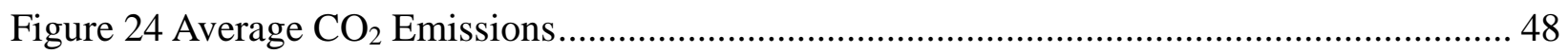

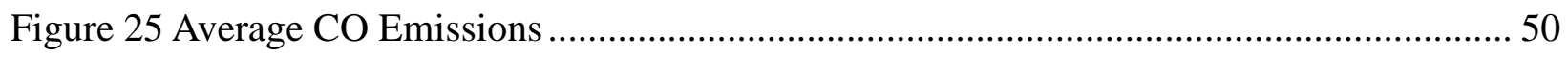

Figure 26 Average Fuel Economies derived from Carbon Balance............................................... 51

Figure 27 Average $\mathrm{NO}_{\mathrm{x}}$ Emissions from Chassis Dynamometer.................................................. 52

Figure 28 Average $\mathrm{CO}_{2}$ Emissions from Chassis Dynamometer .................................................. 54

Figure 29 Average CO emissions from Chassis Dynamometer ..................................................... 56

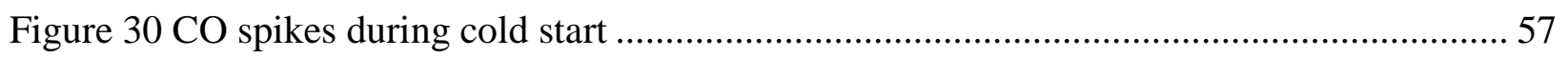

Figure 31 Average fuel economy from carbon balance ............................................................... 58

Figure $32 \mathrm{NO}_{\mathrm{x}}$ comparison from Morgantown on-road and chassis test..................................... 59

Figure $33 \mathrm{NO}_{\mathrm{x}}$ comparison between on-road Bruceton route \& US06, HWFET.......................... 61

Figure $34 \mathrm{NO}_{\mathrm{x}}$ and Exhaust temperature during a regen and non-regen event over Morgantown

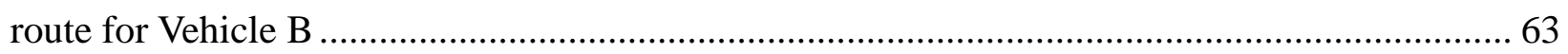




\section{Introduction and Objectives}

\subsection{Introduction}

Persisting air quality problems in the US have triggered several policy responses that are targeted at lowering the emissions of light-duty vehicles. In addition, the promulgation of Clean Air Act of 1963 and other stringent emissions regulations in the recent times (USEPA Tier 2 Bin 5) to improve the quality of ambient air, mandated the OEMs to develop advanced engine combustion strategies and after-treatment pathways to minimize NOx, PM emissions and attain these ultra-low regulatory targets. Some of the many strategies adopted by the manufacturers include retarding Ignition Timing, Variable Value Timing (VVT), direct fuel injection, Variable Geometry Turbocharger (VGT), Homogeneous Charge Compression Ignition (HCCI), Exhaust Gas Recirculation (EGR), Selective Catalytic Reduction (SCR), Lean $\mathrm{NO}_{\mathrm{x}}$ Trap (LNT), Diesel Particulate Filter (DPF), and Diesel Oxidation Catalyst (DOC).

In use emissions testing with Portable Emissions Measurement System (PEMS) has become a key element to gauge the correctness/representation of the actual emission values reported from chassis dyno testing, especially in the light duty segment. The on-road emissions tests conducted by independent researchers worldwide, with PEMS show that the real-world NOx emissions of light duty vehicles substantially exceed the regulatory emissions standards. Concerns arise pertaining to the reason that type approval testing under controlled laboratory conditions might not represent the actual on-road emissions of light-duty vehicles with sufficient accuracy. Several studies have indicated that specifically real world NOx emissions of light-duty diesel vehicles during off-cycle operations might substantially exceed the regulatory limit. The present study addresses the knowledge gap in the understanding of off-cycle emissions of light duty diesel vehicles across various topographies, routes and driving cycles. Four light duty diesel trucks were 
tested over four pre-defined, on-road routes, certification and non-certification chassis dynamometer cycles to investigate the difference in emission rates during off-cycle operation.

\subsection{Objective}

The global objective of this research is to characterize $\mathrm{NO}_{\mathrm{x}}$ emission rates from Light duty trucks during off-cycle operation. The Specific objectives include

1) Conduct in-use emissions testing of four light duty diesel trucks of two different model years using Portable Emissions Measurement System (PEMS).

2) Conduct emissions testing on a chassis dynamometer over certification cycles and realworld cycles developed from PEMS data. 


\section{Literature Review}

\subsection{Light Duty Trucks and its Emission regulations}

United States Department of Energy classifies Light Duty Trucks into three classes based on their Gross Vehicle Weight Rating (GVWR) as shown in Table 2.1 (U.S. Department of Energy 2012).

Table 2.1 Light Duty Truck Classification based on GVWR (U.S. Department of Energy 2012)

\begin{tabular}{|c|c|c|c|}
\hline \multicolumn{2}{|c|}{ Classes } & $\begin{array}{c}\text { GVWR } \\
\text { [lbs.] }\end{array}$ & Examples \\
\hline \multicolumn{2}{|c|}{ Class 1 } & $<6000$ & $\begin{array}{c}\text { GMC Canyon } \\
\text { Dodge Dakota }\end{array}$ \\
\hline \multirow{2}{*}{ Class 2 } & Class 2a & $6001-8500$ & $\begin{array}{c}\text { Ford F-150, } \\
\text { Dodge Ram 1500 }\end{array}$ \\
\cline { 2 - 4 } & Class 2b & $8501-10000$ & $\begin{array}{c}\text { Ford F-250, } \\
\text { Dodge Ram 2500 }\end{array}$ \\
\hline \multicolumn{2}{|c|}{ Class 3 } & $10001-14000$ & GMC Sierra 3500 \\
\hline
\end{tabular}

Exhaust gas regulations for Light duty vehicles were defined in sets of three (or three tiers) because of Clean Air Act Amendments of 1990. Tier I adopted in 1991 and phased in during 1994 and 1997. While, Tier II standards phased in between 2004 to 2009. Tier II is again sub ranked from Bins 1 to 10, 1 being cleanest and 10 being dirtiest. Tier III standards are sub ranked into seven bins restricting the amount of Non-methane organic gases (NMOG) along with $\mathrm{NO}_{\mathrm{x}}$ emissions and is set to phase in from 2017.

These standards are restrictions on emission of Carbon Monoxides, Oxides of Nitrogen, Particulate Matter, Non-methane hydrocarbons. (United States Code 1990)

\subsubsection{Phase 1 or Tier I: 1994-1999}

In this phase, all new vehicles with gross vehicular weight rating (GVWR) less than 8500 lbs. are categorized into five, one for passenger car and others for light duty truck based on 
capacity. Emission standards are measured over Federal Test Procedure (FTP-75) and can be found in Table 2.2 all expressed in grams per mile (g/mile). (U.S. EPA 2016)

Table 2.2 Tier I FTP-75 emission standards (U.S. EPA 2016)

\begin{tabular}{|c|c|c|c|c|c|c|c|c|c|c|c|c|}
\hline & \multicolumn{5}{|c|}{$\mathbf{5 0 , 0 0 0}$ miles/5 years } & \multicolumn{6}{c|}{$\mathbf{1 0 0 , 0 0 0}$ miles/10 years } \\
\cline { 2 - 12 } Category & THC & NMHC & CO & $\begin{array}{c}\text { NOx } \\
\text { Diesel }\end{array}$ & $\begin{array}{c}\text { NOx } \\
\text { Gasoline }\end{array}$ & PM & THC & NMHC & CO & $\begin{array}{c}\text { NOx } \\
\text { Diesel }\end{array}$ & $\begin{array}{c}\text { NOx } \\
\text { Gasoline }\end{array}$ & PM \\
\hline $\begin{array}{c}\text { Passenger } \\
\text { car }\end{array}$ & 0.41 & 0.25 & 3.4 & 1.0 & 0.4 & 0.08 & - & 0.31 & 4.2 & 1.25 & 0.6 & 0.10 \\
\hline $\begin{array}{c}\text { LLDT, } \\
\text { (LVW } \\
<\text { 3750lbs) }\end{array}$ & - & 0.25 & 3.4 & 1.0 & 0.4 & 0.08 & 0.80 & 0.31 & 4.2 & 1.25 & 0.6 & 0.10 \\
\hline $\begin{array}{c}\text { LLDT, } \\
\text { (LVW } \\
>\text { 3750lbs) }\end{array}$ & - & 0.32 & 4.4 & - & 0.7 & 0.08 & 0.80 & 0.40 & 5.5 & 0.97 & 0.97 & 0.10 \\
\hline $\begin{array}{c}\text { HLDT, } \\
\text { (ALVW } \\
\text { <5750lbs) }\end{array}$ & 0.32 & - & 4.4 & - & 0.7 & & 0.80 & 0.40 & 6.4 & 0.98 & 0.98 & 0.10 \\
\hline $\begin{array}{c}\text { HLDT, } \\
\text { (ALVW } \\
>\text { 5750lbs) }\end{array}$ & 0.39 & - & 5.0 & - & 1.1 & & 0.80 & 0.56 & 7.3 & 1.53 & 1.53 & 0.12 \\
\hline
\end{tabular}

\subsubsection{NLEV: 1999-2003}

National Low Emission Vehicle (NLEV) is a voluntary program that came into effect during the transition period of Tier I to Tier II (i.e. 1999 -2003). During this phase the emissions standards were more stringent and are equivalent to California Low emission Vehicle Program. (U.S. EPA. 1997). These standards are summarized in Table 2.3. Vehicles certified to standards lower than Low emission vehicles (LEV) during this transition phase are known as Transitional low emission vehicle (TLEV) standards. During this phase restriction on alcohols and carbonyls along with Non-methane hydro carbons (NMHC) usually referred as Non-methane organic gasses (NMOG) are phased in, while Tier I restricts Non-methane hydro carbons only. $\mathrm{NO}_{\mathrm{x}}$ emission standards for useful life of 100,000 miles/ 10 years is 50\% lower than Tier I standards. 
Table 2.3 NLEV Emission standards in comparison to Tier I and LEV (U.S. EPA 2016)

\begin{tabular}{|c|c|c|c|c|c|c|c|c|c|}
\hline \multirow{2}{*}{\multicolumn{2}{|c|}{ Category }} & \multicolumn{4}{|c|}{50,000 miles/ 5 Years } & \multicolumn{4}{|c|}{100,000 miles $/ 10$ years } \\
\hline & & NMOG & $\mathrm{CO}$ & NOx & $\mathrm{PM}$ & NMOG & $\mathrm{CO}$ & NOx & $\mathrm{PM}$ \\
\hline \multirow{3}{*}{ Passenger car } & Tier I & 0.25 & 3.4 & 0.4 & 0.08 & 0.31 & 4.2 & 0.6 & - \\
\hline & TLEV & 0.125 & 3.4 & 0.4 & - & 0.156 & 4.2 & 0.6 & 0.08 \\
\hline & LEV & 0.075 & 3.4 & 0.2 & - & 0.055 & 4.2 & 0.3 & 0.08 \\
\hline \multirow{3}{*}{$\begin{array}{c}\text { LDT } \\
(\text { LVW }<3750 l b s)\end{array}$} & Tier I & 0.25 & 3.4 & 0.4 & 0.08 & 0.31 & 4.2 & 0.6 & - \\
\hline & TLEV & 0.125 & 3.4 & 0.4 & - & 0.156 & 4.2 & 0.6 & 0.08 \\
\hline & LEV & 0.075 & 3.4 & 0.2 & - & 0.055 & 4.2 & 0.3 & 0.08 \\
\hline \multirow{3}{*}{$\begin{array}{c}\text { LDT } \\
(\mathbf{L V W}>3750 \mathrm{lbs})\end{array}$} & Tier I & 0.32 & 4.4 & 0.7 & 0.08 & 0.40 & 5.5 & 0.97 & - \\
\hline & TLEV & 0.16 & 4.4 & 0.7 & - & 0.200 & 5.5 & 0.9 & 0.10 \\
\hline & LEV & 0.10 & 4.4 & 0.4 & - & 0.130 & 5.5 & 0.5 & 0.10 \\
\hline
\end{tabular}

\subsubsection{Phase 2 or Tier II: 2004-2009}

EPA announced update to Tier I emission regulation in 1999, which were phased in from 2004. (U.S EPA 2016). Tier II standards are not based on vehicle weight, instead it was divided into 10 Bins while the $1^{\text {st }}$ is cleanest and the $10^{\text {th }}$ is Dirtiest. Bins from 1-10 apply for light duty trucks and passenger cars. Bins 9, 10 are phased out at the end of 2006, and from 2009 emission standards of light duty trucks must meet with passenger cars. These standards over FTP cycle are summarized in Table 2.4.. During this phase, Sulphur content in diesel was restricted to 15 ppm from 2007 and was made compulsory from 2010. This diesel with 15 ppm of Sulphur is referred as Ultra-Low Sulphur Diesel (ULSD) (U.S. EPA 2000).

During this phase Light-duty vehicle (LDV)/Light-duty trucks (LDT) were required to meet supplemental exhaust emission standards over US06 and SC03 driving cycles in addition to FTP cycle standard and is referred to as Supplemental Federal Test Procedure (SFTP). It also asks manufacturers to calculate their applicable full useful life SFTP standard as follows.

$$
\text { SFTP Standard }=\text { SFTP } 1-[0.358 *(\text { Tier } 1 \text { FTP }- \text { Tier } 2 \text { FTP })](40 \text { CFR §86.1811-04). }
$$


Table 2.4 Tier II FTP 75 Emission standards

\begin{tabular}{|c|c|c|c|c|c|c|c|c|c|c|}
\hline \multirow{2}{*}{ Bins } & \multicolumn{9}{|c|}{ Intermediate Life (5 years/50,000miles) } & \multicolumn{5}{c|}{ Full Life } \\
\cline { 2 - 12 } & NMOG & CO & NOx & PM & HCHO & NMOG & CO & NOx & PM & HCHO \\
\hline $\mathbf{1 0}$ & 0.125 & 3.4 & 0.4 & - & 0.015 & 0.156 & 4.2 & 0.6 & 0.08 & 0.018 \\
\hline $\mathbf{9}$ & 0.075 & 3.4 & 0.2 & - & 0.015 & 0.090 & 4.2 & 0.3 & 0.06 & 0.018 \\
\hline $\mathbf{8}$ & 0.100 & 3.4 & 0.14 & - & 0.015 & 0.125 & 4.2 & 0.20 & 0.02 & 0.018 \\
\hline $\mathbf{7}$ & 0.075 & 3.4 & 0.11 & - & 0.015 & 0.090 & 4.2 & 0.15 & 0.01 & 0.018 \\
\hline $\mathbf{6}$ & 0.075 & 3.4 & 0.08 & - & 0.015 & 0.090 & 4.2 & 0.10 & 0.01 & 0.018 \\
\hline $\mathbf{5}$ & 0.075 & 3.4 & 0.05 & - & 0.015 & 0.090 & 4.2 & 0.07 & 0.01 & 0.018 \\
\hline $\mathbf{4}$ & - & - & - & - & - & 0.070 & 2.1 & 0.04 & 0.01 & 0.011 \\
\hline $\mathbf{3}$ & - & - & - & - & - & 0.055 & 2.1 & 0.03 & 0.01 & 0.011 \\
\hline $\mathbf{2}$ & - & - & - & - & - & 0.010 & 2.1 & 0.02 & 0.01 & 0.004 \\
\hline $\mathbf{1}$ & - & - & - & - & - & 0.000 & 0.0 & 0.00 & 0.00 & 0.000 \\
\hline
\end{tabular}

\subsubsection{Phase 3A: 2010-2016}

This phase is to reduce greenhouse gas emissions by reducing 1.8 billion barrels of oil consumption, and is planned to achieve by the end of 2016 asking an avg. increase of 8 mpg per vehicle. President Barak Obama announced this policy of fuel economy and emission in 2009, to be phasing in from 2010 to 2016. All vehicles under 10,000 lbs. GVWR need to meet average fuel economy of 35.5 mpg based upon Corporate Average Fuel Economy (CAFE) standards (U.S. EPA 2012).

\subsubsection{Tier III: 2017-2025}

Tier III standards for light duty vehicles were proposed on March 2013, and was signed on third of March 2014. Structure of this standard is similar to Tier II but is closely aligned with California LEV III standards, which also tightens regulation on Sulphur limits in gasoline. (U.S. EPA 2014) 
Tier III has seven certification Bins, from which manufacturers have to meet one among those to certify their vehicles. Standards are expressed with the sum of $\mathrm{NO}_{\mathrm{x}}, \mathrm{NMOG}$ emissions and the average of these emissions must reduce to 30mg per mile by 2025. Durability of vehicles have been increased from 120,000 miles to 150,000 miles. (U.S. EPA 2014)

All vehicles must be certified over HWFET in addition to FTP-75 driving cycle and test procedures. Tier III standards are applicable to all vehicles as shown in Table 2.5.

Table 2.5 Tier III FTP 75 Emission Standards (U.S. EPA 2014)

\begin{tabular}{|c|c|c|c|c|}
\hline \multirow{2}{*}{ Bin } & NMOG + NOx & PM & CO & HCHO \\
\cline { 2 - 5 } Bin 160 & $\mathrm{mg} / \mathrm{mi}$ & $\mathrm{mg} / \mathrm{mi}$ & $\mathrm{g} / \mathrm{mi}$ & $\mathrm{mg} / \mathrm{mi}$ \\
\hline Bin 125 & 160 & 3 & 2.1 & 4 \\
\hline Bin 70 & 125 & 3 & 1.7 & 4 \\
\hline Bin 50 & 70 & 3 & 1.7 & 4 \\
\hline Bin 30 & 50 & 3 & 1.0 & 4 \\
\hline Bin 20 & 30 & 3 & 1.0 & 4 \\
\hline Bin 0 & 20 & 0 & 0 & 0 \\
\hline
\end{tabular}

\subsection{Light Duty Diesel Emission Control Technologies}

NOx and PM emissions from Light Duty Diesel trucks is reduced by $95 \%$ and $80 \%$ respectively from Tier I to meet Tier II standards. Studies show that these reductions in emissions were achieved through modifications in engine designs through the use of cooled EGR, fuel timing retardation and high-pressure fuel injections (Dickey, Ryan III and Matheaus 1998), SCR is capable of reducing NOx emissions by 90\% (Keuper, et al. 2011). Use of NOx traps can reduce NOx emission by $70 \%$ or more (Manufacturers of Emission Controls Association 2007). Particulate Matter can be reduced by $90 \%$ with the use of DPF, and DOC reduces unburned hydrocarbons. 


\subsubsection{Exhaust Gas Recirculation}

To meet 2004 Federal NOx emission regulations manufacturers developed systems for Exhaust Gas Recirculation. EGR is a method through which a portion of exhaust gas is circulated back into combustion chamber through air inlet manifolds. The two principles alluded to reduce NOx using EGR are (1) EGR acts as heat sink reducing peak combustion temperatures, where heat absorbed by EGR is proportional to EGR flow rate (m) times specific heat at $\mathrm{C}_{\mathrm{p}}$ (const. pressure) and temperature difference between EGR and combustion temperature $(\Delta T)$.

(2) Secondly, displacing freshly induced oxygen by inert exhaust gas. NOx is formed as a function of Nitrogen $\left(\mathrm{N}_{2}\right)$, Oxygen $\left(\mathrm{O}_{2}\right)$, combustion temperature and residence time. (Zheng, Reader and Hawley 2003)

The pressure difference that exists between intake and exhaust manifold does not allow free flow of EGR to intake manifolds. Especially in engines with turbo charger, where the pressure at intake manifold is greater than the exhaust, it is difficult to introduce EGR back into intake manifold. Therefore, manufacturers came up with High Pressure and Low Pressure loops.

\subsubsection{High Pressure Loop EGR}

In turbocharged diesel engines, the exhaust is collected upstream of turbo charger, VGT is adjusted to raise the pressure higher than that of intake manifold creating pressure difference. This Pressure difference drives the exhaust gas into intake manifold and is controlled through EGR valve electronically after being cooled. This approach is referred to as High Pressure Loop (HPL) EGR.

HPL EGR in light-duty diesel trucks showed effective results in reducing $\mathrm{NO}_{\mathrm{x}}$ to 0.05g/mile (Yokomura, Kohketsu and Mori 2003). At the same time, it has resulted in increase of fuel consumption associated with PM emissions. 
Some researchers used venturi to increase pressure drop between the exhaust and intake manifolds facilitating EGR flow into inlet. Using the venturi reduced pumping losses of flow as venturi increases kinetic energy of the flow (Yokomura, Kohketsu and Mori 2003).

\subsubsection{Low Pressure Loop EGR}

In this scheme, the exhaust collected downstream of after treatment and circulated ahead of turbocharger, thus the turbine can utilize all of the exhaust. As the pressure at the exhaust is low and to promote the flow EGR is introduced back into engine at upstream of turbocharger. The pressure difference is adequate to reduce the NOx levels.

Low Pressure Loop EGR has advantages of low fuel consumption when compared to HPL EGR, reduced amount of cooling required for EGR, better mixing of EGR with fresh air. At the same time, LPL EGR has disadvantages over HPL EGR as the carbonaceous material present in the exhaust stream can erode the blades of compressor at high speeds and there is a chance of CO gas emission when unburned oil vapors exposed to higher temperatures (Agarwal, Singh and Agarwal 2011). Approximately 50\% reduction in $\mathrm{NO}_{\mathrm{x}}$ emissions with no change in PM levels can be obtained using Low Pressure EGR loop with supplemental cooling (Maiboom, Tauzia and Hetet 2008).

Use of EGR reduces $\mathrm{NO}_{\mathrm{x}}$ formation proportional to the ratio of EGR. Test performed by (Uchido, et al. 1993) show 50\% $\mathrm{NO}_{\mathrm{x}}$ reduction at 20\% EGR rate at certain boost pressures and fuel injection. Whereas excessive EGR amounts resulted in unstable combustion, misfire accompanied by white smoke emission (Peng, et al. 2008).

\subsubsection{Selective catalytic Reduction}

To meet Tier II emission standards, 90\% reduction in NOx is required. Lean NOx Traps (LNT), Selective Catalytic Reduction (SCR) are the available technologies to meet the $\mathrm{NO}_{\mathrm{x}}$ 
standards. While SCR is not effective $\mathrm{NO}_{\mathrm{x}}$ at low exhaust temperatures. There are studies in which combination of both LNT and SCR are used to avoid necessity of Diesel Exhaust Fluid (DEF) known as passive SCR. (Wittka, et al. 2015).

SCR injects DEF through dosing system into exhaust flow. DEF is aqueous urea solution (AUS 32) contains about 32.5 percent urea and 67.5 percent deionized water by weight as this mixture produces lowest freezing point (Scott Sluder, et al. 2005). Aqueous Urea decomposes completely into ammonia in three steps, in first step water is evaporated (thermolysis) releasing urea, next step release one molecule of ammonia along with one molecule of isocyanic acid, finally isocyanic acid releases another ammonia molecule and carbon dioxide molecule (Scott Sluder, et al. 2005), final equation which is referred as hydrolysis of urea is listed below.

$$
\left(\mathrm{NH}_{2}\right)_{2} \mathrm{CO} \rightarrow 2 \mathrm{NH}_{3}+\mathrm{CO}_{2}
$$

This ammonia reacts with Nitrogen oxides to form Nitrogen and water thus reducing oxides of Nitrogen. (Khair, et al. 2004)

$$
6 \mathrm{NO}+4 \mathrm{NH}_{3} \rightarrow 5 \mathrm{~N}_{2}+6 \mathrm{H}_{2} \mathrm{O}
$$

In the exhaust where oxygen is abundantly available at lean combustion process, the standard reaction shown below is considered less relevant (Koebel, Elsener and Kleemann 2000).

$$
4 \mathrm{NO}+4 \mathrm{NH}_{3}+\mathrm{O}_{2} \rightarrow 4 \mathrm{~N}_{2}+6 \mathrm{H}_{2} \mathrm{O}
$$

Slow reaction takes place only with $\mathrm{NO}_{2}$ when $\mathrm{NO}_{x} / \mathrm{NO}$ ratio is more than $50 \%$ as shown below (Bosch and Janssen 1988).

$$
6 \mathrm{NO}_{2}+8 \mathrm{NH}_{3} \rightarrow 7 \mathrm{~N}_{2}+12 \mathrm{H}_{2} \mathrm{O}
$$

Most desired and fast reaction is known to be obtained when $\mathrm{NO}$ and $\mathrm{NO}_{2}$ are in equal ratios. This reaction is given in the following equation, which is also known, as "Fast SCR" reaction (Bosch and Janssen 1988). 


$$
\mathrm{NO}+\mathrm{NO}_{2}+2 \mathrm{NH}_{3} \rightarrow 2 \mathrm{~N}_{2}+3 \mathrm{H}_{2} \mathrm{O}
$$

Ammonia sometimes reacts with Nitrogen dioxide to form ammonium nitrate $\left(\mathrm{NH}_{4} \mathrm{NO}_{3}\right)$, which occurs at temperatures below $200^{\circ} \mathrm{C}$ (Koebel, Madia and Elsener 2002).

$$
2 \mathrm{NH}_{3}+2 \mathrm{NO}_{2} \rightarrow \mathrm{NH}_{4} \mathrm{NO}_{3}+\mathrm{N}_{2}+\mathrm{H}_{2} \mathrm{O}
$$

Sulphur present in fuel can be oxidized during combustion and over DOC might react with water to form Sulfuric acid which might deactivate SCR catalysts forming Ammonium Sulphate (Huang, et al. 2003) and these reactions are shown below.

$$
\begin{gathered}
\mathrm{SO}_{2}+1 / 2 \mathrm{O}_{2} \rightarrow \mathrm{SO}_{3} \\
\mathrm{SO}_{3}+\mathrm{H}_{2} \mathrm{O} \rightarrow \mathrm{H}_{2} \mathrm{SO}_{4} \\
2 \mathrm{NH}_{3}+\mathrm{H}_{2} \mathrm{SO}_{4} \rightarrow\left(\mathrm{NH}_{4}\right)_{2} \mathrm{SO}_{4}
\end{gathered}
$$

The purpose of SCR is to reduce $\mathrm{NO}_{\mathrm{x}}$ and its efficiency depends on many factors such as $\mathrm{NO} / \mathrm{NO}_{2}$ ratio entering SCR, catalyst material, urea decomposition, and reaction temperatures inside SCR (Keuper, et al. 2011). These parameters are interdependent with each other for SCR performance.

Using SCR with AUS 32 technology $90 \%$ reduction in $\mathrm{NO}_{\mathrm{x}}$ levels from exhaust gas can be achieved (Keuper, et al. 2011). The same paper also shows that there is chance of increasing conversion efficiency by another 5\%, which might drop the necessity of having an EGR.

\subsubsection{Lean NOx Trap}

Lean $\mathrm{NO}_{\mathrm{x}}$ Trap (LNT) catalysts are used to reduce $\mathrm{NO}_{\mathrm{x}}$ from lean burn engine. Its works on the principle of trapping $\mathrm{NO}_{\mathrm{x}}$ during engine lean operation and reducing the stored $\mathrm{NO}_{\mathrm{x}}$ to $\mathrm{N}_{2}$ under rich conditions with reducing agents like $\mathrm{CO}, \mathrm{H}_{2}$ and THC (Kim, et al. 2003). This process of reducing the $\mathrm{NO}_{\mathrm{x}}$ is called regeneration which uses fuel addition (Parks, et al. 2008). Rich conditions can be obtained by injecting additional fuel into the cylinders, reducing oxygen availability and this kind of regeneration is call in-cylinder regeneration. In-cylinder regeneration 
affects total hydro carbons but did not affect any engine out $\mathrm{CO}$ and $\mathrm{H}_{2}$ emissions (West, et al. 2004).

LNT working temperature window is in the range of $200^{\circ} \mathrm{C}$ to $450^{\circ} \mathrm{C}$, the conversion efficiencies are in range of $80-90 \%$ observed at $350-380^{\circ} \mathrm{C}$ (Epling, et al. 2004). LNT efficiency drops as the exhaust temperature increases at high engine loads. Can be used only at low loads where SCR is ineffective, and cannot meet Tier II emission standards. Sulphur poisoning of fresh and aged traps requires Desulfation by exposing it to rich feed gas at higher temperatures, $\mathrm{NO}_{\mathrm{x}}$ storage efficiency reduces if Desulfation is not performed at regular intervals (Li, et al. 2001).

\subsubsection{Diesel Particulate Filter}

Diesel Particulate Filter (DPF) is used from 2004 to meet stringent EPA regulations on Particulate Matter. This filter collects particles (ash and soot) which is produced from diesel combustion. The particles accumulate in the filter over time and requires periodic regeneration of DPF. If the soot accumulated is not cleaned, there would be a pressure increase in the exhaust affecting engine operation. Soot is burned at regular exhaust temperatures by lowering oxidation temperatures with the use of oxidation catalyst or $\mathrm{NO}_{\mathrm{x}}$ catalyst which is known as passive regeneration and at temperatures from $550{ }^{\circ} \mathrm{C}$ to $700^{\circ} \mathrm{C}$ by addition of fuel to exhaust gasses known as active regeneration (Kong, et al. 2005). The particle number during a regeneration event is 3-4 times the order of magnitude when compared to particles during normal operational conditions. (Bergmann, et al. 2009), however the efficiency of DPF reduces as the soot-cake layer burns during regeneration (Bergmann, et al. 2009).

“The types of filters used in DPF are divided into three categories as follows:

(i) Non-catalytic filter based systems which use burners and electric heaters to bum the soot once it has been collected on the filter 
(ii) Catalytic filter-based systems which consist of filters with a catalyst coating, or filters used in combination with oxidation catalyst ahead of filter to help reducing the oxidation temperatures for passive regenerations.

Tests performed by (Barone, Storey and Domingo 2010) show 95\% reduction in particle emission by mass with a 4-year field aged DPF. They also show that particulate filters can capture harmful soot from a range of $30 \%$ to $95 \%$. Another journal article by (Herner, et al. 2009) also shows that DPF can reduce $>95 \%$ of PM irrespective of test cycles.

\subsubsection{Diesel Oxidation Catalyst}

Diesel Oxidation catalyst was introduced to oxidize harmful gases and diesel particles from exhaust gas. Gases like Hydrocarbons, carbon monoxide have very harmful effects like smog to the environment, which in turn results in adverse health effects. So, these harmful gases are oxidized to harmless by passing over oxidation catalysts.

Catalyst like palladium, platinum and aluminum oxide are used as DOC in after treatment of exhaust gas (Russell and Epling 2011). They serve as oxidation catalysts to oxidize hydrocarbons and carbon monoxides to water and carbon dioxides (Salomons, et al. 2006)

$$
\begin{gathered}
2 \mathrm{CO}+\mathrm{O}_{2} \rightarrow 2 \mathrm{CO}_{2} \\
\mathrm{C}_{i} \mathrm{H}_{2 i+2}+\left(\frac{3 i+1}{2}\right) \mathrm{O}_{2} \rightarrow i \mathrm{CO}_{2}+(i+1) \mathrm{H}_{2} \mathrm{O}
\end{gathered}
$$

Along with the oxidation of hydrocarbons, some of the undesired reactions like oxidation of sulfur dioxide to trioxide, which might later react with moisture to form sulfuric acid as follows

$$
\begin{gathered}
2 \mathrm{SO}_{2}+\mathrm{O}_{2}=2 \mathrm{SO}_{3} \\
\mathrm{SO}_{3}+\mathrm{H}_{2} \mathrm{O}=\mathrm{H}_{2} \mathrm{SO}_{4}
\end{gathered}
$$

In addition, oxidation of $\mathrm{NO}$ to $\mathrm{NO}_{2}$ which is more toxic, but can be used for passive DPF regeneration (Cooper, Jung and Thoss 1990) and to control SCR efficiency. 


\subsection{OBD Monitoring}

On-Board Diagnostics (OBD) is a self-diagnostic algorithm in automotive vehicles that monitors the health of various components. Earlier, if a malfunction is detected, OBD illuminates a light called "Malfunction Indicator Light" (MIL) which is not standardized. Later on devices developed standardized communications along with standardized trouble shooting codes, which can be used to identify type of malfunction occurred.

California Air Resources Board introduced OBD I regulation for all 1991 and newer vehicles using light-duty and heavy-duty engines in United States, which requires manufacturer to monitor components that control emissions. Later in 1996, OBD II regulation is implemented which requires all new gasoline and alternate fuel cars and trucks sold in California. From 1997, even diesel cars and trucks are required to follow OBD II regulations. (Santini 2011)

\subsubsection{OBD I}

OBD I is mostly about engine management, which includes Fuel, Ignition and Cooling. Figure 1 shows how engine management is done by the control unit taking inputs from sensors like to start an engine, inputs from Engine Coolant Temperature (ECT). Vehicle processor uses information from Intake Air Temperature (IAT), Crank shaft Position (CKP) and Cam Shaft Position (CMP) sensors and controls amount of fuel addition, time of ignition as an output. After the start of the engine it monitors other operations like advancing/retarding the timing of ignition through electronic ignition module, turning cooling fan ON/OFF based on engine operating temperature to maintain coolant temperatures. Oxygen Sensor $\left(\mathrm{O}_{2} \mathrm{~S}\right)$ that is present in exhaust manifold is used to control the fuel injection and it is important to check all the injected fuel is burnt. OBD I failed in identifying open fuel injector or a dead cylinder. OBD I dependency on 
sensors that are inaccurate lead to development of OBD II. (Santini 2011). OBD I codes from early 1980's through 1995 have two and three digit numbers without any letters.

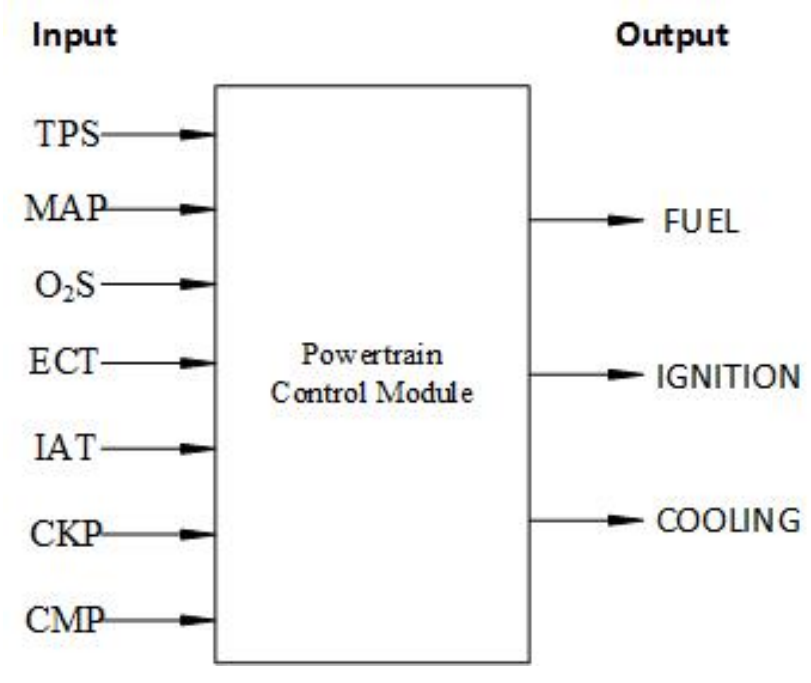

Figure 1 Schematic of $O B D I$

\subsubsection{OBD II}

OBD II is an improved version of OBD I in terms of capabilities and standards built inside Powertrain Control Module (PCM) of the vehicle. OBD II is designed in such a way that even a failure in chemical, mechanical and electrical component that might result in failure of emission reduction is considered as a malfunction. If a malfunction in any component is occurred, a freeze frame is generated with all information like speed, load, fuel levels etc. accompanied by MIL and Diagnostic Trouble Codes (DTC). Freeze frame, MIL, DTC are all functions of monitoring system. If OBD monitor cannot finish within the required timeframe it will set a code, OBD erases the code if same malfunction is not detected during next driving cycle (Santini 2011). 


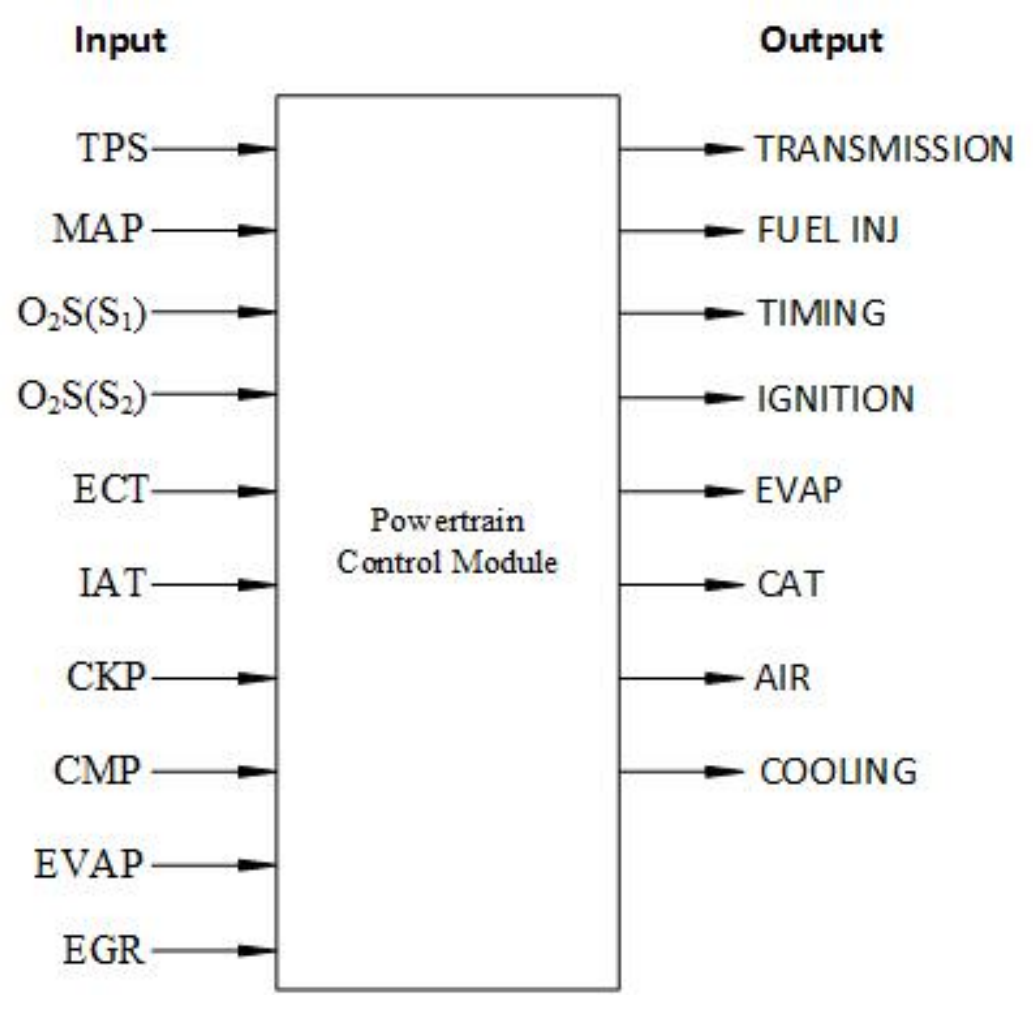

Figure 2 Schematic of $O B D$ II

Various operations that OBD II perform include monitoring all commands given by PCM like Transmission, Fuel injection, valve timing, Ignition timing, catalyst operation, cooling etc. with the feedback from sensors like Throttle Position Sensor (TPS), Manifold Absolute Pressure (MAP), EGR, ECT, IAT, CKP Etc..

\subsection{Comparison of $\mathrm{NO}_{\mathrm{x}}$ emission rates from chassis and real world}

Number of studies have been conducted across US and Europe to compare emission rates from on-road measurements and chassis dynamometer measurements. All those studies show drastic difference in $\mathrm{NO}_{\mathrm{x}}$ emissions rates. Summary from some of those studies are discussed here.

Luc Pelkmans and Patrick Debal in 2006 conducted a series of on-road tests and chassis dynamometer tests on a light duty diesel car certified on EURO 3. Dynamometer driving cycles used for this test were mostly focused on was European Drive Cycle (EDC) and cycles that are 
generated from real world speed profiles as similar to our current study. Whereas on-road testing was done on routes of Belgium and Spain which contain urban, rural and motor way traffic. The reported $\mathrm{NO}_{\mathrm{x}}$ emissions rates are 10 times higher on road than compared to NEDC, whereas fuel consumption and $\mathrm{CO}_{2}$ emissions are underestimated by 10-20 \% in NEDC cycle compared to real time traffic (Pelkmans and Debal 2006).

(Anderson, et al. 2014) Performed on-road testing on two Euro 6 diesel vehicles using PEMS and compared the emissions with those obtained on chassis dynamometer. $\mathrm{NO}_{\mathrm{x}}$ emissions from on-road routes were $\sim 4$ time's higher than those obtained on NEDC cycle. Vehicle with dual EGR showed $\mathrm{NO}_{\mathrm{x}}$ average of about $0.17 \mathrm{~g} / \mathrm{km}$ on-road, while it was $0.02 \mathrm{~g} / \mathrm{km}$ on NEDC. Vehicle with SCR showed $\mathrm{NO}_{\mathrm{x}}$ average of about $0.16 \mathrm{~g} / \mathrm{km}$ on-road and $0.28 \mathrm{~g} / \mathrm{km}$ on NEDC cycle. It shows that $\mathrm{NO}_{\mathrm{x}}$ emissions are approximately 8 times lower on chassis dynamometer cycles than on-road.

(Alves, et al. 2015) Conducted a series of test on five light duty diesel vehicles and three light duty gasoline vehicles. This study was performed on chassis dynamometer with EDC and ARTEMIS (real-world driving) cycles. The study shows a variation of $5-10$ times in $\mathrm{NO}_{\mathrm{x}}$ emissions levels compared to the standard certification cycles, while some of them could not meet the emission standards. Total hydrocarbon emissions \& particles emitted from gasoline vehicles are low when compared to diesel vehicles but emitted particles are negligible for diesel vehicles equipped with DPF (Alves, et al. 2015). The study also shows 35\% increase in fuel consumption during DPF regeneration event, while hydrocarbons, $\mathrm{NO}_{\mathrm{x}}, \mathrm{CO}$ and $\mathrm{CO}_{2}$ emissions increased by 95, 95, 35 and 99\% respectively. 


\subsection{Chassis Dynamometer Cycles}

\subsubsection{FTP 72 or LA-4}

This is a transient test cycle, which simulates urban route with stops regularly performed on chassis dynamometer for cars and light duty trucks. This test cycle can also be called as Urban Dynamometer Schedule (UDDS) or LA-4.

This cycle has a maximum speed of $91.2 \mathrm{~km} / \mathrm{h}$, average of about $31.5 \mathrm{~km} / \mathrm{h}$ over an urban route of $12.07 \mathrm{~km}$. The following figure is plot of speed vs time of this test cycle.

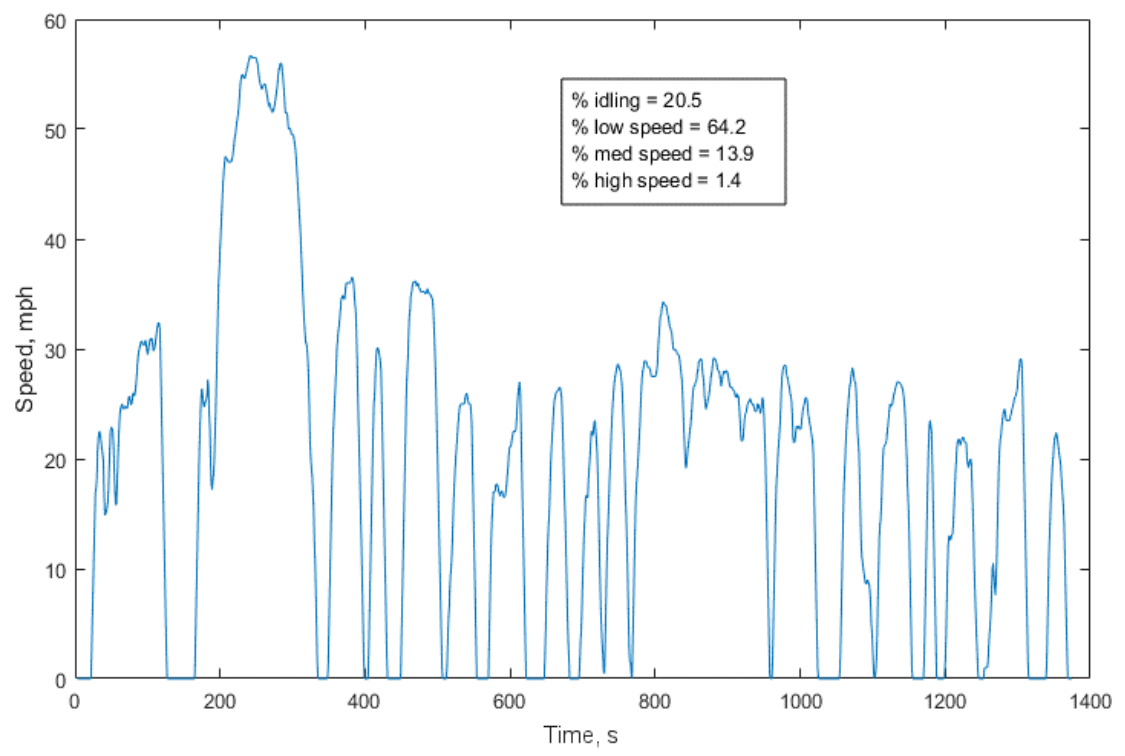

Figure 3 US EPA Urban Dynamometer Driving Schedule (FTP-72)

FTP-72 has two phases; one is a cold start with an average speed of $41.2 \mathrm{~km} / \mathrm{h}$ for 505 seconds $(5.78 \mathrm{~km})$ and other at $25.75 \mathrm{~km} / \mathrm{h}$ for 867 seconds $(6.20 \mathrm{~km})$. Weighting factors for both the phases are 0.43 and 0.57 respectively.

\subsubsection{FTP 75}

FTP-75 is another variant of Urban Dynamometer Driving Schedule (UDDS). This cycle is used in United States to certify emission and fuel economy testing. FTP-75 has three phases: first two identical to FTP-72, third phase is a hot start for 505 seconds with an average speed of 
$41.2 \mathrm{~km} / \mathrm{h}$ for 505 seconds $(5.79 \mathrm{~km})$ with a soak period of ten minutes after phase two. The weighting factors for each phase is $0.43,1 \& 0.57$ respectively.

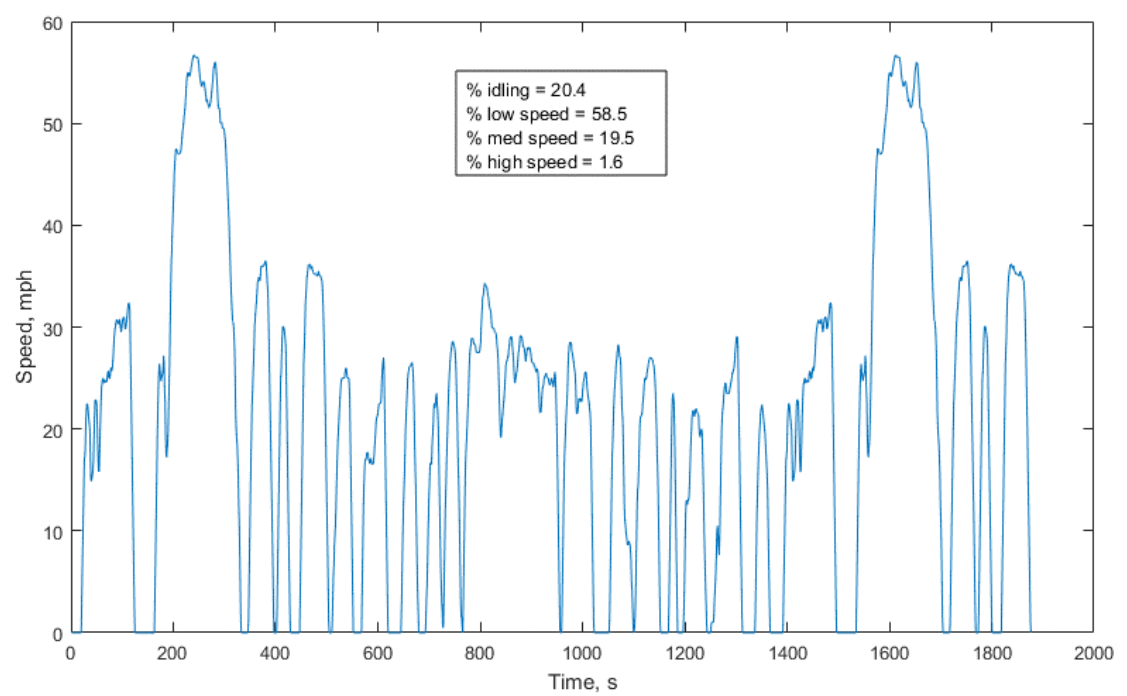

Figure 4 US EPA Urban Dynamometer Driving Schedule (FTP-75)

Total distance travelled in this driving cycle is $17.77 \mathrm{~km}$ with maximum speed of 91.25 km/h. Fuel economy calculations are based on FTP-75 HWFET, US06 and SC03. FTP 75 does not have rapid fluctuations or aggressive driving patterns like US06 and LA-4.

\subsubsection{Highway Fuel Economy Test}

Highway Fuel Economy Test - HWFET is a driving schedule developed to determine fuel economy of light duty vehicles by US EPA. The test run first for pre-conditioning and second time to measure emissions. This driving cycle is for a total duration of 765 seconds covering a distance of $16.45 \mathrm{~km}$ with a maximum speed of $96.3 \mathrm{~km} / \mathrm{h}$ and average speed of $77.7 \mathrm{~km} / \mathrm{h}$. 


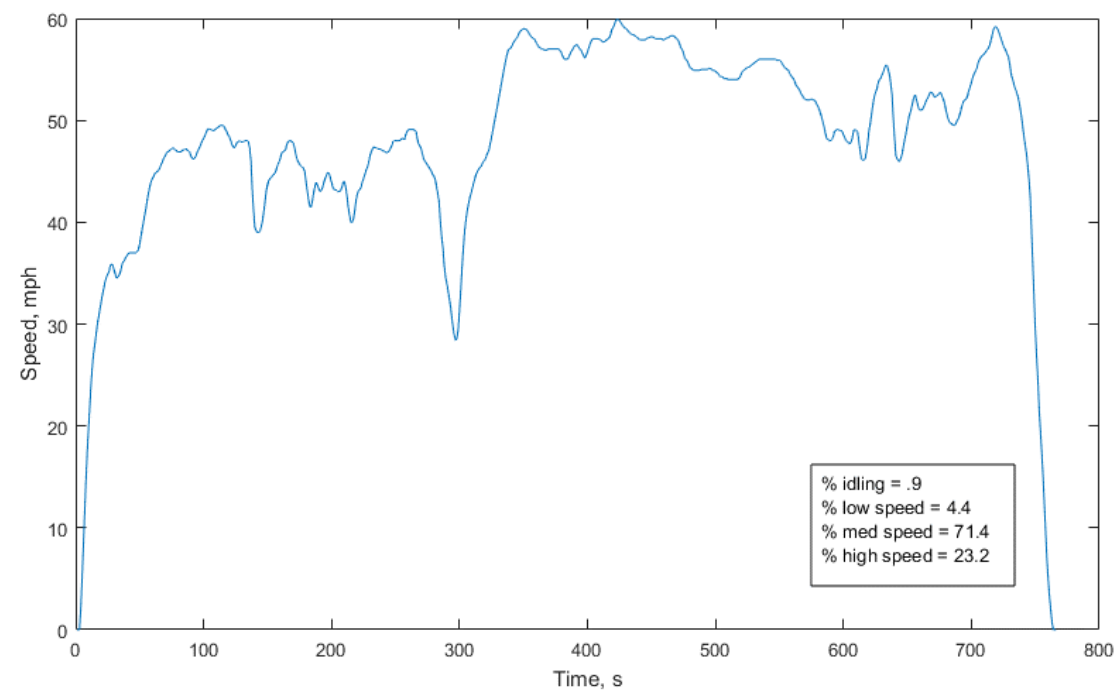

Figure 5 HWFET Driving Schedule

\subsubsection{SFTP US06}

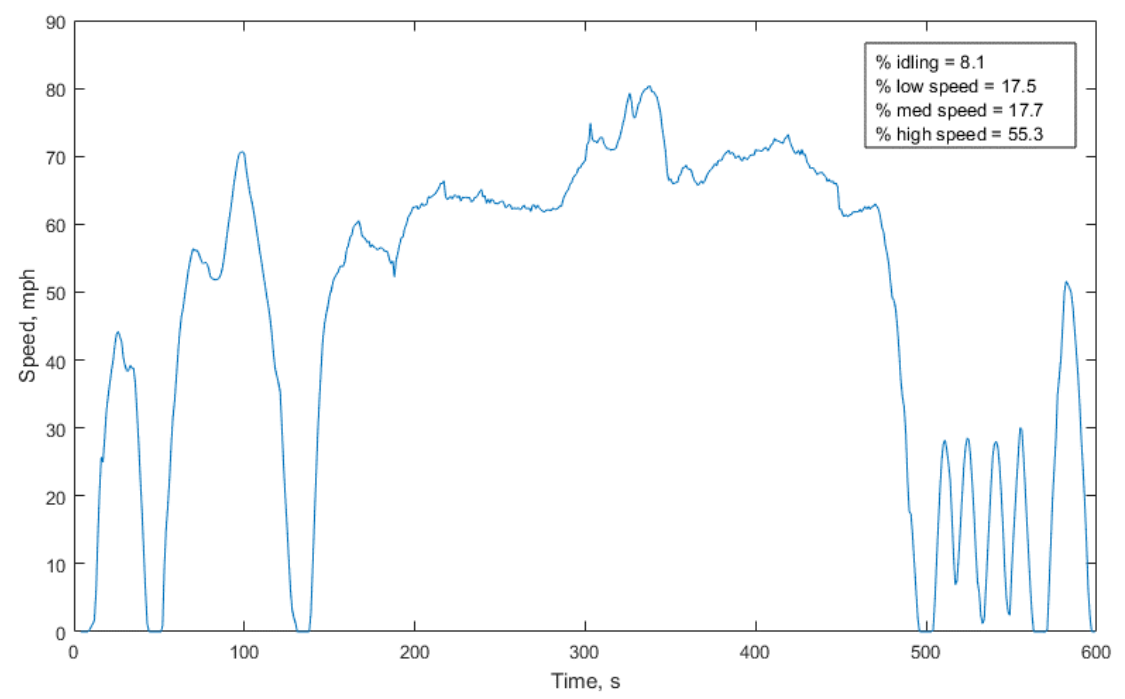

Figure 6 SFTP US06 Driving Cycle

SFTP refers to Supplemental Federal Test Procedure, designed to capture off-cycle emissions that are not reflected in FTP. US06 and SC03 are two cycles that come under SFTP and are used along with FTP-75 and HWFET from Tier II regulations. 
US06 is a representation of high speed and quick acceleration cycle, which is over a stretch of $12.8 \mathrm{~km}$ with a maximum speed of $129.2 \mathrm{~km} / \mathrm{h}$ and an average speed of $77.9 \mathrm{~km} / \mathrm{h}$ for a duration of 596 seconds.

\subsubsection{New European Driving Cycle}

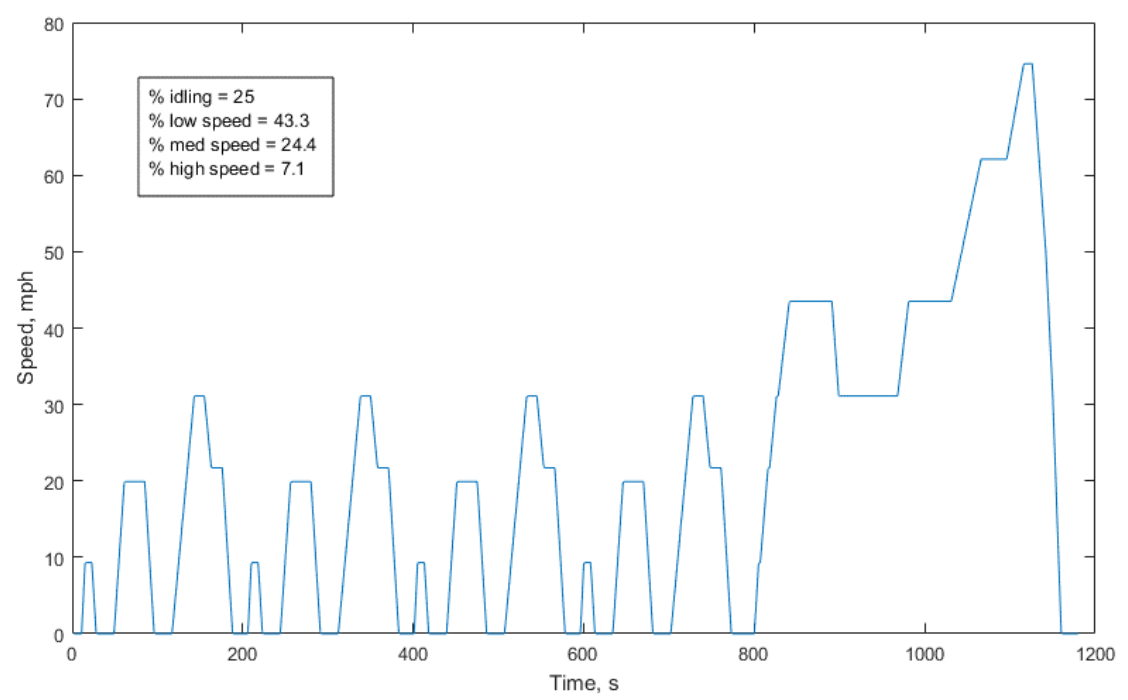

Figure 7 NEDC Driving Cycle

Figure 7 represents New European Driving cycle used to measure emission levels and fuel economy of passenger cars in Europe. This Cycle represents typical road driving patterns of Europe and consists four repetitions ECE-15 also known as urban driving cycle and one ExtraUrban driving cycle. NEDC cycle is over a stretch of $10.931 \mathrm{~km}$ with maximum speed of $120 \mathrm{~km} / \mathrm{h}$ and an average speed of $33.35 \mathrm{~km} / \mathrm{h}$ including stops and $43.10 \mathrm{~km} / \mathrm{h}$ excluding stops, total duration of the cycle is 1180 seconds with idle time for 267 seconds.

\subsubsection{Morgantown on-road Cycle.}

A standard road cycle is developed to represent real-world driving characteristics. Here Morgantown chassis cycle is created with the speed traces measured from real driving in the Morgantown city. This cycle covers a distance of $35.9 \mathrm{~km}$ over a duration of 2410 seconds with 
maximum speed of about $124.7 \mathrm{~km} / \mathrm{h}$ and an average speed of $53.6 \mathrm{~km} / \mathrm{h}$. This cycle represents on-road test route 1 of the current report. Figure 8 represents speed distribution of Morgantown chassis cycle.

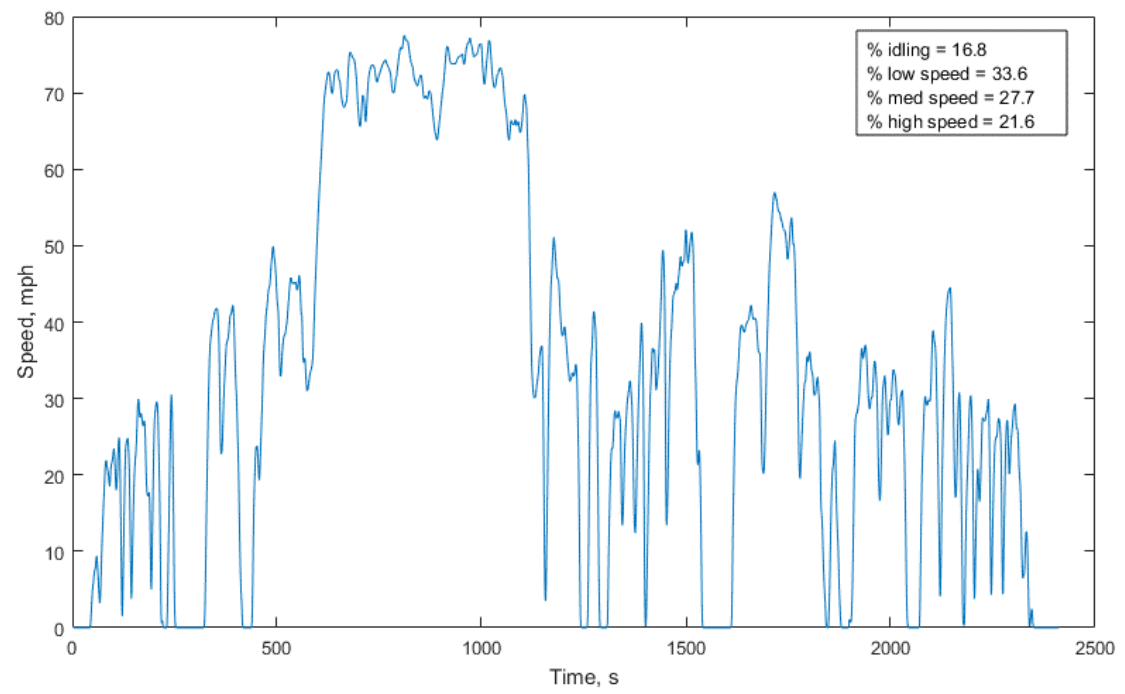

Figure 8: Morgantown Chassis Cycle

\subsection{European RDE}

European Union’s emissions type approval procedures includes Real-Driving Emissions (RDE) test for passenger cars, from September 2017. Ultimate goal of this regulation is to address the high $\mathrm{NO}_{\mathrm{x}}$ emissions from diesel cars in real world driving (ICCT 2015).

First European RDE testing requirements are published in March 2016, which states that test routes must contain three segments namely urban $(<60 \mathrm{~km} / \mathrm{h})$, rural $(60-90 \mathrm{~km} / \mathrm{h})$ and motor way $(>90 \mathrm{~km} / \mathrm{h})$ with each segment covering a distance of $16 \mathrm{~km}$ at least and contributing for a third of total. This RDE states that CO, NOx emissions should be measured on all Euro 6 vehicles that include passenger cars and light commercial vehicles. It also states that data obtained from 
PEMS should be processed in $\mathrm{CO}_{2}$ moving average window method and power binning method. (European Union 2016).

European Commission - Press release states that RDE testing requirements are introduced in three phases:

1. Monitoring phase - entered into force for new approvals from April 2016 without any Conformity Factor (CF).

2. Approval testing - $\mathrm{NO}_{\mathrm{x}}$ CF of 2.1 for MY 2017 to MY 2019 and 1.5 for MY 2020 and later. In addition, Particulate Number (PN) CF to be introduced in 2017 as RDE package 3.

3. In-service conformity requirements are expected by the end of 2016. (Brussels 2015)

RDE emission regulations limits are calculated as a Conformity Factor (CF) with respective NEDC emission limit.

\subsection{CAFE Standards}

Corporate Average Fuel Economy (CAFE) standards were first established in 1975 to reduce energy consumption by increasing fuel economy of vehicles. Department of Transportation established first fuel economy standards to Light Duty trucks. For MY 2007 engines the economy standards was set to 22.2 miles per gallon (mpg). The energy legislation signed and passed by the then president George W. Bush in 2007 set a goal for economy standard of 35 mpg by 2020. (THE WHITE HOUSE 2009).

Department of Energy (DOT) and Environmental Protection Agency (EPA) worked together to set a new standard of 35.5 mpg by the end of 2020 which surpassed the standard set by CAFE earlier (THE WHITE HOUSE 2009). 
EPA and DOT’s National Highway Traffic Safety Administration (NHTSA) set new standards to reduce Greenhouse Gas (GHG) emissions and improve fuel economy. EPA set GHG emission standards under Clean Air Act, which apply to passenger cars, light duty trucks and medium duty passenger vehicles. This standard is set to reduce $\mathrm{CO}_{2}$ to $163 \mathrm{~g} / \mathrm{mile}$ by the end of 2025 and fuel economy to 54.5 mpg for MY 2017 through MY 2025 light duty trucks (U.S. EPA 2012). This standard is set to save 4 billion barrels of crude oil approximately and GHG emissions by 2 billion metric tons (US EPA 2012). 


\section{Test setup and Methodology}

Test vehicles selected for this study with their specifications along with the test routes and their details are discussed briefly in Sections 3.1 and 3.2. The sampling instrument and its setup during the test is discussed in Section 3.3

\subsection{Test Vehicle information}

The Vehicles used for this study comprise one 2015 MY and three 2014 MY engine ultralow Sulphur diesel (ULSD) fueled Light duty trucks. These vehicles will be referred to as 'Vehicle A', 'Vehicle B', 'Vehicle C' and 'Vehicle D', and their specifications are shown in Table 3.1. All four vehicles are equipped with 3.0L turbocharged; six-cylinder base engine equipped with urea based SCR system, DOC and DPF to control $\mathrm{NO}_{\mathrm{x}}$ and PM emissions respectively. All four vehicles fall into Tier II- Bin 5 of US EPA emission standards whereas LEV-II ULEV in California emission standards.

Gross vehicle weight ratings (GVWR), and Actual test weights, which is a sum of curb weight and payload during on-road PEMS testing is listed in Table 3.2. Payload includes weight of measuring device and its associated equipment, weight of driver and one passenger. The diesel fuel used during this study is ultra-low Sulphur diesel purchased from Sheetz gas station Morgantown.

\subsection{Vehicle test routes and dynamometer test cycles}

On-road PEMS testing was done over four pre-defined routes, in which first two start and end at Engine and Emissions Research Laboratory (EERL) located at 360 Evansdale Drive Morgantown, while the other two start and end at Vehicle Engine Testing Laboratory (VETL)

located at 165 Distributor's Drive Morgantown. These on-road routes are be described briefly in 
the section 3.2.1. While Section 3.2.2 will describe briefly the chassis dynamometer cycles used during this study.

Table 3.1 Test Vehicles and engine specifications

\begin{tabular}{|c|c|c|c|c|c|}
\hline \multicolumn{2}{|c|}{ Vehicle } & A & $\mathbf{B}$ & $\mathbf{C}$ & $\mathbf{D}$ \\
\hline \multicolumn{2}{|c|}{ Model Year } & 2015 & 2014 & 2014 & 2014 \\
\hline \multicolumn{2}{|c|}{ Engine Family } & FCRXT03.05PV & ECRXT03.05PV & ECRXT03.05PV & ECRXT03.05PV \\
\hline \multicolumn{2}{|c|}{ Odometer [km] } & 3060 & 21626 & 28924 & 43236 \\
\hline \multicolumn{2}{|c|}{ Fuel } & ULSD & ULSD & ULSD & ULSD \\
\hline \multicolumn{2}{|c|}{ Engine Displacement [L] } & 3.0 & 3.0 & 3.0 & 3.0 \\
\hline \multicolumn{2}{|c|}{ Engine aspiration } & $\begin{array}{l}\text { Turbocharged/ } \\
\text { Intercooled }\end{array}$ & $\begin{array}{l}\text { Turbocharged/ } \\
\text { Intercooled }\end{array}$ & $\begin{array}{l}\text { Turbocharged/ } \\
\text { Intercooled }\end{array}$ & $\begin{array}{l}\text { Turbocharged/ } \\
\text { Intercooled }\end{array}$ \\
\hline \multicolumn{2}{|c|}{ After-treatment } & $\begin{array}{l}\text { OC, DPF, urea- } \\
\text { SCR }\end{array}$ & $\begin{array}{l}\text { OC, DPF, urea- } \\
\text { SCR }\end{array}$ & $\begin{array}{l}\text { OC, DPF, urea- } \\
\text { SCR }\end{array}$ & $\begin{array}{l}\text { OC, DPF, urea- } \\
\text { SCR }\end{array}$ \\
\hline \multirow{2}{*}{$\begin{array}{l}\text { Applicable } \\
\text { Limit }\end{array}$} & U.S EPA & $\begin{array}{c}\text { Tier-II Bin } 5 \\
\text { (LDT4) }\end{array}$ & $\begin{array}{c}\text { Tier-II Bin } 5 \\
\text { (LDT4) }\end{array}$ & $\begin{array}{c}\text { Tier-II Bin } 5 \\
\text { (LDT4) }\end{array}$ & $\begin{array}{c}\text { Tier-II Bin } 5 \\
\text { (LDT4) }\end{array}$ \\
\hline & CARB & LEV-II ULEV & LEV-II ULEV & LEV-II ULEV & LEV-II ULEV \\
\hline \multirow{3}{*}{$\begin{array}{c}\text { EPA Fuel } \\
\text { Economy } \\
\text { Values[mpg] }\end{array}$} & City & 19 & 19 & 19 & 19 \\
\hline & Highway & 27 & 27 & 27 & 27 \\
\hline & Combined & 22 & 22 & 22 & 22 \\
\hline \multicolumn{2}{|c|}{ EPA CO 2 Values [g/mile] } & 459 & 459 & 459 & 459 \\
\hline
\end{tabular}

Table 3.2: Test weights for vehicles

\begin{tabular}{|c|c|c|c|c|c|}
\hline & $\begin{array}{c}\text { Curb Weight } \\
\text { [lbs.] }\end{array}$ & $\begin{array}{c}\text { GVWR } \\
\text { [lbs.] }\end{array}$ & $\begin{array}{c}\text { ETW } \\
{[\text { lbs.] }}\end{array}$ & $\begin{array}{c}\text { Payload } \\
{[\text { lbs.] }}\end{array}$ & $\begin{array}{c}\text { Actual Test } \\
\text { Weight [lbs.] }\end{array}$ \\
\hline Vehicle & 5792 & 6950 & 6000 & 800 & 6592 \\
\hline Vehicle A & 5792 & 6950 & 6000 & 800 & 6592 \\
\hline Vehicle B & 5792 & 6950 & 6000 & 800 & 6592 \\
\hline Vehicle C & 5792 & 6950 & 6000 & 800 & 6592 \\
\hline
\end{tabular}




\subsubsection{Pre-defined On-road Test Routes}

Four test routes are prepared such that they start and end in Morgantown, with different topological conditions. Based on the vehicle operational speed these routes can be split into four categories such as i) urban driving, low speeds and frequent stops, ii) rural driving, medium speeds with occasional stops, iii) highway driving, high speeds with few or no stops and iv) uphill/downhill driving, medium to high speed on steeper road grades. (G. J. Thompson, et al. 2014). On-road test route characteristics are summarized in Table 3.3.

1) Route 1: rural and highway driving starting from EERL, Morgantown

2) Route 2: highway and uphill/downhill driving from EERL, Morgantown

3) Route 3: urban, rural and highway driving starting from VETL, Morgantown

4) Route 4: highway and uphill/downhill driving from VETL, Morgantown

Table 3.3: Comparison of test routes

\begin{tabular}{|c|c|c|c|c|}
\hline Routes & Route 1 & Route 2 & Route 3 & Route 4 \\
\hline Route distance $[\mathrm{km}]$ & 35.9 & 102 & 40 & 80 \\
\hline Avg. vehicle speed [km/h] & 46 & 93 & 53 & 82 \\
\hline Max. vehicle speed $[\mathrm{km} / \mathrm{h}]$ & 120 & 123 & 122 & 125 \\
\hline Avg. RPA $\left[\mathrm{m} / \mathrm{s}^{2}\right]$ & 0.31 & 0.37 & 0.34 & 0.26 \\
\hline \multicolumn{5}{|l|}{ Characteristic Power $\left[\mathrm{m}^{2} / \mathbf{s}^{3}\right]$} \\
\hline Min. elevation [m a.s.l] & 260 & 260 & 261 & 275 \\
\hline Max. elevation [m a.s.l] & 381 & 683 & 385 & 683 \\
\hline$\%$ Idling ( $\leq 2 \mathrm{~km} / \mathrm{h})$ & 20 & 5 & 11 & 3 \\
\hline$\%$ low speed $(>2, \leq 50 \mathrm{~km} / \mathrm{h})$ & 41 & 15 & 42 & 15 \\
\hline$\%$ med speed $(>50, \leq 90 \mathrm{~km} / \mathrm{h})$ & 19 & 9 & 27 & 24 \\
\hline \% high speed (>90 km/h) & 20 & 70 & 20 & 55 \\
\hline
\end{tabular}


Relative Positive Acceleration (RPA) is a metric used to analyze driving pattern and is used to develop chassis dynamometer cycle representing real world driving. The RPA is calculated as integral of the products of vehicle speed and positive acceleration for each instance in time over a given 'micro-trip' (Weiss, et al. 2011). For this study 'micro-trip' is defined as proposed by (Weiss, et al.) for any proportion for the test route, where vehicle speed is larger than $2 \mathrm{~km} / \mathrm{h}$ for next seconds or more. Instantaneous vehicle acceleration was calculated using the following equation using vehicle speed data which is obtained from OBD-II and subsequently filtered with negative values being converted to zero.

Where: $t_{j} \quad$ duration of micro-trip j

$$
R P A=\frac{\int_{0}^{t_{j}}\left(v_{i} \cdot a_{i}\right) d t}{x_{j}}
$$

$$
\begin{aligned}
& x_{j} \quad \text { distance of micro-trip j } \\
& v_{j} \quad \text { speed during each time increment } i \\
& a_{j} \quad \text { instantaneous positive acceleration during each time increment } i \text { contained } \\
& \quad \text { in the micro-trip } j
\end{aligned}
$$

Acceleration are calculated with forward difference for first data point, backward difference for last data point whereas central difference for rest of the data as suggested by (G. J. Thompson, et al. 2014).

Characteristic Power $\left(\mathrm{P}_{\mathrm{ch}}\right)$ is another metric derived by (Delgado, Clark and Thompson 2011) taking kinematic power and potential power over the driving route into account. It is a representative of positive mechanical energy supplied per unit mass and unit time. The following equation shows outline of characteristic power calculation in $\left[\mathrm{m}^{2} / \mathrm{s}^{3}\right]$.

$$
P_{c h}=\frac{1}{T} \sum_{i=2}^{N}\left[\frac{1}{2}\left(v_{i}^{2}-v_{i-1}^{2}\right)+g\left(h_{i}-h_{i-1}\right)\right]^{+}
$$


Where: $T$ duration of route

$$
\begin{array}{ll}
g & \text { gravitational acceleration } \\
v_{i} & \text { vehicle speed at each time step } \\
h_{i} & \text { altitude at each time step }
\end{array}
$$

Gravitational acceleration is taken as $9.81 \mathrm{~m} / \mathrm{s}^{2}$, vehicle speed and altitude at each time step is obtained from Engine Control Unit (ECU) and Global Positioning Sensor (GPS) respectively. GPS sensor data may not be accurate due to multiple factors like heavy cloud overcast, underpasses as well as high buildings, so an alternate method to calculate altitude was used. The following equation as a function of barometric pressure with reference to local ambient pressure and temperature.

$$
H=f\left(T_{0}, p_{0}, p_{\text {baro }}\right)=\left(\frac{T_{0}}{L}\right)\left[1-\left(\frac{p_{\text {baro }}}{p_{0}}\right)^{\left[\frac{R \cdot L}{g \cdot M_{\text {air }}}\right]}\right]
$$

Here reference temperature ' $T_{0}$ ' and pressure ' $P_{0}$ ' at ground level is obtained from local station i.e. Morgantown municipal airport, where as ' $P_{b a r o}$ ' is measured with humidity sensor, ' $g$ ', ' $R$ ', ' $M_{\text {air }}$ ' is gravitational acceleration, universal gas constant and molar mass of dry air and ' $L$ ' is temperature lapse rate $0.0065 \mathrm{~K} / \mathrm{m}$.

Table 3.3 represents driving characteristics of test routes on a working day with regular traffic. To compare these results from the road test, vehicles are tested on chassis dynamometer over certification test cycles currently being used by US EPA (FTP-75, US06, and HWFET), the European Union (NEDC) along with two custom made real world driving cycles (MGW and LA4). Table 3.4 shows comparison of dynamometer test cycles.

The geographic map of route 1 can be seen in Figure 9 and is approximately 36 kilometers in distance, which starts and ends 360 Evansdale drive. This route comprises highway driving for 
approximately $20 \%$ between exit 155 on I-79 South and exit 4 on I-68 East. Altitude elevation difference of 120 meters between highest and lowest elevation points above sea level in the route.

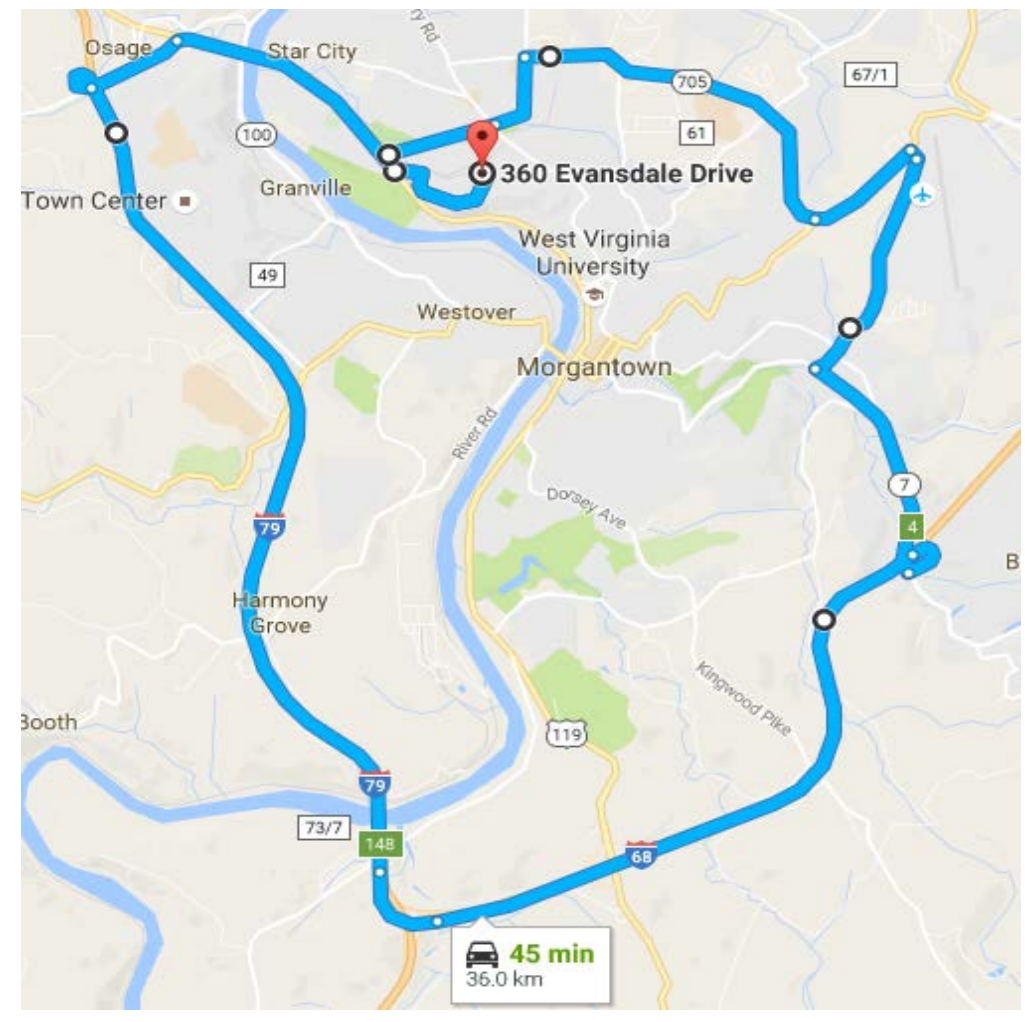

Figure 9 Geographic map of Route 1, rural and highway driving

Figure 10 shows the geographic map of route 2, the total distance is approximately $103 \mathrm{~km}$ with 70\% of highway driving with uphill and downhill driving starting from exit 155 on I-79 South and headed back from exit 23 on I-68 East. This route started, ended at 360 Evansdale drive with highest elevation 683 meters above sea level, and lowest elevation being 260 meters above sea level.

Figure 11 shows the geographic map of route 3 , the total distance is about $40 \mathrm{~km}$ with highway driving approximating to $20 \%$. The altitude difference is approximately 125 meters to the highest and lowest elevations points. The route starts and ends at 163 Distributor drive, and this route has more traffic during noon than compared to other routes. This route takes on an average of 55 min without traffic. 


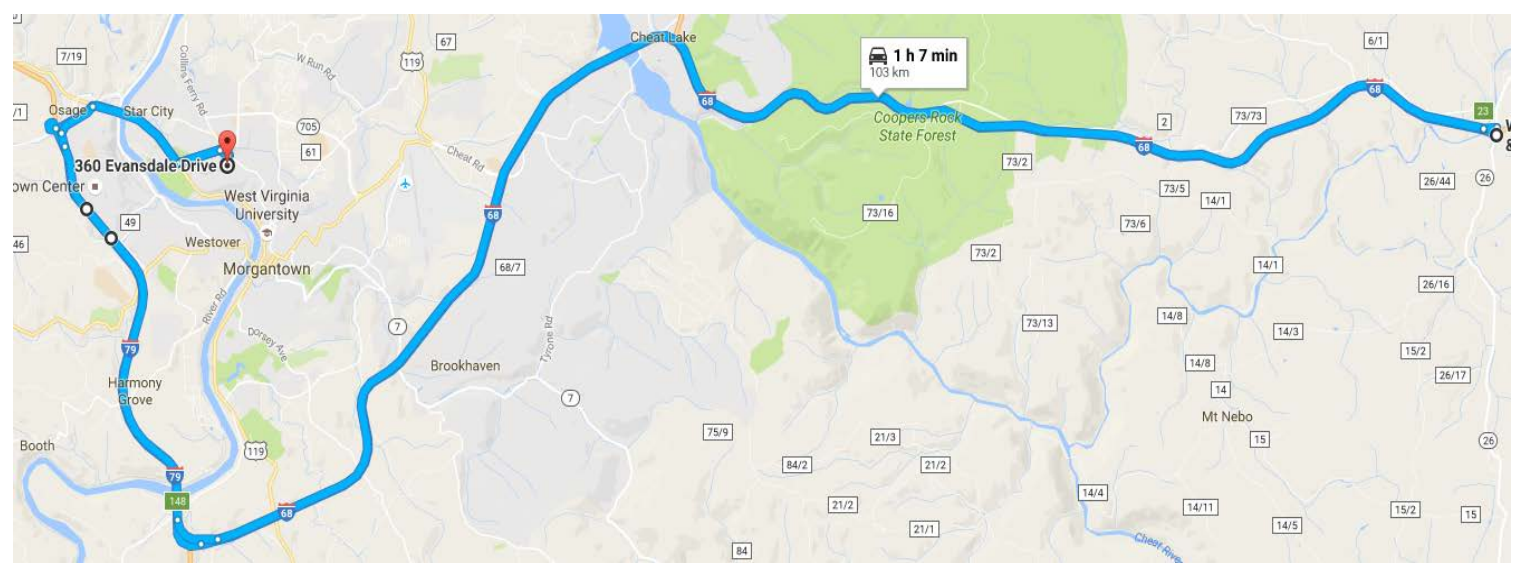

Figure 10 Geographic map of route 2, rural, highway and uphill/downhill driving

Figure 12 shows the geographic map of route 4 , the total distance is about $80 \mathrm{~km}$ with highway driving approximately $78 \%$ of the total distance. The highest altitude is approximately 680 meters above sea level where as the lowest observed altitude is 275 meters approximately. This routes starts and ends at 163 Distributor drive same as the route 3.

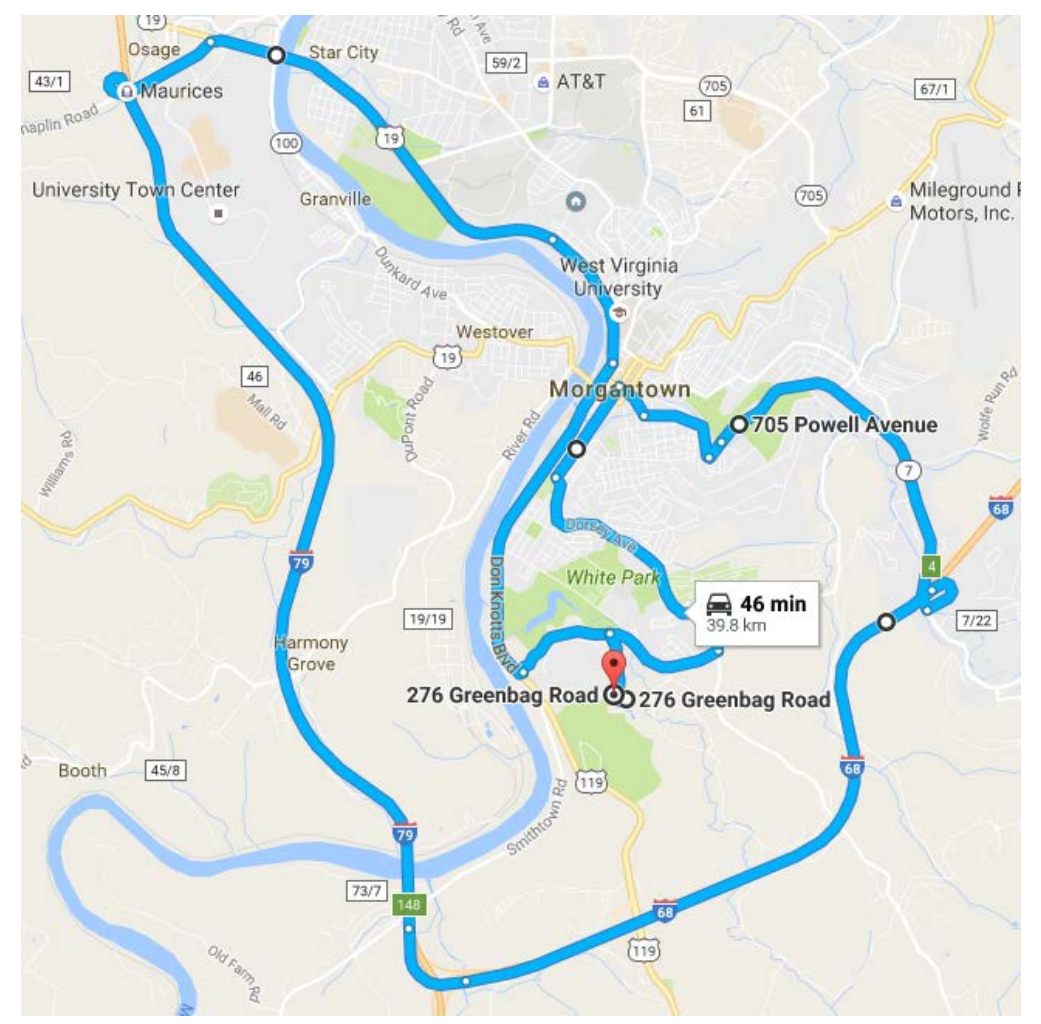

Figure 11 geographic map of route 3, urban, rural and highway driving 


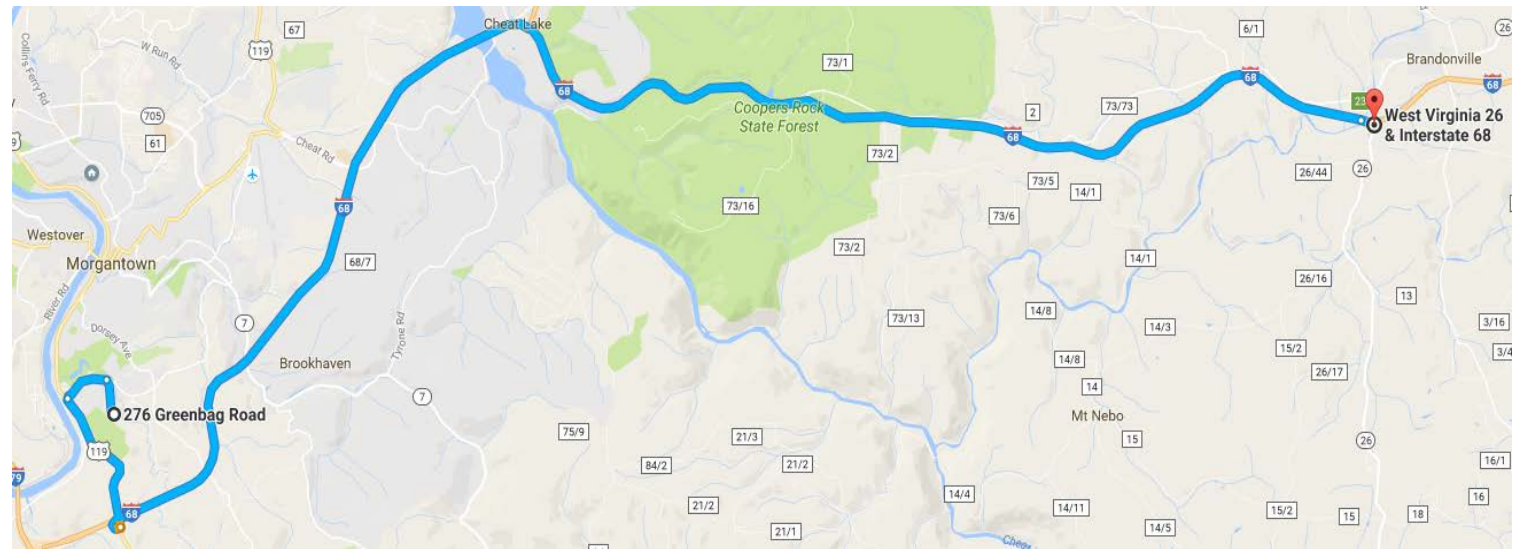

Figure 12 Geographic map of route 4, rural, highway and uphill/downhill driving

\subsubsection{Pre-defined dynamometer test cycles}

Four vehicles were tested on chassis dynamometer at Vehicle and Engines testing laboratory over three certification cycles (FTP-75, NEDC and US06), highway driving cycle (HWFET) and two custom made real world driving cycles (LA-4 and MGW). The characteristics of all these cycles has been discussed in Section 2.5of this report. The summary of these cycles can been seen in Table 3.4.

Table 3.4: Comparison of dynamometer cycles

\begin{tabular}{|c|c|c|c|c|c|c|}
\hline Cycle & FTP-75 & NEDC & US06 & HWFET & LA-4 & MGW \\
\hline Cycle duration [sec] & 1877 & 1180 & 596 & 765 & 2426 & 2410 \\
\hline Cycle distance [km] & 17.77 & 10.93 & 12.89 & 16.45 & 25.1 & 35.90 \\
\hline Avg. vehicle speed [km/h] & 34.08 & 33.35 & 77.84 & 77.7 & 37.3 & 53.63 \\
\hline Max. vehicle speed [km/h] & 91.25 & 120.0 & 129.23 & 96.3 & 111.8 & 124.66 \\
\hline Avg. RPA [m/ $\left.\mathrm{s}^{2}\right]$ & 0.23 & 0.15 & 0.52 & 0.18 & 0.32 & 0.27 \\
\hline Characteristic Power $\left[\mathrm{m}^{2} / \mathrm{s}^{3}\right]$ & 1.65 & 1.04 & 4.55 & 1.49 & 2.73 & 2.44 \\
\hline$\%$ Idling $(\leq 2 \mathrm{~km} / \mathrm{h})$ & 20.40 & 25.08 & 8.17 & 0.91 & 21.5 & 16.89 \\
\hline$\%$ low speed $(>2, \leq 50 \mathrm{~km} / \mathrm{h})$ & 58.50 & 43.31 & 17.67 & 4.44 & 42.8 & 33.69 \\
\hline$\%$ med speed $(>50, \leq 90 \mathrm{~km} / \mathrm{h})$ & 19.50 & 24.41 & 17.83 & 71.41 & 28.0 & 27.76 \\
\hline \% high speed (>90 km/h) & 1.60 & 7.12 & 55.67 & 23.24 & 7.5 & 21.66 \\
\hline
\end{tabular}




\subsection{Emissions Testing Procedure and Equipment}

The emissions sampling equipment used during this study consists of two sub-systems, one is to measure exhaust gas and other to measure particulate number. Figure 13 shows schematic of measurement test setup used for all vehicles. Exhaust gasses are measured using on-board emissions measurement system, OBS-One GS, from Horiba. Real-time particle number concentration are measured using Pegasor particle sensor (PPS), model PPS-M from Pegasor Ltd. PN is not a primary objective of this study, so it's not discussed in detail.

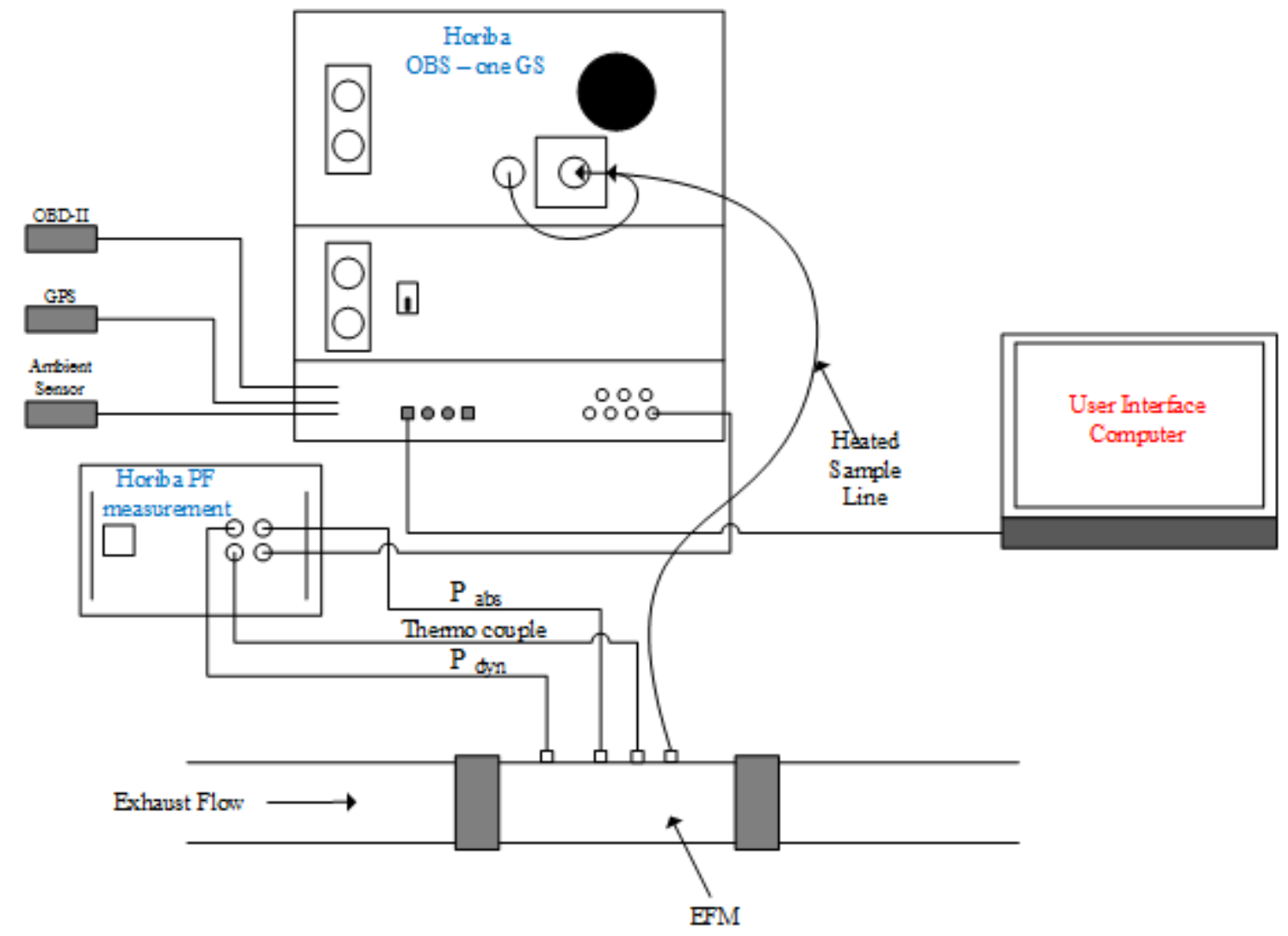

Figure 13 Schematic of measurement setup

OBS-one measurement system consists of one Non-Dispersive Infra-Red (NDIR) spectroscopy and two Chemi Luminescent Detector (CLD) analyzers to measure carbon and nitrogen components in the exhaust respectively. NDIR works on principle that $\mathrm{CO}$ and $\mathrm{CO}_{2}$ absorbs infrared light of wavelength $4.26 \mu \mathrm{m}$. A chopper wheel with $\mathrm{CO}, \mathrm{CO}_{2}$ and reference filter 
is mounted in front of detector. The change in intensity of light is measured by thermopile. The difference intensity is directly proportional to number of $\mathrm{CO}$ and $\mathrm{CO}_{2}$ molecules inside the analyzer (Shade 2000). Figure 14 is an image of NDIR cell along with Chopper Disk of filters.

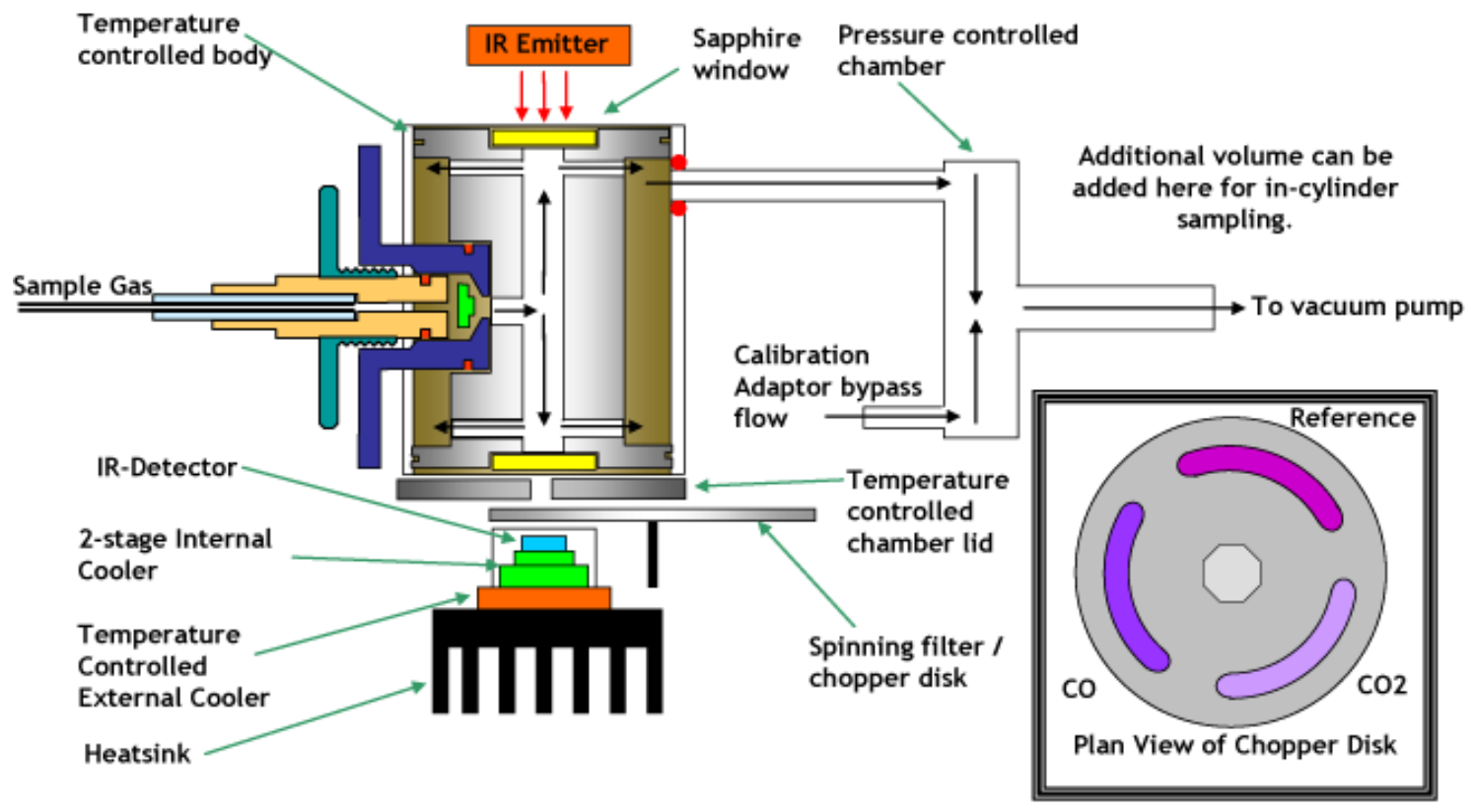

Courtesy: www.cambustion.com/products/ndir500/operating-principle

Figure 14: NDIR Cell

CLD (Chemi-luminescence Detector) analyzer is used to measure $\mathrm{NO}$ and $\mathrm{NO}_{\mathrm{x}}$, which produces photons when NO reacted with ozone. These photons are detected using photo multiplier tube (PMT), and the output voltage is proportional to concentration of NO inside the analyzer. OBS-one has two CLD analyzers, in which one measures NO directly while the other is used to measure $\mathrm{NO}_{\mathrm{x}}$ by converting all $\mathrm{NO}_{2}$ to $\mathrm{NO}$ and the difference of the measurement gives number of $\mathrm{NO}_{2}$ molecules. (Shade 2000). Figure 15 is a schematic of CLD analyzer, while Figure 16 is a schematic of CLD analyzers in OBS-One. 


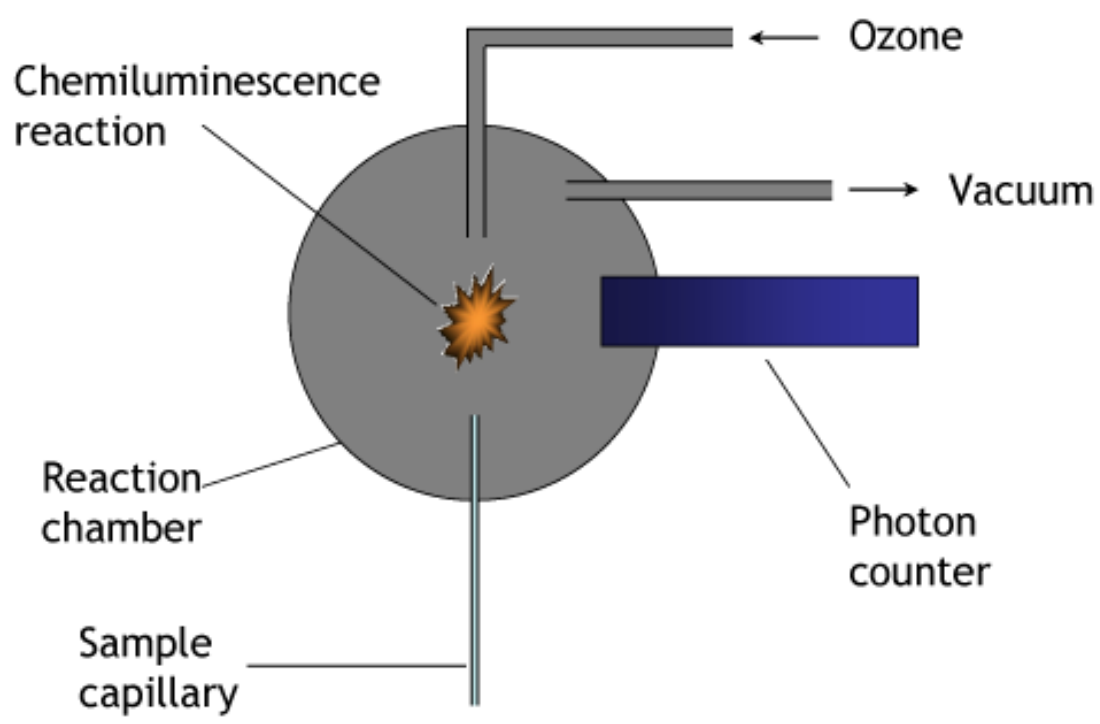

Courtesy: www.cambustion.com/products/cld500/cld-principles

Figure 15: CLD Analyzer

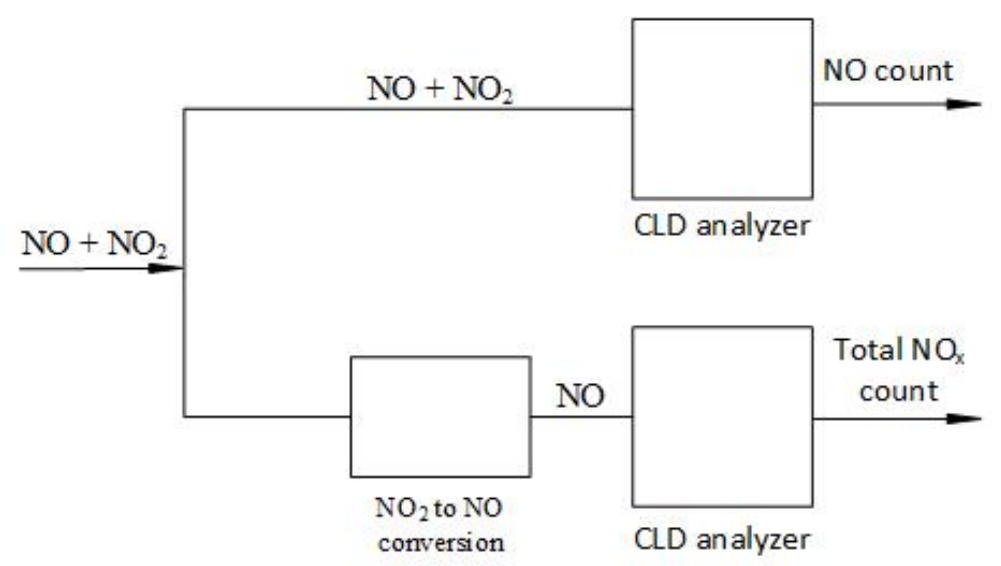

Figure 16 Schematic of CLD analyzers in OBS one

Table 3.5 lists of all parameters that have been measured during the test. Emission parameters are sampled and stored continuously at $10 \mathrm{~Hz}$ frequency whereas Engine Control Unit (ECU) and Global Positioning System (GPS) data is updated at $1 \mathrm{~Hz}$ but stored at $10 \mathrm{~Hz}$ frequency by data acquisition systems. Emission parameters are directly sampled by OBS-One through heated sample line from flow meter connected to exhaust. Two external sensors (GPS sensor, ambient temperature/ humidity sensor) are connected to data acquisition system. GPS receiver is used to measure relative speed, latitude, longitude and altitude. Ambient temperature / humidity 
sensor gives ambient conditions including temperature, barometric pressure and relative humidity. Exhaust flow is measured using pitot flow tubes from the flow meter. K-type thermocouple is used to measure exhaust gas temperature. Engine specific parameters are recorded from OBD-II port of the vehicle through OBD-II adaptor provided by Horiba along with OBS-one.

Table 3.5 List of measured parameters and respective instruments/analyzers

\begin{tabular}{|c|c|c|}
\hline \multirow{4}{*}{ Category } & Parameter & Measurement Technique \\
\hline \multirow{4}{*}{ Exhaust gas pollutants } & CO [ppm] & NDIR (Horiba OBS-one) \\
\cline { 2 - 3 } & CO2 [ppm] & NDIR (Horiba OBS-one) \\
\cline { 2 - 3 } Exhaust flow & NOx [ppm] & CLD (Horiba OBS-one) \\
\hline \multirow{3}{*}{ Exhaust PN/PM emissions } & Exhaust flow rate [m3/min] & PF (Horiba OBS-one) \\
\cline { 2 - 3 } & Exhaust temperature [oC] & PF (Horiba OBS-one) \\
\hline \multirow{4}{*}{ Ambient conditions } & Exhaust absolute pressure [kPa] & PF (Horiba OBS-one) \\
\hline \multirow{4}{*}{ Vehicle/route characteristics } & Ambient temperature [oC] & Pegasor Particle Sensor \\
\cline { 2 - 3 } & Ambient humidity [\%] & Temp. Sensor (OBS-one) \\
\cline { 2 - 3 } & Barometric Pressure [kPa] & Pressure Sensor (OBS-one) \\
\hline & Vehicle speed [km/h] & GPS \\
\cline { 2 - 3 } & Vehicle position [o] & GPS \\
\cline { 2 - 3 } & Vehicle altitude [m a.s.l] & GPS \\
\cline { 2 - 3 } & Vehicle acceleration [m/s2] & Derived from GPS data \\
\cline { 2 - 3 } & Vehicle distance traveled [km] & Derived from GPS data \\
\hline \multirow{4}{*}{ Engine performance } & Engine speed [rpm] & ECU OBD-II \\
\cline { 2 - 3 } & Engine load [\%] & ECU OBD-II \\
\cline { 2 - 3 } & Engine coolant temperature [oC] & ECU OBD-II \\
\cline { 2 - 3 } & Engine intake air flow [kg/min] & ECU OBD-II \\
\cline { 2 - 3 } & Exhaust temperature [oC] & ECU OBD-II \\
\hline
\end{tabular}

Experimental setup and instrument arrangement inside the test vehicles A, B, C and D can be seen in Figure 17, Figure 18. For on-road testing, sampling instrument (OBS-One) and its related accessories including air and gas bottles, compressor to supply dry air for PN measurement device, generator to meet power demands by the instruments are payload weighing approximately about $300 \mathrm{~kg}$ other than driver and passenger. This payload is not installed on the vehicle while testing them on chassis dynamometer. 


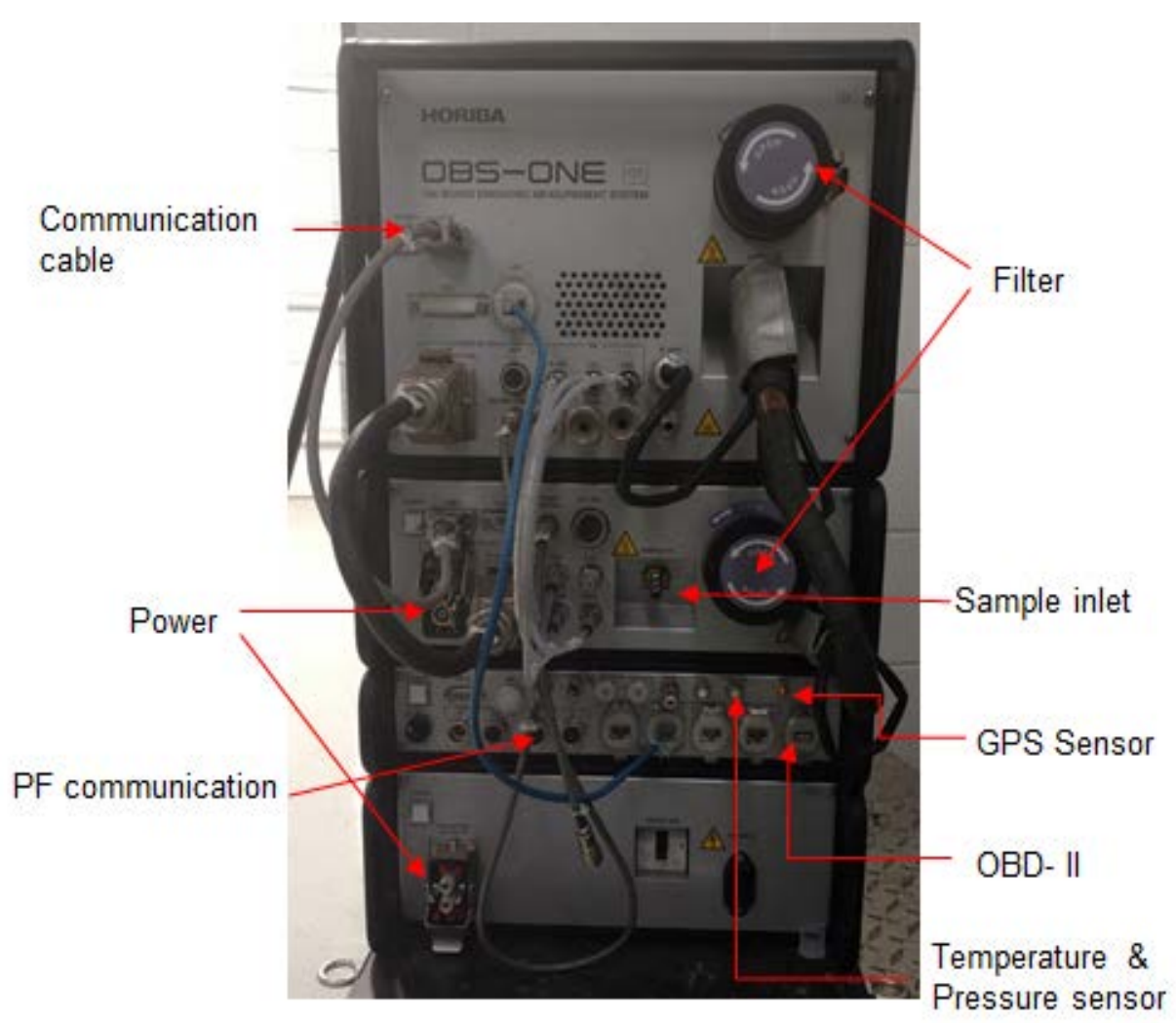

Figure 17 Measurement device setup

\subsection{Emissions Sampling - Horiba OBS-one}

OBS-One is a Portable Emission Measurement System manufactured by Horiba as per regulations mentioned in 40 CFR Part 1065. Exhaust gases are collected through a sample line, which is maintained at $191^{\circ} \mathrm{C}$ to prevent gases condensing in the sample line. $\mathrm{CO}$ and $\mathrm{CO}_{2}$ are measured using Non-Dispersive Infrared (NDIR) spectrometer, and $\mathrm{NO}_{\mathrm{x}}$ is measured using Chemiluminescence Detector (CLD) whose working principles are discussed earlier. Table 3.6 gives complete information regarding gasses measurement ranges and span values of each analyzer. These analyzers are calibrated and is tested for linearity. 


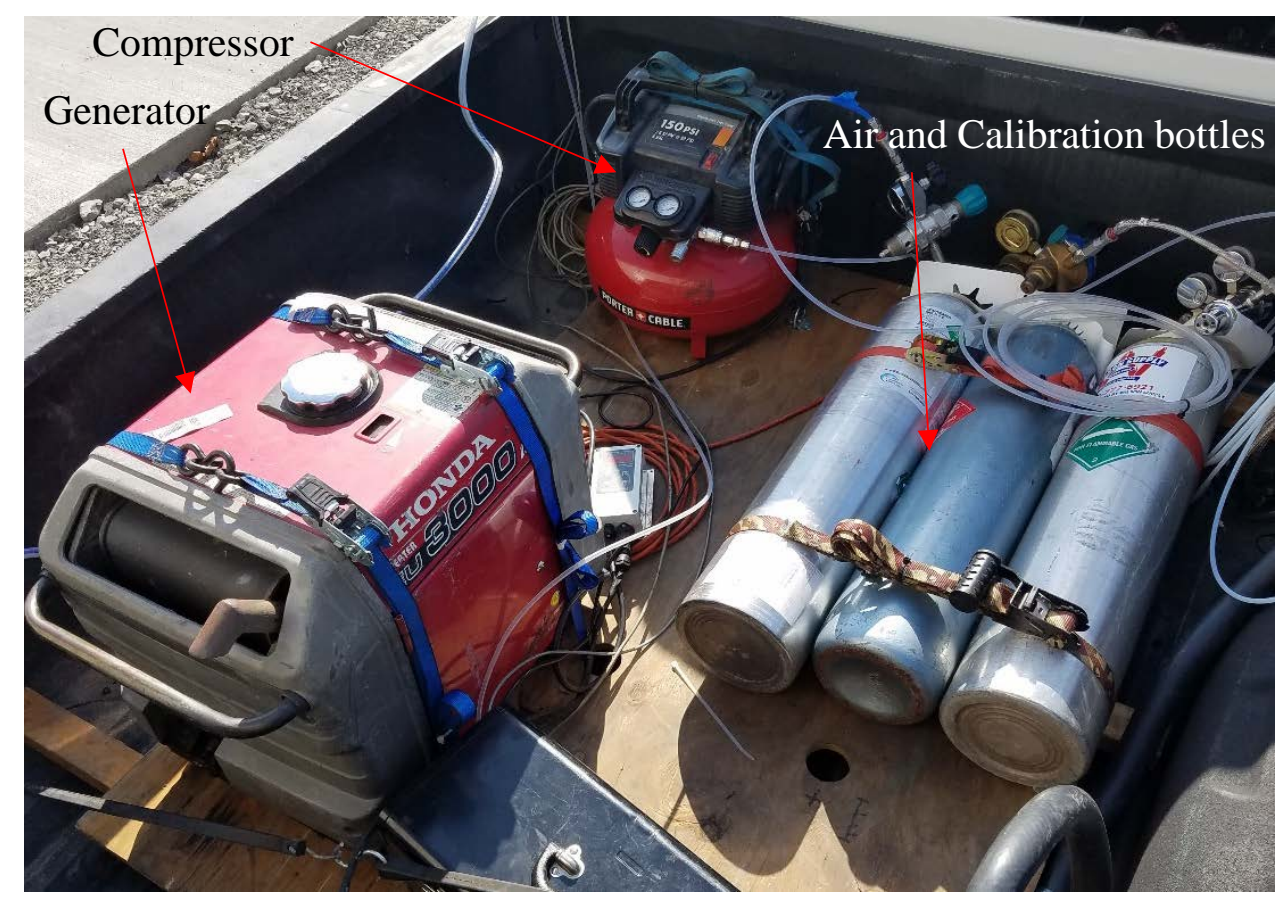

Figure 18 Instrumentation setup

Table 3.6: Horiba OBS-one, Gaseous analyzer specifications

\begin{tabular}{|c|c|c|c|c|}
\hline Component & Range & Span & Linearity & Accuracy \\
\hline CO & $10 \%$ & $0.10 \%$ & within $\pm 1.0 \%$ of full scale & within $\pm 2.5 \%$ of full scale \\
\hline CO $_{2}$ & $20 \%$ & $12.5 \%$ & within $\pm 1.0 \%$ of full scale & within $\pm 2.5 \%$ of full scale \\
\hline NO & $3000 p p m$ & $1396 \mathrm{ppm}$ & within $\pm 1.0 \%$ of full scale & within $\pm 2.5 \%$ of full scale \\
\hline NO $_{\mathbf{x}}$ & $3000 \mathrm{ppm}$ & $1396 \mathrm{ppm}$ & within $\pm 1.0 \%$ of full scale & within $\pm 2.5 \%$ of full scale \\
\hline
\end{tabular}

Emissions are collected through 1/2” National Pipe Thread Taper standard port installed on 2” diameter Exhaust Flow Meter (EFM) adapter mounted to exhaust end pipe. EFM has probes to measure flow rate by differential pressure and port for thermocouple to read exhaust gas temperature. The EFM used for all four vehicles during this study is shown in Figure 19. EFM installation, tail pipe adapter setup is similar for all Vehicles and can be seen in Figure 20 


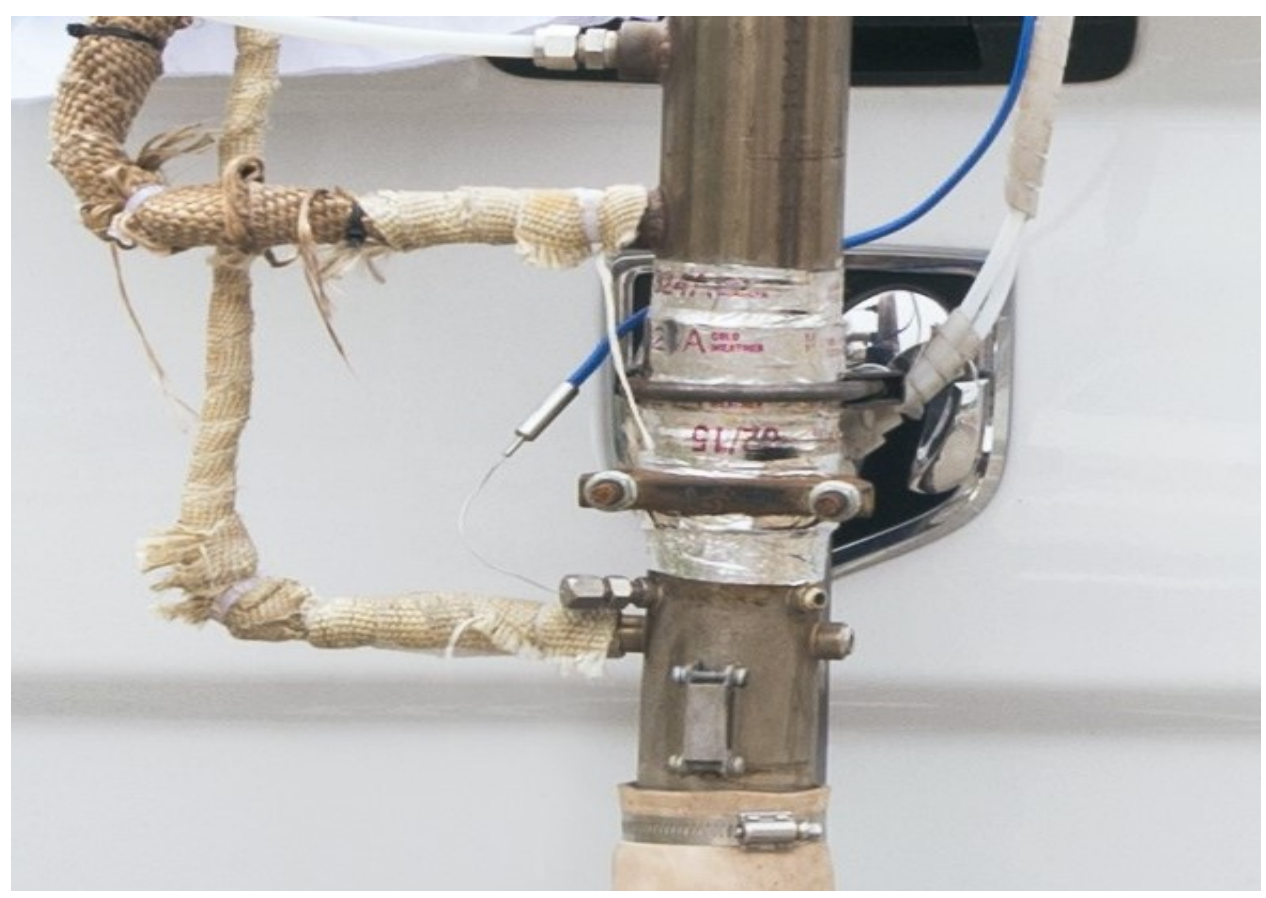

Figure 19 Exhaust Flow Meter [EFM]

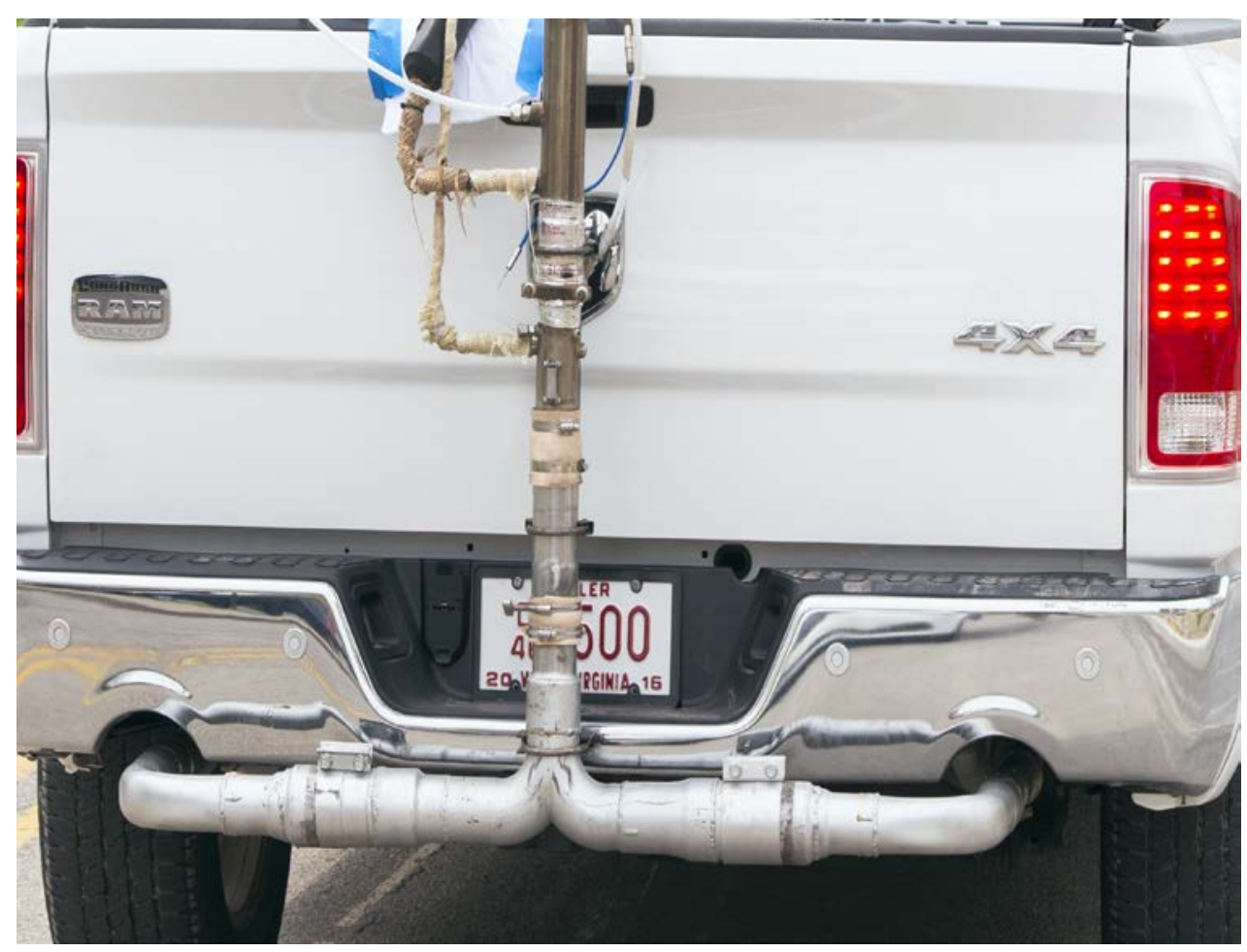

Figure 20 Tail pipe adapter setup for all Vehicles 


\subsection{PEMS Installation and pre-test checks}

\subsubsection{PEMS Verification and Analyzer Checks}

All measurement instruments used for this study is calibrated and verified as per regulations mentioned in CFR, Title 40, Part 1065, Subparts D and J. All the analyzers (CO, $\mathrm{CO}_{2}$ and $\left.\mathrm{NO}_{\mathrm{x}}\right)$ are individually verified for linearity by passing calibration gas mixture and blended Nitrogen at 10 ratios equally spaced. Least squares regression analysis is performed between analyzer’s response and theoretical calculations of calibration gas as per 40 CFR §1065.307.

All analyzers are checked for $\mathrm{H}_{2} \mathrm{O}$ interference. In addition, heated sample line is checked for vacuum leak using a pressure calibration device and thermocouple using thermocouple calibrator. Table 3.7 shows list of analyzer checks performed and their pass criteria.

\subsubsection{PEMS Installation and Testing}

OBS is installed on test vehicles as shown in previous figures. Every day before the start of the test, the OBS is warmed-up until it is stabilized thermally. After warm up and before testing on a route, "zero" and "span" checks were performed and these checks are automated during the test.

Table 3.7 Analyzer checks and their pass criteria

\begin{tabular}{|c|c|c|c|}
\hline Check & Analyzer & Method & Pass Criteria \\
\hline Gas analyzer linearity & $\begin{array}{c}\mathrm{CO}-\mathrm{NDIR}, \\
\mathrm{CO}_{2}-\mathrm{NDIR}, \\
\mathrm{NO} \& \mathrm{NO}_{\mathrm{x}} \mathrm{CLD}\end{array}$ & 11 point Linear regression & $\mathrm{R}^{2} \geq 0.998$ \\
\hline $\mathrm{H}_{2} \mathrm{O}$ interference & $\mathrm{CO}_{2}-\mathrm{NDIR}$ & $\begin{array}{c}\text { Arthematic mean of } 30 \\
\text { sec data }\end{array}$ & $0 \pm 0.4 \mathrm{mmol} / \mathrm{mol}$ \\
\hline $\mathrm{CO}_{2} \& \mathrm{H}_{2} \mathrm{O}$ interference & CO - NDIR & $\begin{array}{c}\text { Arthematic mean of } 30 \\
\text { sec data }\end{array}$ & Within $\pm 2 \%$ \\
\hline $\mathrm{CO}_{2} \& \mathrm{H}_{2} \mathrm{O}$ quench & CLD & $\begin{array}{c}\text { Arthematic mean of } 30 \\
\text { sec data }\end{array}$ & Within $\pm 2 \%$ \\
\hline $\begin{array}{c}\mathrm{NO}_{2} \text { to NO conversion } \\
\text { efficiency }\end{array}$ & Ozone generator & Efficiency & $\geq 95 \%$ \\
\hline
\end{tabular}


OBS performs "zero" and "span" checks and adjustments before and immediately after sampling. Analyzer drift values are recorded automatically by OBS to perform drift correction while calculating results.

\subsection{Chassis Dynamometer and setup}

Chassis Dynamometer coast-down is performed before and after each vehicle is fixed on dyno for testing. Coast-down is a procedure performed to account for aerodynamic drag, rolling resistance, axle and transmission spinning losses etc. Coast-down on chassis dynamometer is performed to reproduce the road load force at various speeds assuming a flat road.

$$
\begin{gathered}
F_{\text {total }}=A+B v+C v^{2}+M \frac{d v}{d t} \\
F_{\text {road load }}=-M \frac{d v}{d t}=A+B v+C v^{2}
\end{gathered}
$$

The coefficients A, B and C from the road load equation is calculated by linear regression of vehicle velocity relative to wind as a function of time. These coefficients are given to dynamometer controller as target coefficients. Coast-downs on dynamometer are performed to produce same road load curve, which does not match in the first run as the dynamometer losses are not accounted. So the coast-downs are now iterated such that calculated forces in all speed ranges are within tolerance of $\pm 10 \mathrm{~N}$ after a least square regression of forces for three consecutive coast-down adjusting the load coefficients previously used by changing the resistance applied on rollers. The coefficients at which load curve on the chassis is within $\pm 0.05 \%$ of road load curve are used as set coefficients for further tests on dynamometer (40 CFR §1066.210). The target coefficients and set coefficients used for chassis dynamometer during this study are listed in Table 3.8 . 
Table 3.8 Chassis Dynamometer Coefficients from EPA

\begin{tabular}{|c|c|c|c|c|c|c|c|}
\hline \multirow{2}{*}{ Vehicle } & \multirow{2}{*}{$\begin{array}{c}\text { ETW } \\
{[\mathbf{l b s} .]}\end{array}$} & $\begin{array}{c}\mathrm{A} \\
{[\mathrm{lbf}]}\end{array}$ & $\begin{array}{c}\text { B } \\
{[\mathrm{lbf} / \mathrm{mph}]}\end{array}$ & $\begin{array}{c}\mathrm{C} \\
{\left[\mathrm{lbf} / \mathrm{mph}^{2}\right]}\end{array}$ & $\begin{array}{c}\mathrm{A} \\
{[\mathrm{lbf}]}\end{array}$ & $\begin{array}{c}\text { B } \\
{[\mathrm{lbf} / \mathrm{mph}]}\end{array}$ & $\begin{array}{c}\mathrm{C} \\
{\left[\mathrm{lbf} / \mathrm{mph}^{2}\right]}\end{array}$ \\
\hline A & 6000 & 11.01 & 0.3262 & 0.03264 & 51.33 & 0.0451 & 0.0385 \\
\hline B & 6000 & 11.01 & 0.3262 & 0.03264 & 51.33 & 0.0451 & 0.0385 \\
\hline C & 6000 & 11.01 & 0.3262 & 0.03264 & 51.33 & 0.0451 & 0.0385 \\
\hline D & 6000 & 11.01 & 0.3262 & 0.03264 & 51.33 & 0.0451 & 0.0385 \\
\hline
\end{tabular}

\subsection{Data analysis and calculations}

Data analysis and its quality assurance used in this report follows recommendations mentioned in CFR, Title 40 Subpart 1065 D, G, and J. Emissions calculations along with drift correction and distance specific emission rates are done according to regulations outlined in CFR, Title 40 Subpart 1065 G. All tests with DPF regeneration events, and those aborted due to failure of any measurement system are invalidated. 


\section{Results and Discussion}

This chapter presents data collected from test both on-road and chassis dynamometer. It will also discuss the average on-road emissions from all four-test vehicles for the pre-defined test routes, followed by in depth analysis of the $\mathrm{NO}_{\mathrm{x}}$ emissions.

In this, report all the emissions mass rates are in [g/s]. Distance-specific emissions [g/km], work-specific emissions [g/bhp-hr] are reported for each emission constituent, which is average of total measure with total distance and total work done during the test respectively. Applicable regulatory emission limits for $\mathrm{NO}_{\mathrm{x}}, \mathrm{CO}$ and $\mathrm{CO}_{2}$ is mentioned in the following table.

Table 4.1 EPA Vehicle Certification standard

\begin{tabular}{|c|c|c|c|c|c|c|c|c|c|}
\hline \multirow{2}{*}{ Vehicles } & \multirow[t]{2}{*}{ Certification } & \multicolumn{2}{|c|}{ CO } & \multicolumn{2}{|c|}{$\mathrm{CO}_{2}$} & \multicolumn{2}{|c|}{$\mathrm{NO}_{\mathrm{x}}$} & \multicolumn{2}{|c|}{$\begin{array}{c}\text { Fuel } \\
\text { Economy }\end{array}$} \\
\hline & & {$[\mathrm{g} / \mathrm{km}]$} & [g/mile] & {$[\mathrm{g} / \mathrm{km}]$} & [g/mile] & {$[\mathrm{g} / \mathrm{km}]$} & [g/mile] & [kmpl] & [mpg] \\
\hline A & \multirow{2}{*}{ FTP-75 } & 0.1040 & 0.1675 & 239.45 & 385.37 & 0.0274 & 0.0442 & 11.22 & 26.4 \\
\hline B, C \& D & & 0.0577 & 0.0929 & 258.05 & 415.30 & 0.0203 & 0.0328 & 10.46 & 24.6 \\
\hline $\mathbf{A}$ & \multirow{2}{*}{ HWFET } & 0.0080 & 0.0129 & 169.07 & 272.1 & 0.0180 & 0.0289 & 17.43 & 41 \\
\hline B, C \& D & & 0.00039 & 0.00064 & 169.07 & 272.1 & 0.0180 & 0.0289 & 15.9 & 37.4 \\
\hline
\end{tabular}

All four vehicles are not tested in all four pre-defined routes. Routes 1 and 3 resemble by more than $70 \%$ except with an additional urban driving for route 3 and is referred as Morgantown route hereafter, while Routes 2 and 4 resemble by $80 \%$ in terms of road grade elevation and highway speeds except the total distance is less by $20 \mathrm{~km}$ in route 4 than route 2 and is referred as Bruceton route. Morgantown routes and Bruceton routes are shown in Figure 21 and Figure 22 respectively.

All emission rates mentioned from here on are in terms of grams per kilometer [g/km]. Elevation is discussed in terms of meters above sea level [m a.s.l]. More discussion about these routes and their influence in total emissions are discussed in later sections of this chapter. 


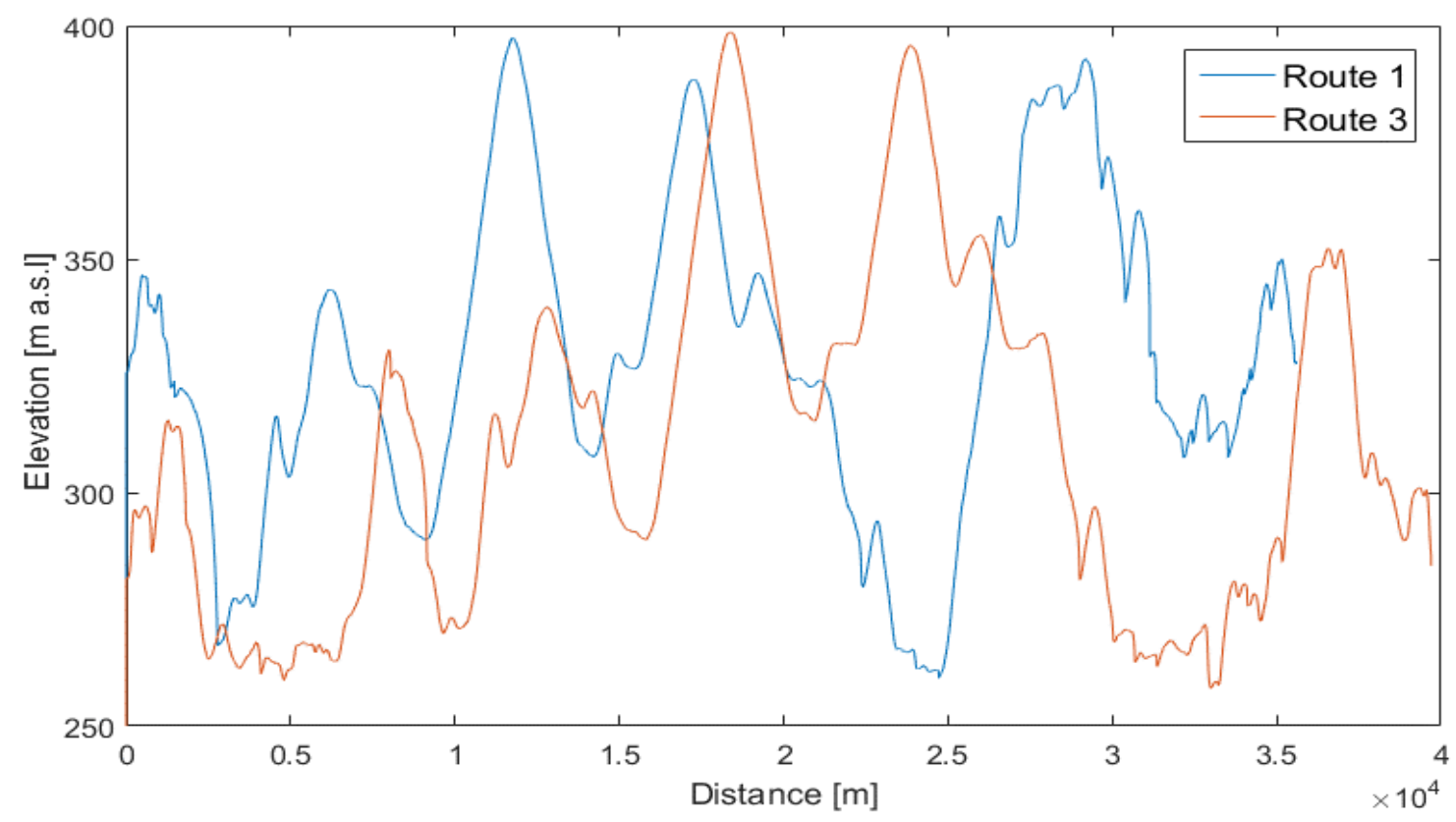

Figure 21 Morgantown on-road routes

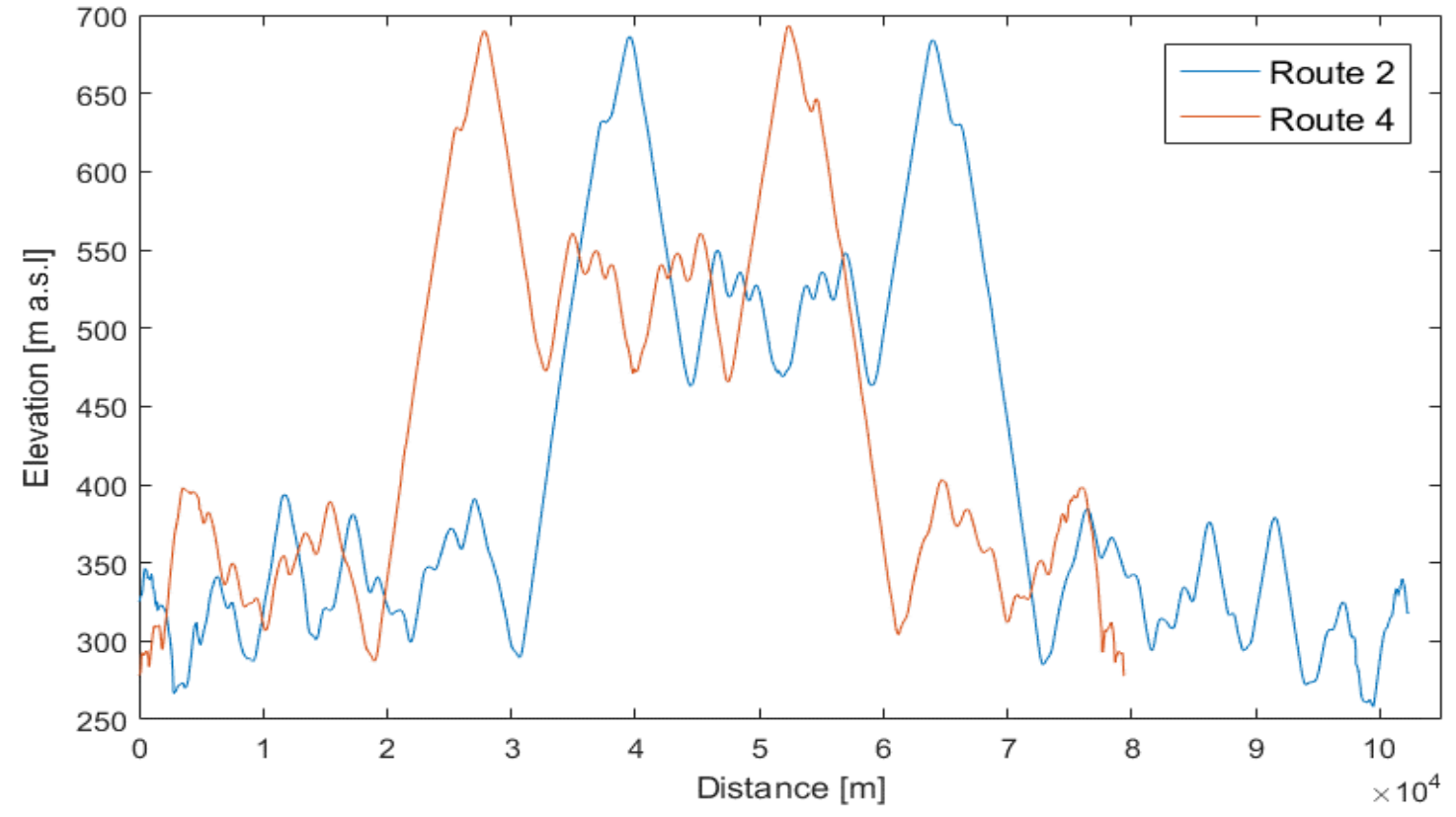

Figure 22 Bruceton on-road routes

Cold start, hot start and Warm start are three types of tests which indicate 12 hours of soak, key on with engine running, key off with engine stopped running before the tests respectively. Type of the test is attached as a suffix to the name of the test route. 
Number of runs each vehicle was tested in different routes both on-road and chassis dynamometer are listed in Table 4.2 and Table 4.3 respectively. A minimum of three repetitions of each test is done on-road whereas a minimum of two repetitions of each driving cycle is done on chassis dynamometer, but all of the repetitions are not considered due to poor quality of measured data or other issues with the measuring instrument during the test.

Table 4.2 On-road test matrix

\begin{tabular}{|c|c|c|c|c|}
\hline & Vehicle A & Vehicle B & Vehicle C & Vehicle D \\
\hline Route 1 & 7 & 11 & - & - \\
\hline Route 2 & 4 & 5 & - & 5 \\
\hline Route 3 & - & - & 6 & 3 \\
\hline Route 4 & - & - & 7 & \\
\hline
\end{tabular}

Table 4.3 Chassis Dynamometer test matrix

\begin{tabular}{|c|c|c|c|c|}
\hline Cycles & Vehicle A & Vehicle B & Vehicle C & Vehicle D \\
\hline FTP-75 & 4 & 3 & 5 & 5 \\
\hline NEDC & 1 & 2 & 1 & 2 \\
\hline US06 & 1 & - & 3 & 2 \\
\hline HWFET & 1 & - & 2 & 2 \\
\hline LA-4 & 1 & - & 2 & 2 \\
\hline MGW & 2 & 2 & 2 \\
\hline
\end{tabular}

DPF regeneration events that occurred during the test are identified with increased concentrations of particulate number measured using Pegasor-M, associated with increased exhaust temperatures and high $\mathrm{NO}_{\mathrm{x}}$. All DPF regen events occurred in four vehicles during the test are listed in the following Table 4.4. ECU data is lost for Regen event occurred during FTP-75 test of Vehicle A. So, this event is discarded. 
Table 4.4 DPF regen event

\begin{tabular}{|c|c|c|}
\hline & On-road route & Chassis \\
\hline Vehicle A & - & NEDC(1) \\
\hline Vehicle B & Route 1(2), Route 2(1) & - \\
\hline Vehicle C & - & FTP-75(1),US06(1) \\
\hline Vehicle D & Route 3(3), Route 4(1) & MGW(1) \\
\hline
\end{tabular}

\subsection{Average On-Road Emissions of Light Duty Vehicles}

This section will present average on-road emissions factors for gaseous, including $\mathrm{NO}_{\mathrm{x}}$, $\mathrm{CO}$ and $\mathrm{CO}_{2}$ emissions as measured for four vehicles over pre-defined test routes. Results presented in this section are reported as total emission over the respective routes.

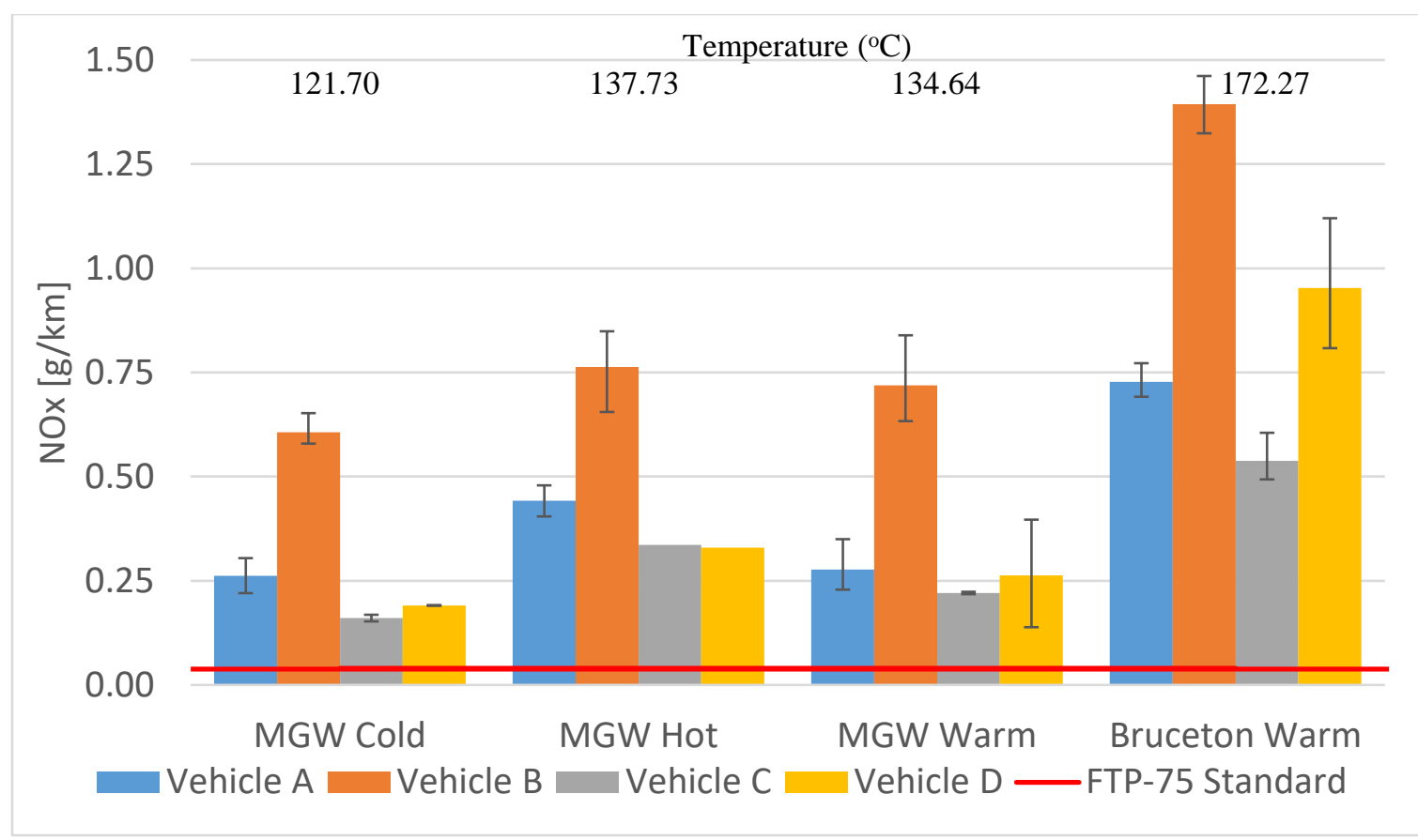

Figure 23 Average $\mathrm{NO}_{x}$ Emissions

Figure 23 shows average on-road $\mathrm{NO}_{\mathrm{x}}$ emissions for Vehicles $\mathrm{A}, \mathrm{B}, \mathrm{C}$ and $\mathrm{D}$ measured in routes 1 to 4 as explained above. Table 4.5 shows average $\mathrm{NO}_{\mathrm{x}}$ emissions along with standard deviations computed over at least two repetitions of a given test in a given vehicles. 
Usually high $\mathrm{NO}_{\mathrm{x}}$ is observed in uphill/downhill and low for highway driving. Here in this report all four vehicles showed distinct $\mathrm{NO}_{\mathrm{x}}$ levels in all routes, Vehicle B exhibiting about 8 to 20 times more than Tier2-Bin5 $\mathrm{NO}_{\mathrm{x}}$ standards whereas other vehicles exhibiting about 3 to 13 times. All vehicles exhibited more $\mathrm{NO}_{\mathrm{x}}$ during uphill/downhill driving compared to other driving routes. Vehicle $\mathrm{C}$ exhibited low $\mathrm{NO}_{\mathrm{x}}$ throughout the testing, even at uphill/downhill driving average $\mathrm{NO}_{\mathrm{x}}$ is about $0.53 \mathrm{~g} / \mathrm{km}$ ( $\sim 7$ times) the standard.

Although, all the vehicles are outfitted with engine from same manufacturer and have same rated power, engine of Vehicle A belongs to a different Model year and family from the others. Though all the vehicles use similar after treatment technologies, they exhibit different $\mathrm{NO}_{\mathrm{x}}$ levels for same test routes. This might be due to many reasons like i) different after-treatment control strategies, ii) a difference in catalytic substrate, iii) different diesel exhaust fluid (DEF) injection strategy and iv) reduction in catalytic activity due to aging.

All vehicles are checked for possible Malfunction Illumination Light on the dashboard, an ECU scanning tool is also used to log any malfunction code prior to test of these vehicles and none have shown any codes related to after-treatment systems.

Table 4.5 Average $\mathrm{NO}_{x}$ emissions $[\mathrm{g} / \mathrm{km}]$

\begin{tabular}{|c|c|c|c|c|c|c|c|c|}
\hline \multirow{2}{*}{ Routes } & \multicolumn{2}{|c|}{ Vehicle A } & \multicolumn{2}{c|}{ Vehicle B } & \multicolumn{2}{c|}{ Vehicle C } & \multicolumn{2}{c|}{ Vehicle D } \\
\cline { 2 - 9 } & $\mu$ & $\sigma$ & $\mu$ & $\sigma$ & $\mu$ & $\sigma$ & $\mu$ & $\sigma$ \\
\hline Morgantown Cold & 0.262 & 0.059 & 0.606 & 0.040 & 0.160 & 0.011 & 0.190 & 0.001 \\
\hline $\begin{array}{c}\text { Morgantown Hot } \\
\text { Morgantown } \\
\text { Warm }\end{array}$ & 0.441 & 0.052 & 0.763 & 0.098 & 0.336 & - & 0.329 & - \\
\hline \begin{tabular}{c} 
Bruceton Warm \\
\hline
\end{tabular} & 0.727 & 0.033 & 1.394 & 0.054 & 0.537 & 0.059 & 0.952 & 0.108 \\
\hline
\end{tabular}


Figure 24 shows average $\mathrm{CO}_{2}$ emissions from Vehicles A to D measured over four predefined routes. Average emissions along with the standard deviations computed at least over two repetitions of given test are summarized in Table 4.6

Table 4.6 Average $\mathrm{CO}_{2}$ Emissions

\begin{tabular}{|c|c|c|c|c|c|c|c|c|}
\hline \multirow{2}{*}{ Routes } & \multicolumn{2}{|c|}{ Vehicle A } & \multicolumn{2}{c|}{ Vehicle B } & \multicolumn{2}{c|}{ Vehicle C } & \multicolumn{2}{c|}{ Vehicle D } \\
\cline { 2 - 9 } & $\mu$ & $\sigma$ & $\mu$ & $\sigma$ & $\mu$ & $\sigma$ & $\mu$ & $\sigma$ \\
\hline Morgantown Cold & 293.1 & 2.870 & 267.8 & 8.285 & 262.5 & 8.029 & 268.7 & 9.631 \\
\hline $\begin{array}{c}\text { Morgantown Hot } \\
\text { Morgantown } \\
\text { Warm }\end{array}$ & 275.6 & 31.86 & 256.1 & 16.21 & 277.8 & - & 262.5 & - \\
\hline \begin{tabular}{c} 
Bruceton Warm \\
\hline
\end{tabular} & 259.5 & 19.85 & 267.3 & 4.857 & 247.5 & 7.140 & 266.8 & 7.421 \\
\hline
\end{tabular}

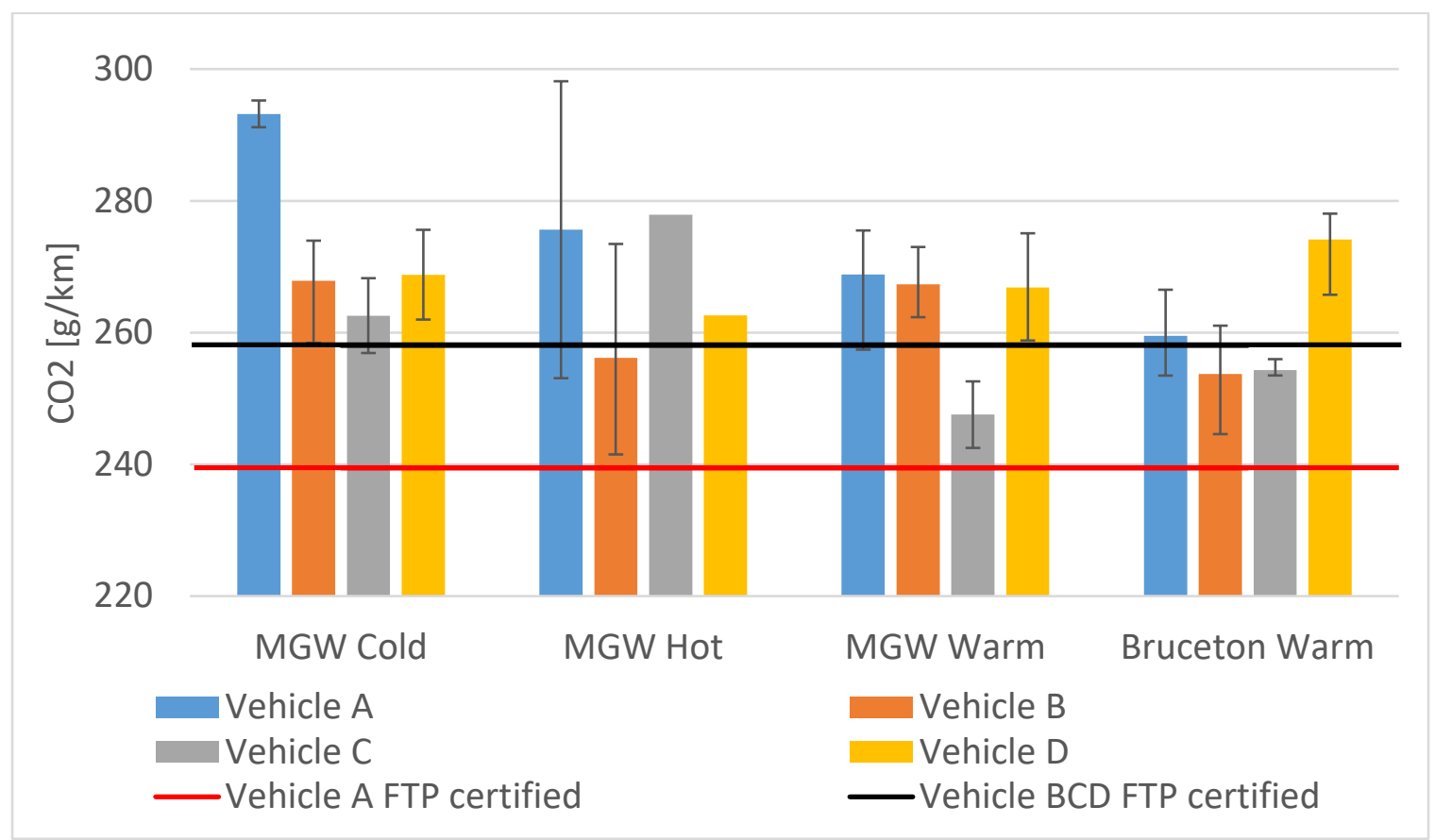

Figure 24 Average $\mathrm{CO}_{2}$ Emissions

It is interesting to observe that Vehicle $\mathrm{B}$ which emitted high $\mathrm{NO}_{\mathrm{x}}$ through-out does not follow same trend in $\mathrm{CO}_{2}$ emissions. $\mathrm{CO}_{2}$ emissions from all vehicles are in range of 245 to 295 $\mathrm{g} / \mathrm{km}$, with standard deviations from all vehicles less than $10 \mathrm{~g} / \mathrm{km}$ except for hot start. Usually 
higher emission rates appear in routes with higher grade elevations, but Bruceton route which have an elevation difference of $400 \mathrm{~m}$ produced same average $\mathrm{CO}_{2}$ emissions. This might be due to extent of highway distance in the route and very less urban speed distance.

Table 4.7 summarize the average $\mathrm{CO}$ emissions from four vehicles tested over predefined test routes along with standard deviations calculated from repetitions. Figure 25 shows the averaged emission rates with the error plots calculated from standard deviations.

Table 4.7Average CO Emissions

\begin{tabular}{|c|c|c|c|c|c|c|c|c|}
\hline \multirow{2}{*}{ Routes } & \multicolumn{2}{|c|}{ Vehicle A } & \multicolumn{2}{c|}{ Vehicle B } & \multicolumn{2}{c|}{ Vehicle C } & \multicolumn{2}{c|}{ Vehicle D } \\
\cline { 2 - 9 } & $\mu$ & $\sigma$ & $\mu$ & $\sigma$ & $\mu$ & $\sigma$ & $\mu$ & $\sigma$ \\
\hline Morgantown Cold & 0.107 & 0.035 & 0.224 & 0.024 & 0.358 & 0.015 & 0.304 & 0.069 \\
\hline $\begin{array}{c}\text { Morgantown Hot } \\
\text { Morgantown } \\
\text { Warm }\end{array}$ & 0.033 & 0.001 & 0.145 & 0.054 & 0.154 & - & 0.169 & - \\
\hline \begin{tabular}{c} 
Bruceton Warm \\
\hline
\end{tabular} & 0.040 & 0.005 & 0.157 & 0.009 & 0.128 & 0.027 & 0.197 & 0.031 \\
\hline
\end{tabular}

In general CO emissions are function of routes / driving conditions, which says vehicles follow the trend based on routes. But the observed emission rates from all vehicles are 8 to 75 lower than the FTP standard $2.6 \mathrm{~g} / \mathrm{km}$. Vehicle A produced lowest CO emissions of all, in all routes. This could be due because of advanced combustion strategy as it equipped with new MY engine and from other engine family. All vehicles exhibited more $\mathrm{CO}$ emissions during the cold start while they were reduced for later tests. Interestingly Vehicle $C$ which produced CO emissions about 0.35 $\mathrm{g} / \mathrm{km}$ during cold start dropped it by half for hot start and warm starts. 


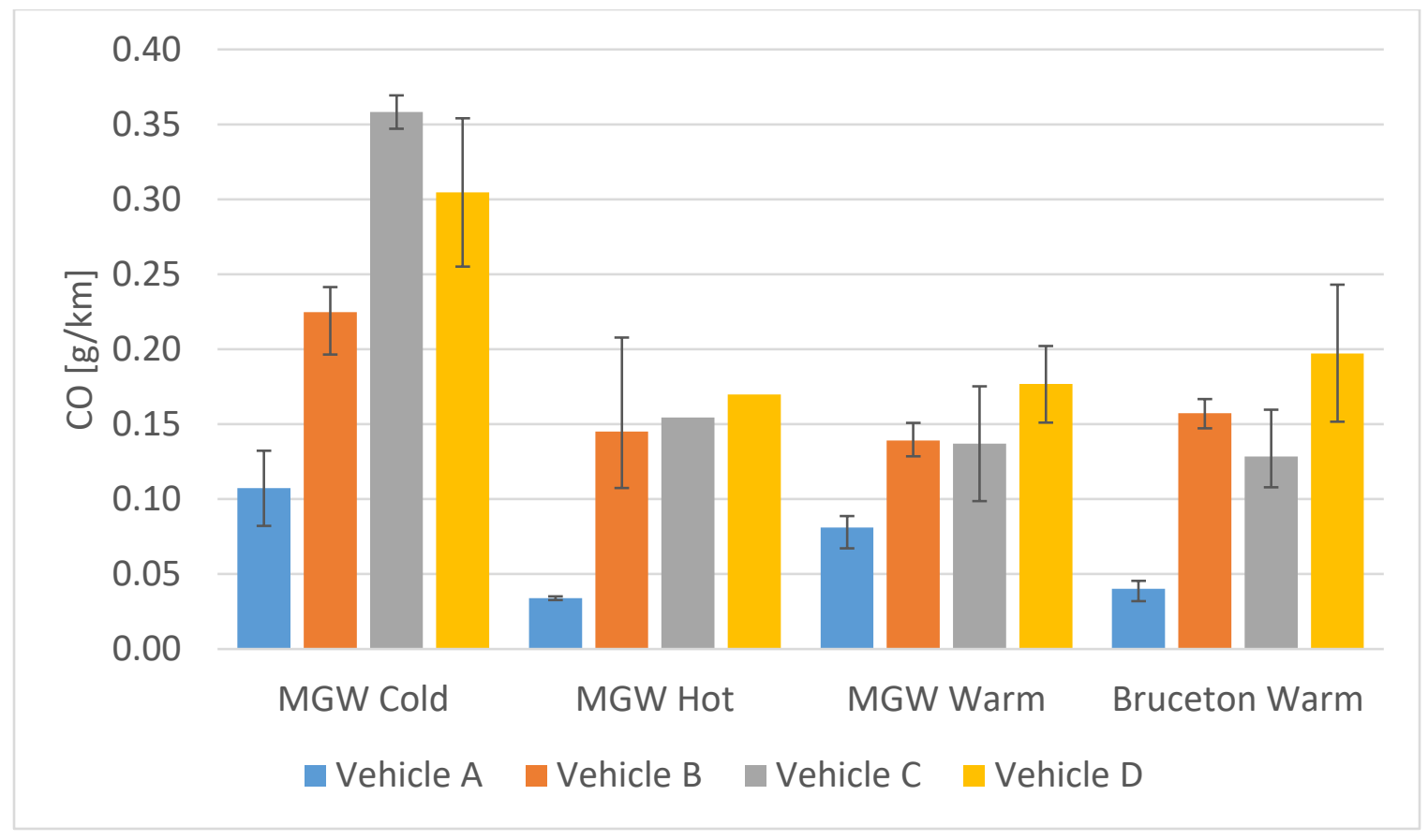

Figure 25 Average CO Emissions

Figure 26 shows the Average Fuel Economies presented in mpg, derived from carbon balance in four pre-defined test routes. And Table 4.8 summarizes Fuel economies along with standard deviations calculated for test with minimum of two repetitions.

As $\mathrm{CO}_{2}$ is major fraction in carbon balance calculation, more the $\mathrm{CO}_{2}$ emissions more fuel is consumed over the specified route. As $\mathrm{CO}_{2}$ emissions were discussed earlier, observations are valid for low fuel economy too. All vehicles gave Fuel Economy ranging from 23-25 mpg in route $2 \& 4$ which consists both highway and uphill/downhill driving. Vehicles A and C show a reduction of Fuel economy by $5 \%$ in cold start from warm start, whereas Vehicle B and D show less than $1 \%$ reduction. 


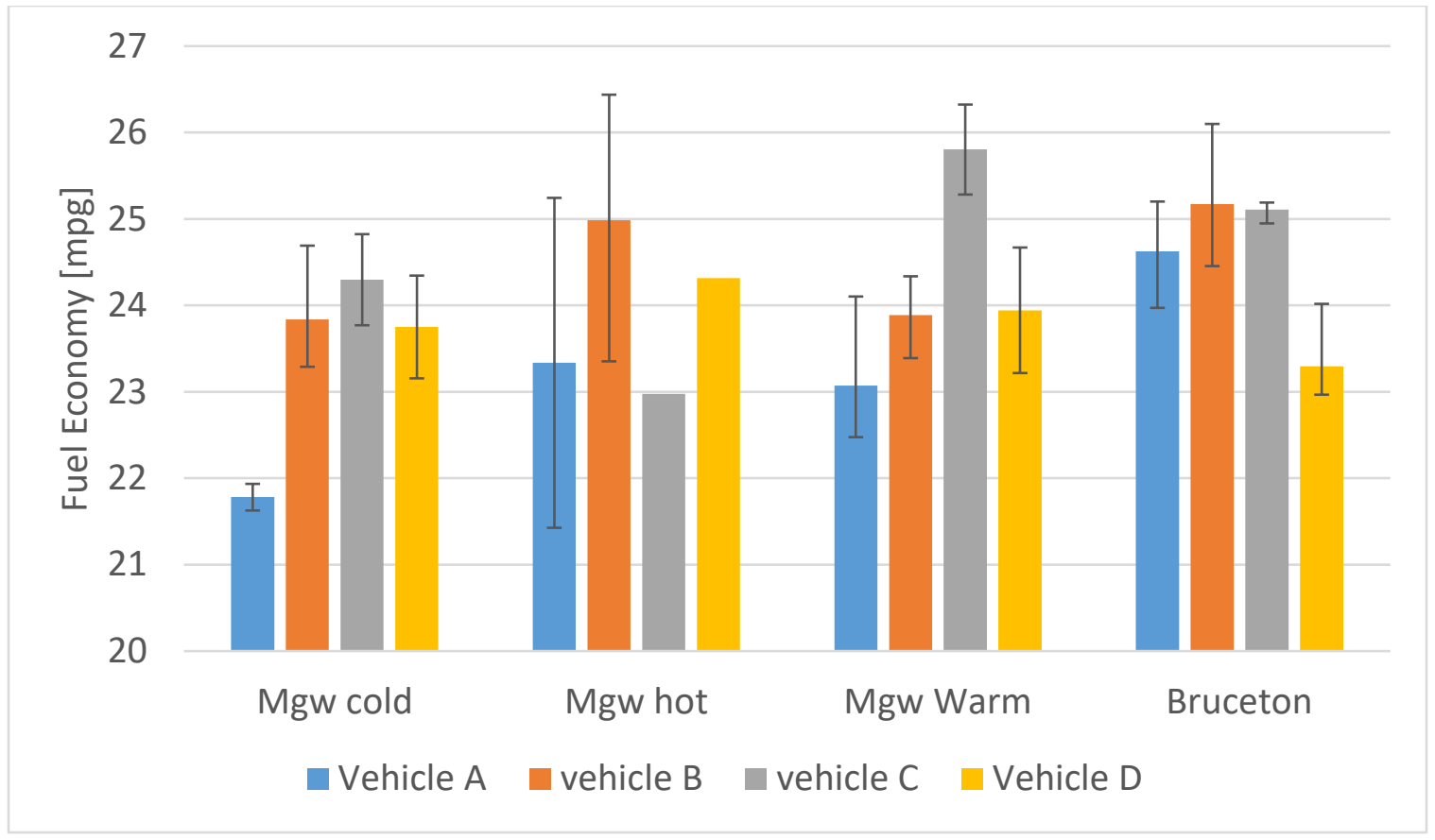

Figure 26 Average Fuel Economies derived from Carbon Balance

It’s interesting to observe that Vehicle $\mathrm{B}$ which produced more $\mathrm{NO}_{\mathrm{x}}$ than other vehicles in all routes, produced low $\mathrm{CO}_{2}$ emissions and showed high fuel economy. This could be due to strategies employed to gain fuel economy than to reduce $\mathrm{NO}_{\mathrm{x}}$. Test done on chassis dynamometer discussed in next section will give more information.

Table 4.8 Average Fuel Economies derived from Carbon Balance [mpg]

\begin{tabular}{|c|c|c|c|c|c|c|c|c|}
\hline \multirow{2}{*}{ Routes } & \multicolumn{2}{|c|}{ Vehicle A } & \multicolumn{2}{c|}{ Vehicle B } & \multicolumn{2}{c|}{ Vehicle C } & \multicolumn{2}{c|}{ Vehicle D } \\
\cline { 2 - 9 } & $\mu$ & $\sigma$ & $\mu$ & $\sigma$ & $\mu$ & $\sigma$ & $\mu$ & $\sigma$ \\
\hline Morgantown Cold & 21.7 & 0.217 & 23.8 & 0.749 & 24.9 & 0.745 & 23.7 & 0.84 \\
\hline Morgantown Hot & 23.3 & 2.699 & 24.9 & 1.550 & 22.9 & - & 24.3 & - \\
\hline $\begin{array}{c}\text { Morgantown } \\
\text { Warm }\end{array}$ & 23.0 & 1.595 & 23.8 & 0.432 & 25.8 & 0.736 & 23.9 & 1.02 \\
\hline \begin{tabular}{c} 
Bruceton Warm \\
\hline
\end{tabular} & 24.6 & 0.505 & 25.1 & 0.600 & 25.1 & 0.138 & 23.2 & 0.38 \\
\hline
\end{tabular}




\subsection{Average Emissions from chassis dynamometer}

This section will present average chassis dynamometer tests performed at VETL CAFEE, WVU. The emissions factors for gaseous, including $\mathrm{NO}_{\mathrm{x}}, \mathrm{CO}$ and $\mathrm{CO}_{2}$ emissions measured for four vehicles over pre-defined driving cycles are presented in this section are reported as total emission in grams over the respective driving cycles in $\mathrm{km}$.

Figure 27 shows average $\mathrm{NO}_{\mathrm{x}}$ emissions from six chassis dynamometer driving cycles. All tests performed on dynamometer are with engine warmed up, except for FTP which is done both on cold start and warm start. Table 4.9 summarizes average $\mathrm{NO}_{\mathrm{x}}$ emissions from chassis dynamometer and standard deviations calculated for the tests with minimum of two repetitions.

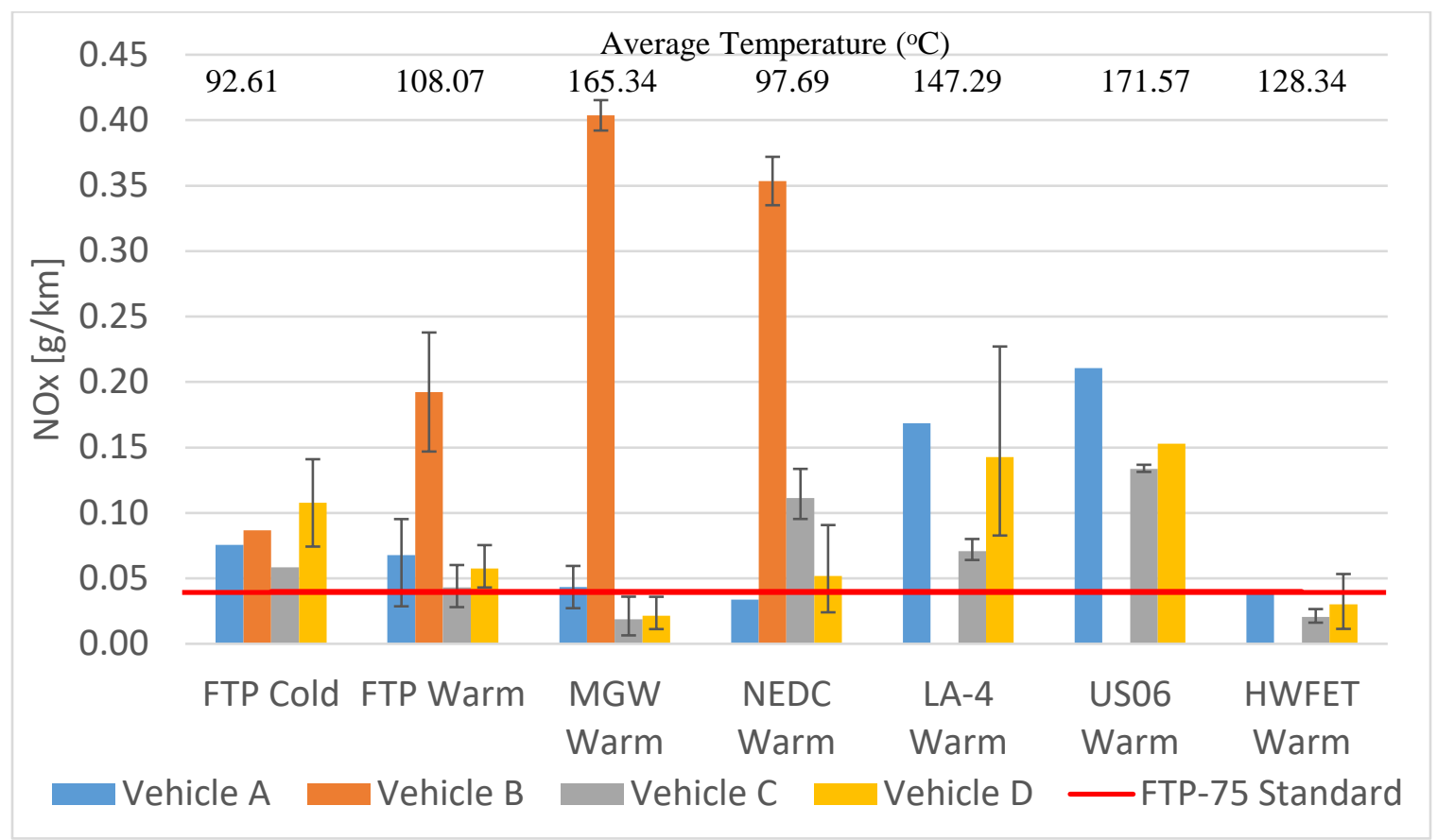

Figure 27 Average $\mathrm{NO}_{x}$ Emissions from Chassis Dynamometer

All the vehicles are certified with $\mathrm{NO}_{\mathrm{x}}$ emissions less than FTP-75 standard of $0.04 \mathrm{~g} / \mathrm{km}$, but when tested on same driving cycle produced more than the standard. Their deviation ratios are in the range of 1-5 times the standard. Vehicle $C$ is the only one which was close to standard in 
both cold and warm start. Vehicle $D$ produced more $\mathrm{NO}_{\mathrm{x}}$ in cold start whereas Vehicle $B$ was the one to produce more during warm start.

If we consider Morgantown cycle which is a representative of route 1 of on-road tests, vehicles $A, C \& D$ produced 6-10 times lower than emissions from on-road tests. This could be because of 1) elevation/grade profile which is not accounted for in chassis cycle. 2) Traffic might be another reason which is not considered while creating the driving cycle.

In fact $\mathrm{NO}_{\mathrm{x}}$ emissions from New European Driving Cycle should be low as this driving cycle is low speed and low load cycle. But, only Vehicle A and Vehicle D meet EU standard of 0.08 $\mathrm{g} / \mathrm{km}$ over NEDC cycle, whereas Vehicle B is 5 times the standard while Vehicle $C$ is slightly over the standard. Emissions from Vehicle $B$ are not repetitive as the standard deviations are more than other vehicles and as emissions rates are high, further tests over chassis dynamometer that are required could not be performed.

Table 4.9 Average $\mathrm{NO}_{x}$ Emissions from chassis dynamometer

\begin{tabular}{|c|c|c|c|c|c|c|c|c|}
\hline \multirow{2}{*}{ Routes } & \multicolumn{2}{|c|}{ Vehicle A } & \multicolumn{2}{c|}{ Vehicle B } & \multicolumn{2}{c|}{ Vehicle C } & \multicolumn{2}{c|}{ Vehicle D } \\
\cline { 2 - 9 } & $\mu$ & $\sigma$ & $\mu$ & $\sigma$ & $\mu$ & $\sigma$ & $\mu$ & $\sigma$ \\
\hline FTP Cold & 0.07 & - & 0.08 & - & 0.05 & - & 0.10 & 0.03 \\
\hline FTP Warm & 0.06 & 0.03 & 0.19 & 0.06 & 0.04 & 0.01 & 0.05 & 0.01 \\
\hline MGW Warm & 0.04 & 0.02 & 0.40 & 0.01 & 0.01 & 0.01 & 0.02 & 0.01 \\
\hline NEDC Warm & 0.03 & - & 0.35 & 0.02 & 0.11 & 0.02 & 0.05 & 0.03 \\
\hline LA-4 Warm & 0.16 & - & - & - & 0.07 & 0.009 & 0.14 & 0.08 \\
\hline US06 Warm & 0.21 & - & - & - & 0.13 & 0.003 & 0.15 & - \\
\hline HWFET Warm & 0.03 & - & - & - & 0.02 & 0.006 & 0.03 & 0.02 \\
\hline
\end{tabular}

Emissions from aggressive US06 cycle are ranging from $0.13-0.21 \mathrm{~g} / \mathrm{km}$ which is 6 to 10 times the standard. Whereas in HWFET highway driving cycle shows reduction by $\sim 40-50 \%$ 
reduction than measured over FTP cycle. All these emissions were close to FTP-75 standards but slightly higher than their certification values.

$\mathrm{CO}_{2}$ emissions which is direct measure of load and fuel consumption, measured over predefined dynamometer cycles is represented in Figure 28. Average $\mathrm{CO}_{2}$ emissions measured in these cycles are summarized in Table 4.10. Standard deviations are calculated for the tests with minimum of two repetitions.

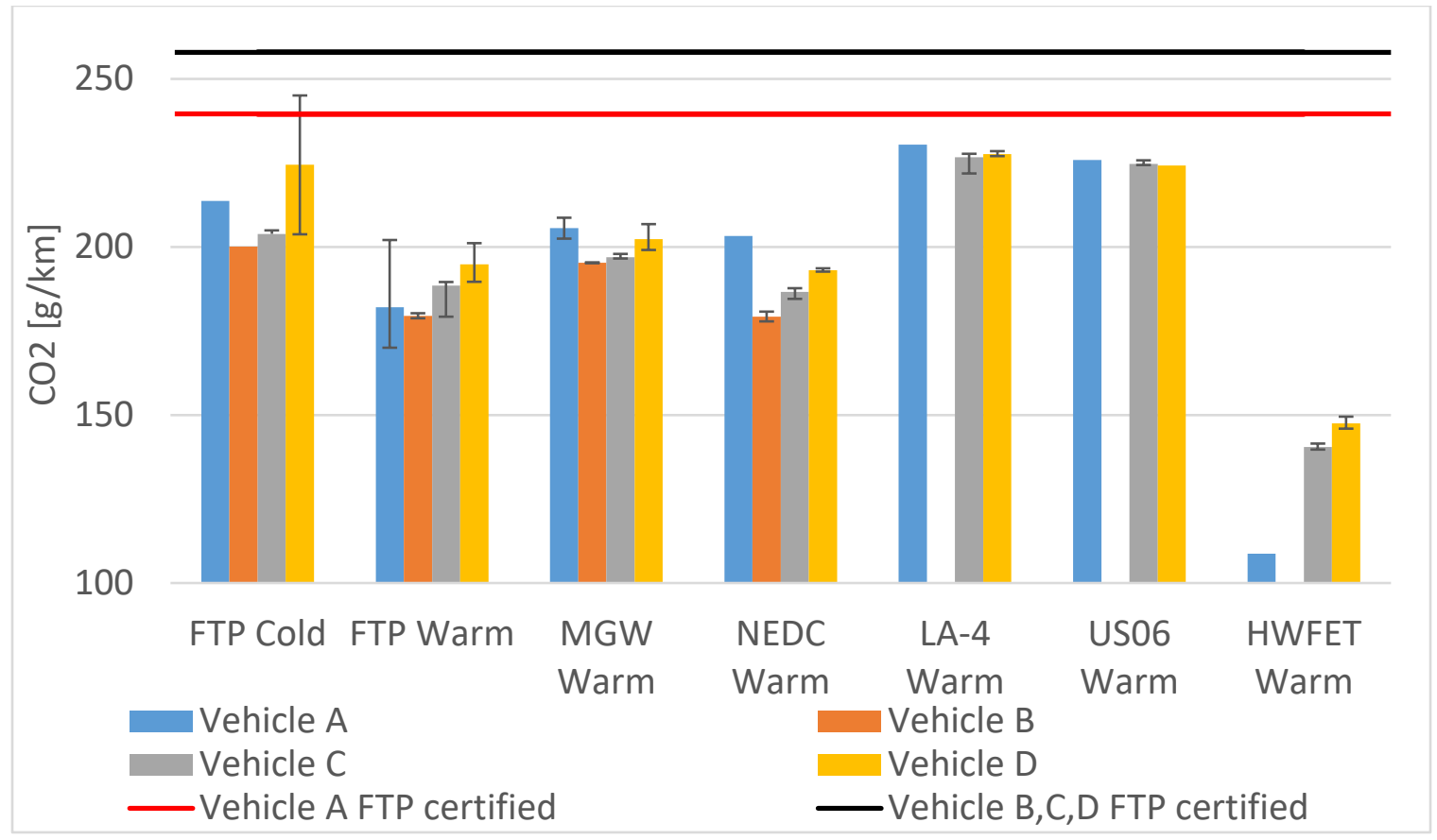

Figure 28 Average $\mathrm{CO}_{2}$ Emissions from Chassis Dynamometer

$\mathrm{CO}_{2}$ emissions from these vehicles doesn't follow the same trend as $\mathrm{NO}_{\mathrm{x}}$ emissions. They are high in aggressive routes like LA-4 \& US06, whereas low in high route HWFET. $\mathrm{CO}_{2}$ emissions are high in cold start as similar to on-road measurements. After the Aftertreatment systems reached high enough the emission rates reduced by 7 - $15 \%$ approximately.

$\mathrm{CO}_{2}$ emission measured over Morgantown cycle are 20-25 \% less than the measured on road. $\mathrm{CO}_{2}$ emission rate from chassis Morgantown cycle ranges from $195 \mathrm{~g} / \mathrm{km}$ to $205 \mathrm{~g} / \mathrm{km}$. Vehicles A to D follow the same trend of on-road emissions, but there were low because chassis cycle did not consider road grade elevation which is a major component and traffic. 
Vehicle $D$ produced $\mathrm{CO}_{2}$ more than any other vehicle in all driving cycles, whereas Vehicle $B$ produced low $\mathrm{CO}_{2}$ among the four tested driving cycles. Vehicle A which produced more carbon dioxide emissions in aggressive and high speed cycles, also produced low emissions in highway driving cycle.

Table 4.10 Average $\mathrm{CO}_{2}$ Emissions from Chassis Dynamometer

\begin{tabular}{|c|c|c|c|c|c|c|c|c|}
\hline \multirow{2}{*}{ Routes } & \multicolumn{2}{|c|}{ Vehicle A } & \multicolumn{2}{c|}{ Vehicle B } & \multicolumn{2}{c|}{ Vehicle C } & \multicolumn{2}{c|}{ Vehicle D } \\
\cline { 2 - 9 } & $\mu$ & $\sigma$ & $\mu$ & $\sigma$ & $\mu$ & $\sigma$ & $\mu$ & $\sigma$ \\
\hline FTP Cold & 213.7 & - & 200.0 & - & 203.8 & - & 224.4 & 20.6 \\
\hline FTP Warm & 182.0 & 17.4 & 179.5 & 1.05 & 188.5 & 10.71 & 194.8 & 6.33 \\
\hline MGW Warm & 205.5 & 4.3 & 195.2 & 0.18 & 196.8 & 0.45 & 202.2 & 4.50 \\
\hline NEDC Warm & 203.2 & - & 179.3 & 2.05 & 186.6 & 3.0 & 193.0 & 0.57 \\
\hline LA-4 Warm & 230.4 & - & - & - & 226.6 & 6.80 & 227.6 & 0.86 \\
\hline US06 Warm & 225.9 & - & - & - & 224.7 & 0.50 & 224.2 & - \\
\hline HWFET Warm & 108.7 & - & - & - & 140.4 & 1.04 & 147.5 & 1.96 \\
\hline
\end{tabular}

Figure 29 Shows average CO emissions from all vehicles tested on chassis dynamometer testing cycles. And Table 4.11 summarizes these emissions in $\mathrm{g} / \mathrm{km}$ with standard deviations calculated from a tests with minimum of two repetitions. CO emissions are high in cold start as they are in on-road cold start emissions. Once the catalysts reach their activation temperature, the emission are close to zero.

Vehicle D showed more CO production while Vehicle A produced low CO than other vehicles and it follows the same trend in all tests performed on dynamometer. All vehicles deviate the FTP CO standard by a ratio of $6-11$ for FTP cold, $1-4$ for other tests. Only Vehicle A showed emission less than its certification value over FTP cycle, while it was 6 times over the HWFET certification value. All other vehicles deviate their FTP certification value by 2 to 3 times, whereas 
HWFET by 176 to 200 times. This could be because CO certification over HWFET was reported wrongly to EPA.

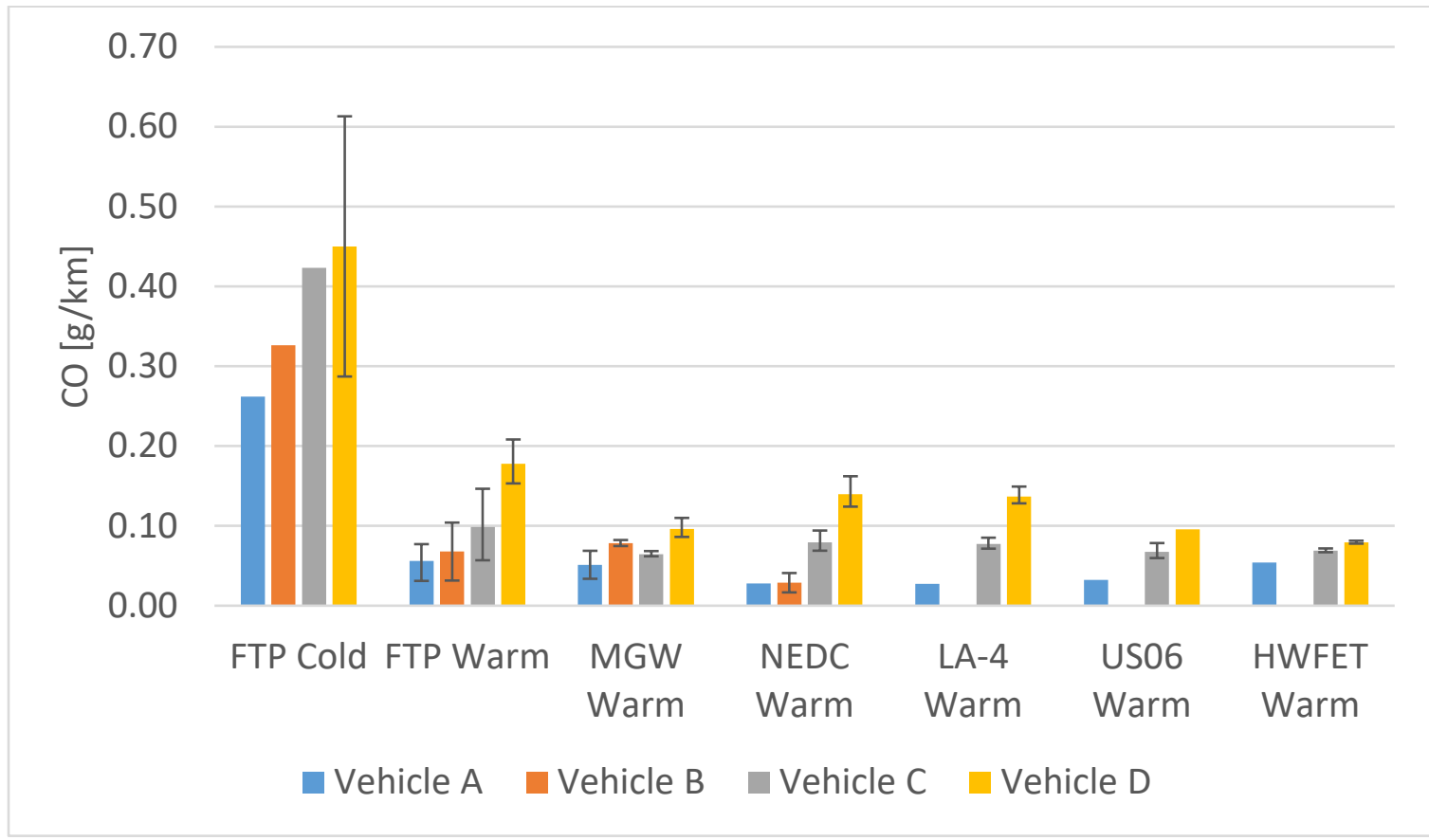

Figure 29 Average CO emissions from Chassis Dynamometer

Table 4.11Average CO emissions from Chassis Dynamometer

\begin{tabular}{|c|c|c|c|c|c|c|c|c|}
\hline \multirow{2}{*}{ Routes } & \multicolumn{2}{|c|}{ Vehicle A } & \multicolumn{2}{c|}{ Vehicle B } & \multicolumn{2}{c|}{ Vehicle C } & \multicolumn{2}{c|}{ Vehicle D } \\
\cline { 2 - 9 } & $\mu$ & $\sigma$ & $\mu$ & $\sigma$ & $\mu$ & $\sigma$ & $\mu$ & $\sigma$ \\
\hline FTP Cold & 0.26 & - & 0.32 & - & 0.42 & - & 0.45 & 0.06 \\
\hline FTP Warm & 0.05 & 0.02 & 0.06 & 0.05 & 0.09 & 0.04 & 0.17 & 0.03 \\
\hline MGW Warm & 0.05 & 0.02 & 0.07 & 0.00 & 0.06 & 0.00 & 0.09 & 0.01 \\
\hline NEDC Warm & 0.02 & - & 0.02 & 0.1 & 0.07 & 0.01 & 0.13 & 0.02 \\
\hline LA-4 Warm & 0.02 & - & - & - & 0.07 & 0.00 & 0.13 & 0.01 \\
\hline US06 Warm & 0.03 & - & - & - & 0.06 & 0.01 & 0.09 & - \\
\hline HWFET Warm & 0.05 & - & - & - & 0.06 & 0.00 & 0.07 & 0.00 \\
\hline
\end{tabular}




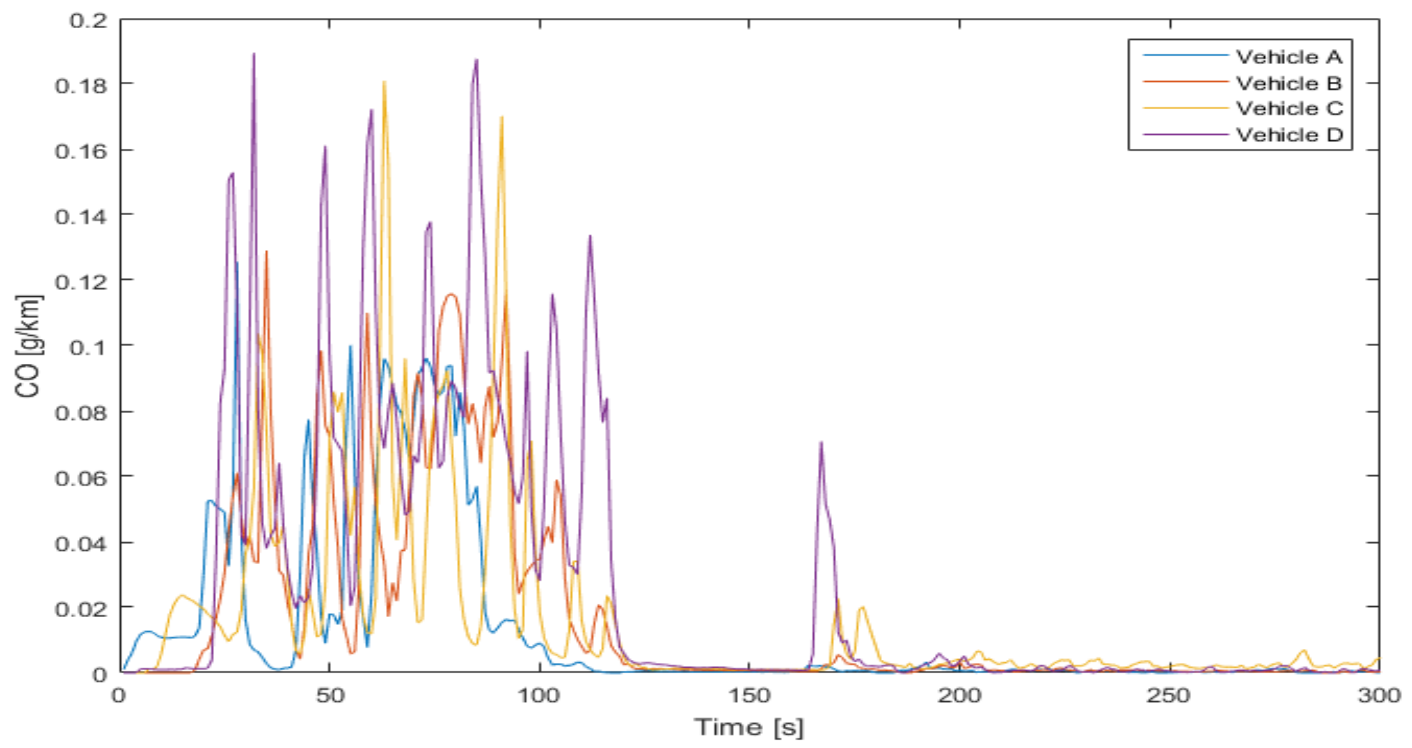

Figure 30 CO spikes during cold start

If we look at Figure 31, it’s clear that fuel economy over chassis dynamometer is more than on-road tests. All vehicles clearly cross the fuel economy values reported to EPA over both FTP and HWFET cycles, even in cold start. Table 4.12 summarizes average fuel economy values obtained from carbon balance along with standard deviations measured from repetitions of two tests.

Table 4.12 Average fuel economy from carbon balance

\begin{tabular}{|c|c|c|c|c|c|c|c|c|}
\hline \multirow{2}{*}{ Routes } & \multicolumn{2}{|c|}{ Vehicle A } & \multicolumn{2}{c|}{ Vehicle B } & \multicolumn{2}{c|}{ Vehicle C } & \multicolumn{2}{c|}{ Vehicle D } \\
\cline { 2 - 9 } & $\mu$ & $\sigma$ & $\mu$ & $\sigma$ & $\mu$ & $\sigma$ & $\mu$ & $\sigma$ \\
\hline FTP Cold & 29.8 & - & 31.8 & - & 31.2 & - & 28.5 & 2.64 \\
\hline FTP Warm & 35.2 & 3.21 & 35.5 & 0.19 & 33.9 & 1.80 & 32.7 & 1.04 \\
\hline MGW Warm & 31.0 & 0.67 & 32.6 & 0.02 & 32.4 & 0.07 & 31.5 & 0.70 \\
\hline NEDC Warm & 31.4 & - & 35.6 & 0.41 & 34.2 & 0.54 & 33.0 & 0.09 \\
\hline LA-4 Warm & 27.7 & - & - & - & 28.1 & 0.84 & 28.0 & 0.10 \\
\hline US06 Warm & 28.2 & - & - & - & 28.4 & 0.06 & 28.4 & - \\
\hline HWFET Warm & 58.7 & - & - & - & 45.4 & 0.33 & 43.2 & 0.57 \\
\hline
\end{tabular}


As fuel economy is a direct measure from obtained $\mathrm{CO}_{2}$ and is inverse proportional to $\mathrm{CO}_{2}$. All vehicles gave fuel economy greater than 30 mpg in regular certification cycles and little lower of 28 mpg in aggressive cycles like LA-4 and US06, and highest economy of 43 mpg in highway driving cycle. Vehicle A showed highest economy of $58 \mathrm{mpg}$ in highway driving cycles as it was run on double HWFET cycle continuously without stopping the sampling.

All Vehicles $A, C$ and $D$ gave a fuel economy more than 43 mpg over HWFET cycle, which is approximately two times more than that is observed in highway driving of Bruceton route. Quality of data has been checked, and found no loss in exhaust sampling, no fault in measurement device. EPA data sheet shows that manufacturers reported about 41 mpg on HWFET cycle, which also supports the fact that the quality of data provided in this research is good.

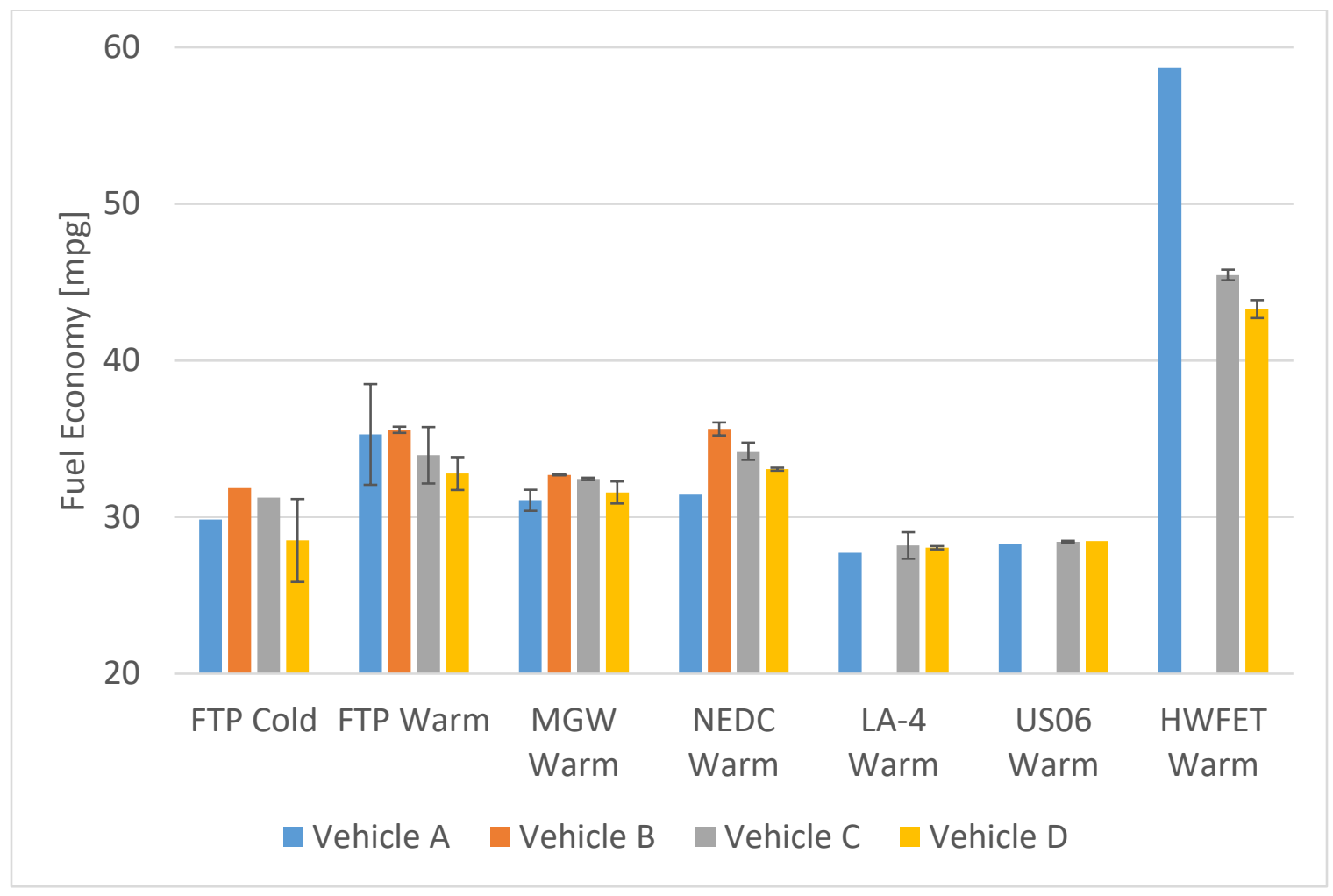

Figure 31 Average fuel economy from carbon balance 


\subsection{Comparison of $\mathrm{NO}_{\mathrm{x}}$ from On-road measurements to Chassis Dynamometer cycle measurements}

Earlier sections show a comparison between emissions rates \& fuel economy rates of four vehicles tested in different on-road routes and chassis dynamometer cycles. Comparisons among these on-road routes and chassis cycles show only variations between the vehicles but, this section shows comparison of $\mathrm{NO}_{\mathrm{x}}$ and Fuel Economy (FE) rates between similar on-road routes and chassis cycles.

\subsubsection{Morgantown on-road route comparison with Morgantown chassis cycle}

In this section, Morgantown on-road cycle $\mathrm{NO}_{\mathrm{x}}$ emission rates are compared with Morgantown chassis cycle emissions. Morgantown chassis cycle resembles on-road route as it is created from real driving speed points from on-road route, and this can be used as common base to compare.

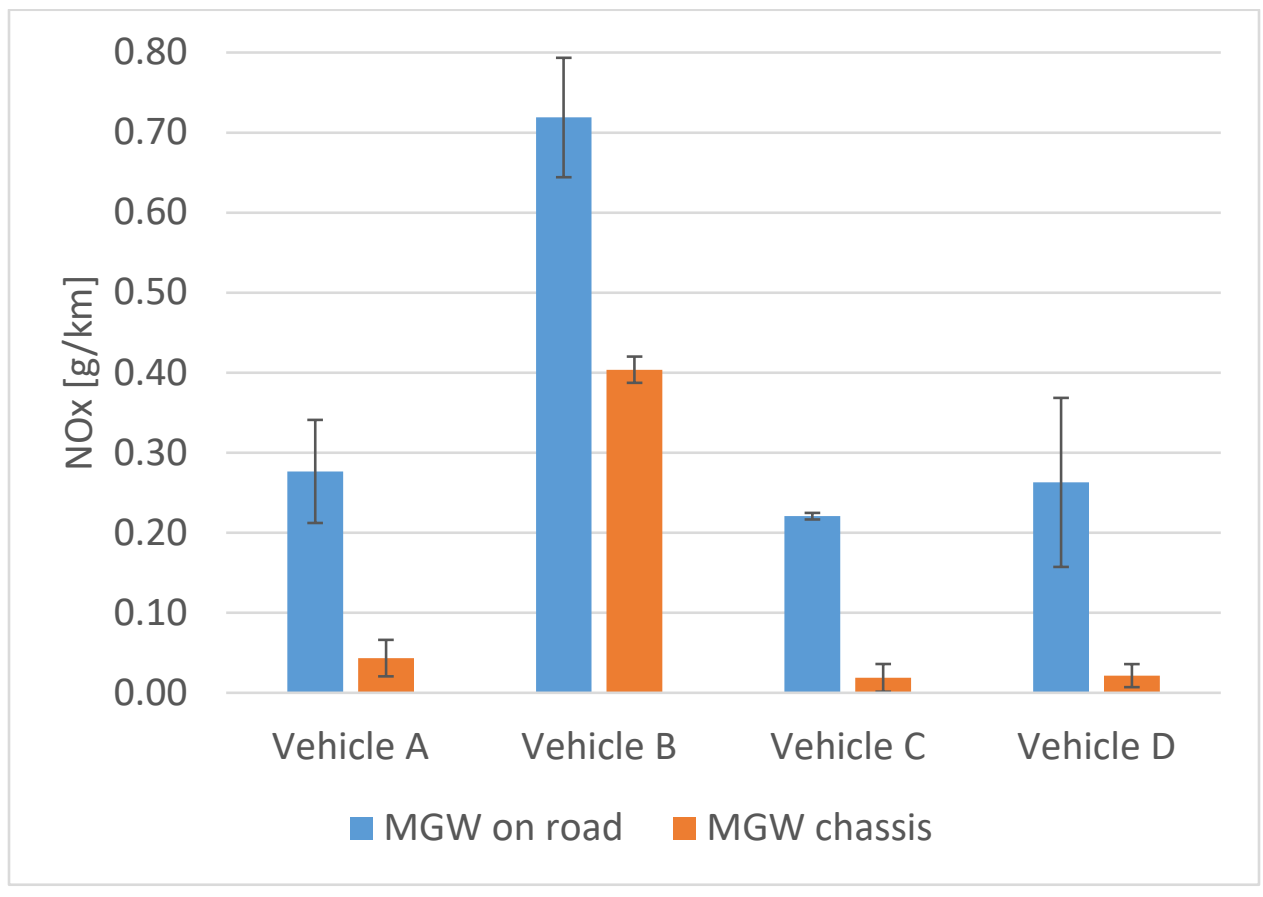

Figure $32 \mathrm{NO}_{x}$ comparison from Morgantown on-road and chassis test. 
Figure 32 shows comparison of average $\mathrm{NO}_{\mathrm{x}}$ emissions from Vehicles $\mathrm{A}$ to $\mathrm{D}$ on on-road tests and chassis tests, along with error bars. Table 4.13 summarizes comparison of $\mathrm{NO}_{\mathrm{x}}$ and Fuel economy rates as percent difference.

On-road $\mathrm{NO}_{\mathrm{x}}$ emissions are approximately $84-92 \%$ high for Vehicle $A, C$ and $D$ on real world driving when compared with emissions from chassis cycle, whereas Vehicle B has $43 \%$ more NOx. As this chassis dynamometer cycle does not account for road grade coefficients, the emissions rates are usually high when there is road grade for most part of the route. This can be justified with Relative Positive Acceleration and Characteristic Power calculated for chassis test and on-road tests.

Table 4.13 $\mathrm{NO}_{x}$ \& Fuel Economy comparison from Morgantown on-road and chassis test as percent difference.

\begin{tabular}{|c|c|c|c|c|c|c|c|c|c|c|c|c|c|c|c|c|}
\hline \multirow{3}{*}{ Routes } & \multicolumn{4}{|c|}{ Vehicle A } & \multicolumn{4}{|c|}{ Vehicle B } & \multicolumn{4}{|c|}{ Vehicle C } & \multicolumn{4}{|c|}{ Vehicle D } \\
\hline & \multicolumn{2}{|c|}{$\mathrm{NO}_{\mathrm{x}}$} & \multicolumn{2}{|c|}{ FE } & \multicolumn{2}{|c|}{$\mathrm{NO}_{\mathrm{x}}$} & \multicolumn{2}{|c|}{ FE } & \multicolumn{2}{|c|}{$\mathrm{NO}_{\mathrm{x}}$} & \multicolumn{2}{|c|}{ FE } & \multicolumn{2}{|c|}{$\mathrm{NO}_{\mathrm{x}}$} & \multicolumn{2}{|c|}{$\mathrm{FE}$} \\
\hline & $\mu$ & $\sigma$ & $\mu$ & $\sigma$ & $\mu$ & $\sigma$ & $\mu$ & $\sigma$ & $\mu$ & $\sigma$ & $\mu$ & $\sigma$ & $\mu$ & $\sigma$ & $\mu$ & $\sigma$ \\
\hline $\begin{array}{c}\text { MGW } \\
\text { On- } \\
\text { road }\end{array}$ & 0.27 & 0.06 & 23.0 & 1.59 & 0.71 & 0.07 & 23.8 & 0.43 & 0.22 & 0.00 & 25.8 & 0.73 & 0.26 & 0.10 & 23.9 & 1.02 \\
\hline $\begin{array}{c}\text { MGW } \\
\text { Chassis }\end{array}$ & 0.04 & 0.02 & 31.0 & 0.67 & 0.40 & 0.01 & 32.6 & 0.02 & 0.01 & 0.01 & 32.4 & 0.07 & 0.02 & 0.01 & 31.5 & 0.70 \\
\hline $\begin{array}{l}\text { Diff } \\
\text { [\%] }\end{array}$ & 8 & & & .6 & & & 36 & & & & & & & & & .8 \\
\hline
\end{tabular}

Characteristic power $\left(P_{c h}\right)$ is derived taking kinematic power, road grade changes and represents mechanical energy. Characteristic power for chassis cycle is low as the elevation is constant throughout the test, making potential energy term to zero. The major difference in characteristic power of on-road test and chassis test is potential energy which also has role in higher $\mathrm{NO}_{\mathrm{x}}$ emission rates as well as fuel consumption. From Table 4.13, we observe fuel economy in chassis dynamometer tests are $~ 25$ to $36 \%$ higher than on-road tests, which implies lower $\mathrm{CO}_{2}$ emissions also. 


\subsubsection{Bruceton on-road route comparison with US06 and HWFET}

This part of section covers $\mathrm{NO}_{\mathrm{x}}$ emission and Fuel Economy rates comparison between On-road Bruceton route with US06 and HWFET cycles of chassis dynamometer tests. Bruceton route has RPA of about $0.37 \mathrm{~m} / \mathrm{s}^{2}$ and characteristic power of about $4 \mathrm{~m}^{2} / \mathrm{s}^{3}$ which are similar to of US06, while Bruceton has an average speed of about $87 \mathrm{~km} / \mathrm{h}$ which is close to HWFET cycle. So, emissions from Bruceton route are compared with US06 and HWFET cycles.

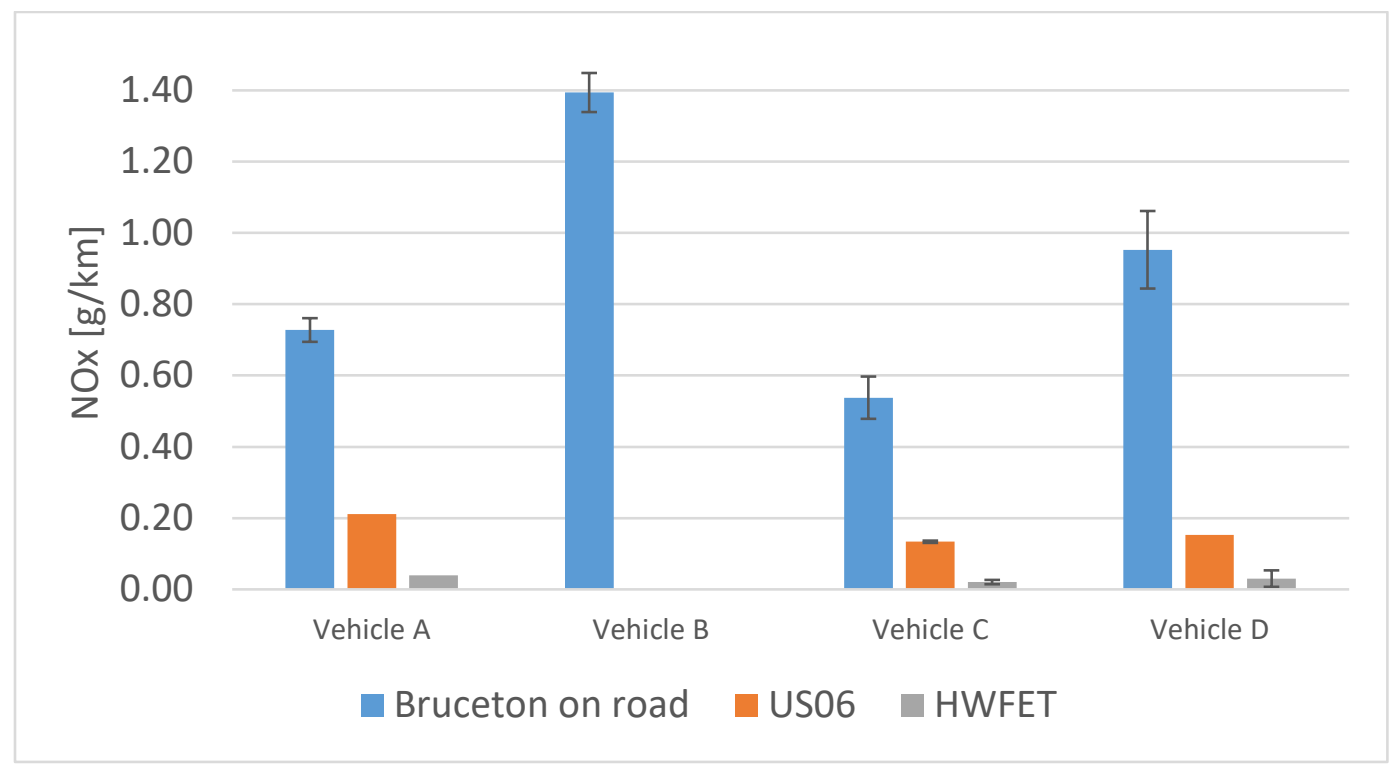

Figure $33 \mathrm{NO}_{x}$ comparison between on-road Bruceton route \& USO6, HWFET.

Figure 33 shows comparison of $\mathrm{NO}_{\mathrm{x}}$ emissions rates between On-road Bruceton routes with HWFET and US06 chassis cycles. Error bars are plot with standard deviation calculated from tests of minimum two repetitions. Vehicle B is not tested on US06 and HWFET chassis cycles so it's represented in the figure. Table 4.14 summarizes the average $\mathrm{NO}_{\mathrm{x}}$ emission and Fuel Economy rates along with percentage differences.

Bruceton has an average RPA of about $0.30 \mathrm{~m} / \mathrm{s}^{2}$, whereas US06 and HWFET has 0.52 and $0.18 \mathrm{~m} / \mathrm{s}^{2}$ respectively. $\mathrm{NO}_{\mathrm{x}}$ emissions from Bruceton route are high when compared to aggressive cycles like US06 and highway cycle HWFET. This could be because both US06 and HWFET 
cycles are for 10 min and 13 min each whereas Bruceton route is 50 min approximately. But when emissions are compared on distance specific, duration of test cannot be a reason until and unless there is passive regeneration during the event. More $\mathrm{NO}_{\mathrm{x}}$ emission rates in Bruceton is only due to high road grades even though it consists of highway driving for more than $80 \%$ of total test. Vehicles A, C \& D exhibited 70 - 80\% low $\mathrm{NO}_{\mathrm{x}}$ emissions in US06 and less than 95\% in HWFET cycle compared to Bruceton route emissions.

Table 4.14 NOx comparison between on-road Bruceton route \& US06, HWFET.

\begin{tabular}{|c|c|c|c|c|c|c|c|c|c|c|c|c|c|c|c|c|}
\hline \multirow{3}{*}{ Routes } & \multicolumn{4}{|c|}{ Vehicle A } & \multicolumn{4}{|c|}{ Vehicle B } & \multicolumn{4}{|c|}{ Vehicle C } & \multicolumn{4}{|c|}{ Vehicle D } \\
\hline & \multicolumn{2}{|c|}{$\mathrm{NO}_{\mathrm{x}}$} & \multicolumn{2}{|c|}{$\mathrm{FE}$} & \multicolumn{2}{|c|}{$\mathrm{NO}_{\mathrm{x}}$} & \multicolumn{2}{|c|}{$\mathrm{FE}$} & \multicolumn{2}{|c|}{$\mathrm{NO}_{\mathrm{x}}$} & \multicolumn{2}{|c|}{$\mathrm{FE}$} & \multicolumn{2}{|c|}{$\mathrm{NO}_{\mathrm{x}}$} & \multicolumn{2}{|c|}{ FE } \\
\hline & $\mu$ & $\sigma$ & $\mu$ & $\sigma$ & $\mu$ & $\sigma$ & $\mu$ & $\sigma$ & $\mu$ & $\sigma$ & $\mu$ & $\sigma$ & $\mu$ & $\sigma$ & $\mu$ & $\sigma$ \\
\hline $\begin{array}{c}\text { Bruceton } \\
\text { On-road }\end{array}$ & 0.72 & 0.03 & 24.6 & 0.50 & 1.39 & 0.05 & 25.1 & 0.60 & 0.53 & 0.05 & 25.1 & 0.13 & 0.95 & 0.10 & 23.2 & 0.38 \\
\hline US06 & 0.21 & - & 28.2 & - & - & - & - & - & 0.13 & 0.0 & 28.4 & 0.06 & 0.15 & - & 28.47 & - \\
\hline HWFET & 0.03 & - & 58.7 & - & - & - & - & - & 0.02 & 0.0 & 45.4 & 0.33 & 0.03 & 0.02 & 43.2 & 0.57 \\
\hline $\begin{array}{c}\text { Bruceton } \\
\text { Vs } \\
\text { US06 }\end{array}$ & & & 14 & & & - & & & 75 & & 13 & & & 96 & 22 & \\
\hline $\begin{array}{c}\text { Bruceton } \\
\text { Vs } \\
\text { HWFET }\end{array}$ & & & 13 & & & - & & - & 96 & & 81 & 07 & & 82 & 85 & \\
\hline
\end{tabular}

Fuel economy which is also a function of Relative Positive Acceleration of the test, Bruceton route has more fuel consumed though US06 has higher RPA than Bruceton. This could be because of quick accelerations that reduce the fuel economy by $30 \%$ on highway and higher elevations. Vehicles A, C \& D exhibited 13 - 20\% higher fuel economy in US06 and about 80\% high in HWFET cycle when compared with Bruceton On-road route. Vehicle A shows 58.7 mpg in HWFET test which is 138\% higher fuel economy than Bruceton route. But the data reported in this report is a Double HWFET cycle which means HWFET cycles are run twice back to back. 


\section{4 $\mathrm{NO}_{\mathrm{x}}$ emissions and temperatures during DPF regen events}

Regeneration of DPF is performed in all vehicles regularly to clean the filter of soot that has been traped. All the vehicles used in this study had regeneration event for atleast one time either on road or on chassis. This section describes more about $\mathrm{NO}_{\mathrm{x}}$ emissions and exhaust temperatures during a regenration event.

Figure 34 shows continuous plot of $\mathrm{NO}_{\mathrm{x}}$ emissions and temperatures of two events, one with regeneration event while the other is a regular event. These events are measured from 'Vehicle $B$ ' while testing in Morgantown route. Regulated $\mathrm{NO}_{\mathrm{x}}$ emissions increased substantially during regenerations.

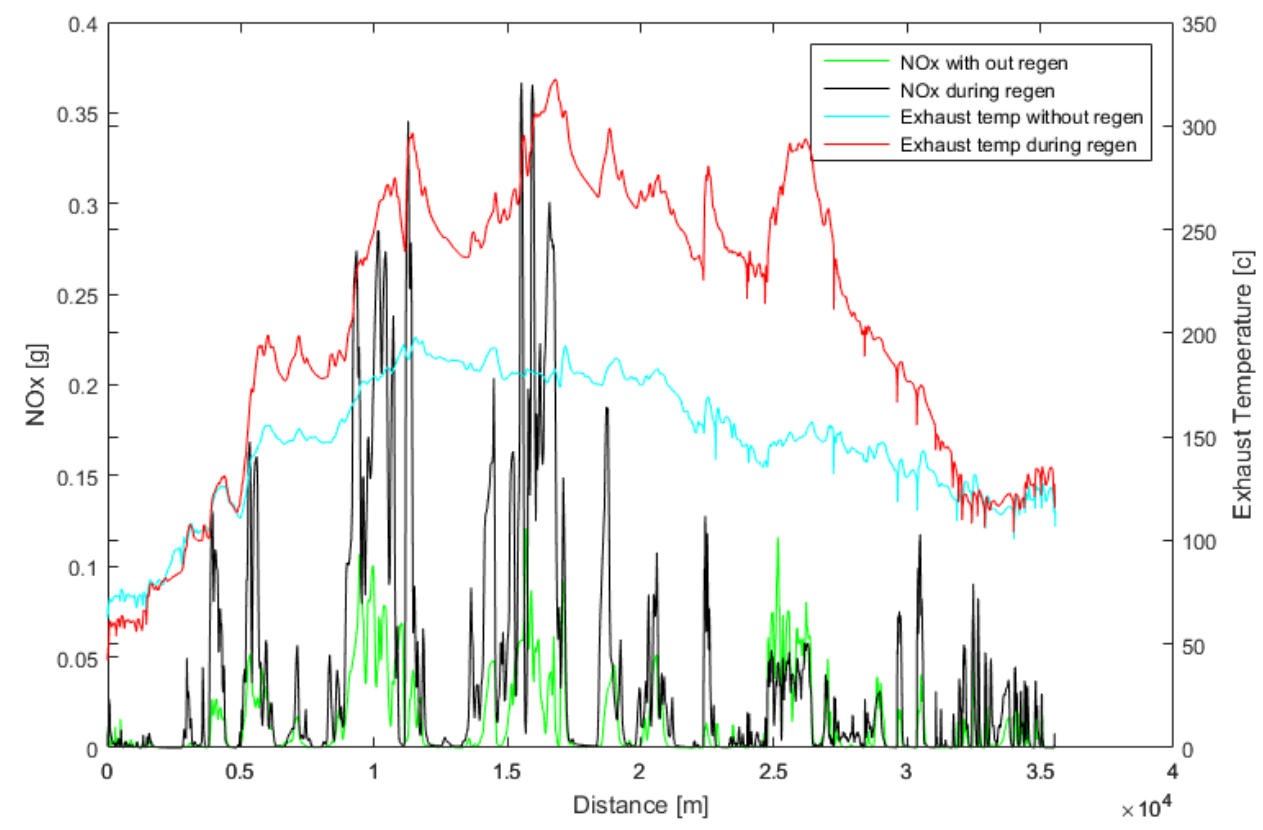

Figure $34 \mathrm{NO}_{x}$ and Exhaust temperature during a regen and non-regen event over Morgantown route for Vehicle B

Necessity for regeneration arises when there is high pressure difference across the DPF, which also indicates amount of soot accumulation. The duration of regeneration is a function of driving pattern, they need enough temperature to initiate regeneration event. The interval for DPF regeneration event is also based on accumulated mileage on the vehicle. 
Table 4.15 Distance based DPF regeneration frequencies \& Max. Temp, Avg. NO $\mathrm{N}_{\mathrm{x}}$ during regen

\begin{tabular}{|c|c|c|c|c|c|c|}
\hline Vehicles & Regen event & $\begin{array}{c}\text { Odometer } \\
{[\mathrm{km}]}\end{array}$ & $\begin{array}{c}\text { Distance } \mathbf{b} / \mathbf{w} \\
\text { events }\end{array}$ & $\begin{array}{c}\text { Duration } \\
\text { [min] }\end{array}$ & $\begin{array}{c}\text { Max. Temp } \\
{\left[{ }^{\circ} \mathrm{C}\right]} \\
\end{array}$ & $\begin{array}{c}\mathrm{NO}_{\mathrm{x}} \\
{[\mathrm{g} / \mathrm{km}]}\end{array}$ \\
\hline Vehicle A & NEDC & 3254 & - & 8 & 298 & 0.4125 \\
\hline \multirow[b]{2}{*}{ Vehicle B } & $\begin{array}{c}\text { Morgantown } \\
\text { On-road }\end{array}$ & 21626 & 384 & 20 & 322 & 1.6407 \\
\hline & $\begin{array}{c}\text { Bruceton } \\
\text { On-road } \\
\end{array}$ & 22010 & - & 30 & 366 & 1.82 \\
\hline \multirow[b]{2}{*}{ Vehicle C } & US06 & 29611 & 248 & 8 & 323 & 0.5795 \\
\hline & FTP-75 & 29859 & - & 15 & 280 & 0.1615 \\
\hline \multirow{4}{*}{ Vehicle D } & $\begin{array}{c}\text { Morgantown } \\
\text { On-road }\end{array}$ & 43236 & 486 & 25 & 354 & 1.1503 \\
\hline & $\begin{array}{c}\text { Bruceton } \\
\text { On-road }\end{array}$ & 43722 & 977 & 25 & 367 & 1.5708 \\
\hline & $\begin{array}{c}\text { Morgantown } \\
\text { chassis }\end{array}$ & 44699 & 664 & 20 & 345 & 0.3475 \\
\hline & $\begin{array}{c}\text { Morgantown } \\
\text { On-road }\end{array}$ & 45363 & - & 20 & 328 & 1.1955 \\
\hline
\end{tabular}

Table 4.15 shows number of regeneration events and the test being performed when regeneration is noticed along with odometer readings before the start of test. This tables provides observed maximum temperature and distance specific $\mathrm{NO}_{\mathrm{x}}$ during the events. The distance two consecutive regeneration events is measured as difference between two odometer readings before commencement of the test, so these values are just approximations.

All the vehicles exhibited similar difference in exhaust temperature and $\mathrm{NO}_{\mathrm{x}}$ emission patterns while comparing events with regeneration events to a test with no regeneration event. Exhaust temperatures reached as high as $350^{\circ} \mathrm{C}$ during regeneration, while the distance specific $\mathrm{NO}_{\mathrm{x}}$ emissions were $1.6 \mathrm{~g} / \mathrm{km}$. As the emissions during regeneration events are unregulated, the frequency of regeneration events depends on strategy that manufacturers employ for $\mathrm{NO}_{\mathrm{x}}$ and $\mathrm{PM}$ emissions.

Vehicle A had only one regeneration event and the total duration was observed during last 8 minutes of the test after which steady state test is run to clear any of the soot that is still present 
in the DPF. Even vehicle C has one short duration regeneration event as the test itself is for 10 minutes, so did not contribute much for total $\mathrm{NO}_{\mathrm{x}}$. Vehicle $\mathrm{D}$ has more number of regeneration but the distance based frequency are in the range of $500-1000 \mathrm{~km}$ based on driving patterns, while other vehicles seem to regenerate for every $250-400 \mathrm{~km}$. Second regeneration of vehicle D is observed after $977 \mathrm{~km}$ which approximately includes $750 \mathrm{~km}$ of continuous highway driving with just three stops in between, while all other events does not include highway driving for more than $200 \mathrm{~km}$ between each regeneration. This supports the statement that regeneration of DPF depends on on-road conditions and driving pattern. 


\section{Conclusion}

The research presented herein had successfully conducted in-use emission testing of four light-duty diesel vehicles in real world driving situation, with an objective of comparing their corresponding off-cycle emission rates to that of a type approval chassis dynamometer testing, while also assessing their conformity to those values. The chassis dyno testing included a variety of standard test cycles, each representative of certain type of chosen driving condition in some form or the other. Also, the chosen vehicles were operated on pre-defined routes exhibiting four different driving characteristics in these demographics, namely - urban, rural, highway and road grade. The criteria pollutants were analyzed from the tailpipe emissions measurement, per the guidelines outlined in CFR Title 40 Part 1065. The measured data was analyzed using a computer programming code written in MATLAB, and the following conclusions were drawn based on the results stated in section 4 .

In summary, real world NOx emissions for all the vehicles under study, were found to exceed the US EPA Tier 2 Bin 5 standard in some way or the other as detailed below. Vehicle $B$ NOx values were 1.2 times more than the combined average of the rest of the fleet, under testing. While the on-road PEMS measurement yielded an average distance specific NOx value of $0.87 \mathrm{~g} / \mathrm{km}$, the FTP-75 based chassis dyno test measured $0.25 \mathrm{~g} / \mathrm{km}$. Focusing specifically on the off-cycle operation as an area of prime interest for this thesis, the on-road real world testing indicates that, irrespective of vehicle conditions, all of them emitted about 4 to 35 times higher NOx emissions, when compared with a FTP-75 drive cycle standard limit of $0.04 \mathrm{~g} / \mathrm{km}$. Furthermore, when the vehicles were tested on a chassis dyno platform with FTP-75 cycle, similar elevated levels of about 1 to 4 times higher values were found with NOx measurement. 
It is interesting to note that, the highest fuel economy among the test candidates was observed in highway route ( $3 \%$ increase) as compared to other urban as well as rural routes. Similarly, on the chassis dyno platform, the highest fuel economy was recorded at 49 mpg with HWFET test cycle, which is a clear representation of a vehicle operating on a highway type driving profile. This figure is $55 \%$ significantly higher than the other test cycles, so chosen.

CO emissions inferred from warm engine-start test, are significantly lower as compared to the same values inferred from a cold engine-start test. On road PEMS testing showed $48 \%$ lower emission values for this case, while the chassis dyno tests performed over a FTP-75 cycle showed 72\% lower $\mathrm{CO}$ emissions on a warm engine start test. Finally, with respect to $\mathrm{CO}_{2}$ emission rates, Vehicle $C$ was the least emitter $(260 \mathrm{~g} / \mathrm{km})$ amongst all the vehicles when measured using a PEMS on road. However, chassis dyno testing proved that Vehicle B was the least emitter $(188 \mathrm{~g} / \mathrm{km})$ of $\mathrm{CO}_{2}$ with $4.6 \%$ lower emission rate among all the vehicles in the fleet.

In general, it can be concluded with substantial evidence that real world scenario exhibits on an average at least two times higher emission rates when compared to the type approval testing performed with representative drive cycle profiles. Although, the standard emissions certification tests, namely FTP-75, NEDC, HWFET have been carefully designed to accommodate the critical parameters that a vehicle experiences while subjected to diverse driving patterns during actual onroad operation, these short timed test procedures carried out on a controlled laboratory environment are not always reliable to provide a realistic evaluation of the vehicle/engine performance. It could be inferred from the present study that, it is always an underestimation of the actual vehicle performance, yielding significantly lower emission concentration values. It is therefore critical to understand and study the emissions trends of light duty engines during off- 
cycle operations and propose guidelines on improvement for policy makers, which would otherwise not be distinctly recognizable during a chassis dyno base certification test method. 


\section{References}

Agarwal, Deepak, Shrawan Kumar Singh, and Avinash Kumar Agarwal. 2011. "Effect of Exhaust Gas Recirculation (EGR) on performance, emissions, deposits and durbility of a constant speed compression ignition engine." Applied Energy 2900-2907. doi:10.1016/j.apenergy.2011.01.066.

Alves, Celia A, Diogo J. Lopes, Ana I. Calvo, Margarita Evtyugina, and Sonia Rocha. 2015. "Emissions from Light-Duty Diesel and Gasoline In-use Vehicles Measured on Chassis Dynamometer Test Cycles." Aerosol and Air Quality Research,15 99-116.

Anderson, Jon, John May, Cecile Favre, Dirk Bosteels, Simon De Vries, Mattew Heaney, Matthew Keenan, and Jonathon Mansell. 2014. "On-Road and Chassis Dynamometer Evaluations of Emissions from Two Euro 6 Diesel vehicles." SAE International. doi:10.4271/2014-012826.

Barone, Teresa L, John M.E. Storey, and Norberto Domingo. 2010. "An Analysis of Field-Aged Diesel Particulate Filter Performance: Particle Emissions before, during, and after Regeneration." Journal of the Air \& Waste Management Association 60 (8): 968-976. doi:10.3155/1047-3289.60.8.968.

Bergmann, Maik, Ulf Kirchner, Rainer Vogt, and Thorsten Benter. 2009. "On-road and laboratory investigation of low-level PM emissions of a modern diesel particulate filter equipped diesel passenger car." Atmospheric Environment 1908-1916.

Bolton, James R. 1974. US Patent 3799131 A.

Bosch, Hans, and Frans Janssen. 1988. "Catalytic Reduction of Nitrogen Oxides." Catalysis Today $\mathrm{V}$.

Brussels. 2015. Commission welcomes Member States' agreement on robust testing of air pollution emissions by cars. Press release, European Commision .

Cooper, B.J, H.J. Jung, and J.E. Thoss. 1990. USA Patent 4902487.

Delgado, Oscar F., Nigel N Clark, and Gregory J. Thompson. 2011. "Method for translation of inuse fuel consumption and NOx emissions between different heavy-duty vehicle routes." ASME 2011 Internal Combustion Engine Division Fall Technical Conference.

Dickey, Daniel W, Thomas W Ryan III, and Andrew C Matheaus. 1998. Nox Control in HeavyDuty Diesel Engines -What is the Limit ? Detroit, Michigan: International Congress and Exposition. 
Epling, William S, Larry E Campbell, Aleksey Yezerets, Neal W Currier, and James E. Parks II. 2004. "Overview of the Fundamental Reactions and Degradation Mechanisms of NOx Storage/Reduction Catalysts." Catalysis Review 163-245.

European Union. 2016. Commission Regulation (EU) 2016/427. Commission Regulation, Official Journal of the European Union.

Herner, Jorn Dinh, Shaohua Hu, William H Robertson, Tao Huai, John F Collins, Harry Dwyer, and Alberto Ayala. 2009. "Effect of Advanced Aftertreatment for PM and NOx Control on Heavy-Duty Diesel Truck Emissions." Environmental Science \& Technology 5928-5933.

Huang, Zhanggen, Zhenping Zhu, Zhenyu Liu, and Qingya Liu. 2003. "Formation and reaction of ammonium sulfate salts on V2O5/AC catalyst during selective catalytic reduction of nitric oxide by ammonia at low temperatures." Journal of Catalysis 213-219. doi:10.1016/S0021-9517(02)00157-4.

ICCT. 2015. THE EUROPEAN REAL-DRIVING EMISSIONS REGULATION. Position Breif, The international Council on Clean Transportation.

Keuper, Andreas, Hiie-Mai Ida Unger, Jia Huang, Harald Bressler, and Wolfgang Albrecht. 2011. "Investigations to Achieve Highest Efficiencies in Exhaust Gas After-Treatment for Commercial Vehicles using an SCR system." SAE international.

Khair, Magdi, Christopher Sharp, Ralph McGill, Christine Lambert, and Robert Hammerle. 2004. Technical Advantages of Urea SCR for Light-Duty. Detroit: SAE World Congress.

Kim, Yong-Wha, Jing Sun, Ilya Kolmanovsky, and Jeff Koncsol. 2003. "A Phenomenological Control Oriented Lean NOx Trap Model." SAE Technical Paper Series. doi:10.4271/200301-1164.

Koebel, M, M Elsener, and M Kleemann. 2000. "Urea-SCR: a promising technique to reduce NOx emissions from automotive diesel engines." Catalysis Today 335-345.

Koebel, Manfred, Giuseppe Madia, and Martin Elsener. 2002. "Selective catalytic reduction of NO and NO2 at low temperatures." Catalysis Today 239-247.

Kong, Yougen, Tom Kozakiewicz, Randy Johnson, Chirs Huffmeyer, Jon Huckaby, John Abel, Jon Baurley, and Kendall Duffield. 2005. "Active DPF Regeneration for 2007 Diesel Engines." SAE Technical Paper Series. doi:10.4271/2005-01-3509. 
Lambert, Christine, Robert Hammerle, Ralph McGill, Magdi Khair, and Christopher Sharp. 2004. "Technical Advantages of Urea SCR for Light-Duty and Heavy-Duty Diesel Vehicle Applications." SAE Technical Paper Series 1. doi:10.4271/2004-01-1292.

Li, J., J. Theis, W. Chun, C. Goralski, R. Kudla, J. Ura, W. Watkins, M. Chattha, and R. Hurley. 2001. "Sulfur Poisoning and Desulfation of the Lean NOx Trap." SAE Technical Paper Series. doi:10.4271/2001-01-2503.

Maiboom, A, X. Tauzia, and J.F. Hetet. 2008. "Influence of high rates of supplemental cooled EGR on NOxand PM emissions of an automotive HSDI diesel engine using an LP EGR loop." International Journal of Energy Research 32 (15): 1383. doi:10.1002/er.1455.

Manufacturers of Emission Controls Association. 2007. Emission Control Technologies for DieselPowered Vehicles. Washington, D.C: MECA.

Parks, Jim, Brian West, Matt Swartz, and Shean Huff. 2008. "Characterization of Lean NOx Trap Catalysts with In-Cylinder Regeneration Strategies." SAE Technical Paper Series. doi:10.4271/2008-01-0448.

Pelkmans, Luc, and Patrick Debal. 2006. "Comparison of on-road emissions with emissions measured on chassis dynamometer test cycles." Transportation Research Part D: Transport and Environment 233-241.

Peng, Haiyong, Yi Cui, Lei Shi, and Kangyao Deng. 2008. "Effects of exhaust gas recirculation (EGR) on combustion and emissions during cold start of direct injection (DI) diesel engine." Energy 471-479. doi:10.1016/j.energy.2007.10.014.

Russell, April, and William S. Epling. 2011. "Diesel Oxidation Catalysts." Catalysis Reviews 337423. doi:10.1080/01614940.2011.596429.

Salomons, S., M. Votsmeier, R.E. Hayes, A. Drochner, H Vogel, and J. Gieshof. 2006. "CO and H2 oxidation on a platinum monolith diesel oxidation catalyst." Catalysis Today 491-497. doi:10.1016/j.cattod.2006.06.001.

Santini, Al. 2011. OBD-II: Functions, Monitors and Diagnostic Techniques. New York: Delmar, Cengage learning.

Scott Sluder, C, John M. E. Storey, Samuel A Lewis, and Linda A. Lewis. 2005. "Low Temperature Urea Decomposition and SCR Performance." SAE Techinical Paper Series. doi:10.4271/2005-01-1858. 
Shade, Benjamin C. 2000. A performance evaluation of the MEMS: An on-road emissions measurement system study. Master's Thesis, Morgantown: West Virginia University, Proquest Dissertations Publishing.

THE WHITE HOUSE. 2009. President Obama Announces National Fuel Efficiency Policy. 519.

Accessed 10 18, 2016. https://www.whitehouse.gov/the-press-office/president-obamaannounces-national-fuel-efficiency-policy.

Thompson, Gregory J, Daniel K. Carder, Marc C Besch, Arvind Thiruvengadam, and Hemanth K Kappanna. 2014. In-Use Emissions Testing of Light-Duty Diesel Vehicles in the United States . Morgantown: Center for Alternative Fuels, Engines \& Emissions. West Virginia University.

Thompson, Gregory J., Daniel K. Carder, Marc C. Besch, Arvind Thiruvengadam, and Hemanth K. Kappanna. 2014. In-Use Emissions testing of Light-Duty Diesel Vehicles in the United States. Final Report, Morgantown: CAFEE WVU.

U.S EPA. 2016. "EPA Emission Standards for Light-Duty Vehicles and Trucks." US Environmental $\begin{array}{llllll}\text { Protection } & \text { Agency. } & \text { March. } & \text { Accessed } & 10 & \text { 18, }\end{array}$ https://nepis.epa.gov/Exe/ZyPDF.cgi?Dockey=P100O9ZW.pdf.

U.S. Department of Energy. 2012. "Vehicle Weight Classes \& Categories." Alternative Fuels Data Center. Accessed 10 18, 2016. http://www.afdc.energy.gov/data/10380.

U.S. EPA. 2012. EPA and NHTSA Set Standards to. Regulatory Announcement, Office of Transportation and Air Quality. Accessed 10 19, 2016. https://www3.epa.gov/otaq/climate/documents/420f12051.pdf.

U.S. EPA. 2014. EPA Sets Tier 3 Tailpipe and Evaporative. Regulatory Announcement, Office of Transportation and Air Quality.

U.S. EPA. 2000. Heavy-Duty Engine and Vehicle. Regulatory Announcement, Office of Transport and Air Quality.

—. 2016. "Light-Duty Vehicles and Light-Duty Trucks:Tier 1 and National Low Emission Vehicle (NLEV) Supplemental Federal Test Procedure." US Environmental Protection Agency. $\begin{array}{llll}\text { March. } & \text { Accessed } & 10 & 18,\end{array}$ https://nepis.epa.gov/Exe/ZyPDF.cgi?Dockey=P100O9ZR.pdf. 
U.S. EPA. 1997. "Final Rule for the National Low Emission Vehicle Program." US EPA. $\begin{array}{lllll}\text { December. } & \text { Accessed } & 11 & 28,\end{array}$ https://nepis.epa.gov/Exe/ZyPDF.cgi/P100B3GY.PDF?Dockey=P100B3GY.PDF.

Uchido, Noboru, Yasuhiro Daisho, Takeshi Saito, and Hideaki Sugano. 1993. "Combined Effects of EGR and Supercharging on Diesel Combustion and Emissions." SAE Technical Paper Series.

United States Code. 1990. 42- THE PUBLIC HEALTH AND WELFARE. U.S. Government Publishing Office.

US EPA. 2012. 2017 and Later Model Year Light-Duty Vehicle Greenhouse Gas Emissions. Final Rule, Department of Transportation.

Weiss, Martin, Pierre Bonnel, R. Hummel, U. Manfredi, R. Colombo, G. Lanappe, P. Le Lijour, and M. Sculati. 2011. "Analyzing on-road emissions of light-duty vehicles with Portable Emission Measurement Systems (PEMS)." JRC Scientific and Technical Reports.

West, Brian, Shean Huff, james Parks, Sam Lewis, Jae-Soon Choi, William Partridge, and John Storey. 2004. "Assessing Reductant Chemistry During In-Cylinder Regeneration of Diesel Lean NOx Traps." SAE Technical Paper Series. doi:10.4271/2004-01-3023.

Wittka, Thomas, Bastian Holderbaum, Peter Dittmann, and Stefan Pischinger. 2015. "Experimental Investigation of Combined LNT + SCR Diesel Exhaust Aftertreatment." Emission Control Science and Technology 167-182.

Yokomura, Hitoshi, Susumu Kohketsu, and Koji Mori. 2003. "EGR System in a Turbocharged and Intercooled Heavy-Duty Diesel Engine -Expansion of EGR Area with Venturi System-." Technical review.

Zheng, Ming, Graham T Reader, and Gary J Hawley. 2003. "Diesel engine gas recirculation-a review on advanced and novel concepts." Energy Conversion and Management 883-900. 